\title{
Food, Poetry, and the Aesthetics of Consumption
}




\section{Series Title}

Series Editor, Editor's School 


\section{Food, Poetry, and the Aesthetics of Consumption \\ Eating the Avant-Garde}

\section{Michel Delville}


First published 2008

by Routledge

270 Madison Ave, New York, NY 10016

Simultaneously published in the UK

by Routledge

2 Park Square, Milton Park, Abingdon, Oxon OX14 4RN

Routledge is an imprint of the Taylor \& Francis Group, an informa business

(C) 2008 Taylor and Francis Group

Typeset in Sabon by IBT Global

Printed and bound in the United States of America on acid-free paper by IBT Global

All rights reserved. No part of this book may be reprinted or reproduced or utilised in any form or by any electronic, mechanical, or other means, now known or hereafter invented, including photocopying and recording, or in any information storage or retrieval system, without permission in writing from the publishers.

Trademark Notice: Product or corporate names may be trademarks or registered trademarks, and are used only for identification and explanation without intent to infringe.

Library of Congress Cataloging in Publication Data

A catalog record has been requested for this book (or add CIP data if already in)

British Library Cataloguing in Publication Data

A catalogue record for this book is available from the British Library

ISBN10: 0-415-95831-8 (hbk)

ISBN10: TK (ebk)

ISBN13: 978-0-415-95831-8 (hbk)

ISBN13: TK (ebk) 


\section{Contents}

Acknowledgments $\quad$ ix

Introduction 1

1 Tasting Is Believing: A Few Thoughts on Still Life Poetics (Greenaway, Stein, Stevens, Bly, Ponge, Claudel) 10

2 On Tender Buttons and Brussels Sprouts:

Modernism and the Aesthetics of Consumption

(Stein, Lewis, Duchamp, Joyce)

34

3 Pop Serialism: Soup Cans, Pie Counters, and Things that Look like Meat (Mullen, Ponge, Warhol, Pignatari, Oldenburg, Hirst, Thiebaud, Broodthaers) 58

4 Minimalists and Anorexics (Beckett, Dali, Broodthaers, Robbe-Grille)

5 Uncontrollable Materialities: Food and the Body in Performance (Baroness Elsa, Marinetti, Schneemann, Finley, Beuys, Fluxus and Beyond)

Epilogue The Food and Hunger Poet at the Turn of the Century; Anorexia, Anthropoemia, and Abjection (Antin, Manzoni, Delvoye) 


\section{$(4)$}

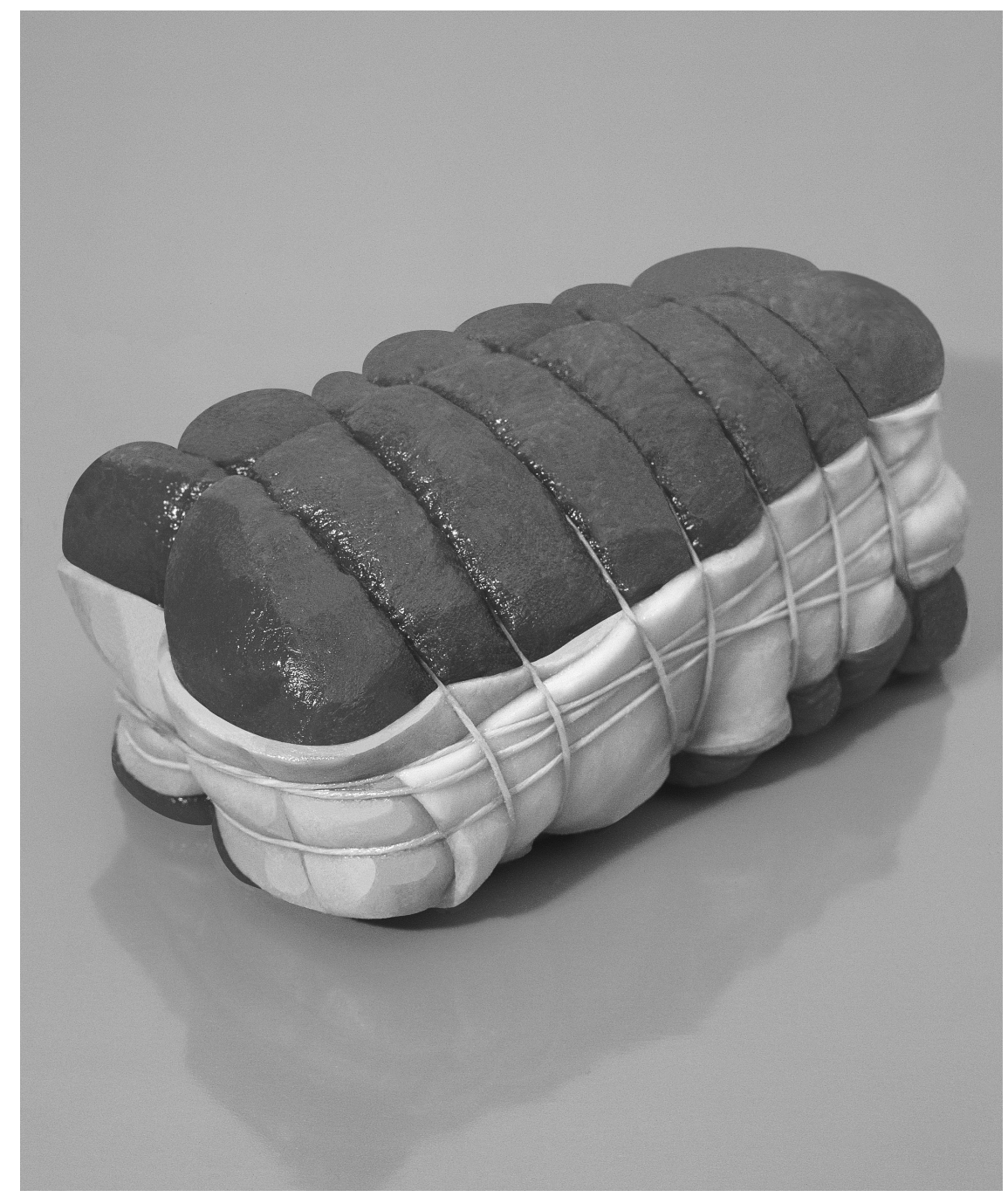

$\oplus$

Figure 1. Florent Mattei. Untitled. From the "Biotoniquesseries," 1999, 100x120cm. Courtesy Galerie Espace à Vendre, Nice, France. 


\section{Acknowledgments}

This book is dedicated to my father, Gilbert Delville, my mother, Lucia Delville-Furlanetto (who cooked for me daily for more than a quarter of a century), my brother Gilbert, my wife Elisabeth, my son Romain, and my daughter Louise, who have taught me and continue to teach me all I know about seeing, tasting, and believing. I would also like to acknowledge the intellectual feedback and good company of my colleagues at the Interdisciplinary Center for Applied Poetics of the University of Liège (http://www. cipa.ulg.ac.be/), an environment which offered critical opportunities to work through parts of this book and experience the risks and delights of truly interdisciplinary work. Special thanks go to the following people for their helpful comments and encouragements along the way: Pierre Michel (who gently nudged me on when he detected a slack in my writing), Jan Baetens, Marjorie Perloff, David Caplan, Livio Belloï, Steve McCaffery, Christophe Den Tandt, Stéphane Dawans, Jean-Michel Rabaté, Laurent Demoulin, Luciano Curreri, Peter Johnson, Peter Middleton, Gérald Purnelle, Thierry Ramais, Andrew Norris, Peter Nicholls, and Louis Armand. Short sections of this volume began their lives, in rather different forms, in the following publications: the subchapter on Marinetti appeared in Vol. 2 of the e-journal Interval(le)s (CIPA/University of Liège, 2007) and is reprinted here by permission of CIPA; the short, introductory sections to Bly's object poems and Stein's Tender Buttons were based on and reworked from the corresponding passages in The American Prose Poem: Poetic Form and the Boundaries of Genre (UP of Florida, 1998); embryonic versions of the sections on Ponge, Stein, Greenaway, Mullen, and Robbe-Grillet were published in L'Euvre en morceaux: esthétiques de la mosä̈que (Livio Belloï and Michel Delville, eds.; Paris, Brussels: Les Impressions Nouvelles, 2006), Reading Without Maps? Cultural Landmarks in a Post-Canonical Age (Christophe Den Tandt, ed.; Brussels, Bern, Frankfurt, New York: Presses Interuniversitaires Européennes, Peter Lang, 2006), and in the Proceedings of the Conference of the German Association of University Teachers of English Vol. 24 (Ewald Mengel, Hans-Jörg Schmid, and Michael Steppat, eds; Trier: Trier Wissenschaftlicher Verlag, 2003). Excerpts from Robert Bly's Ten Poems of Robert Bly Inspired by the Poems of Francis Ponge, Harryette 


\section{$\mathrm{x}$ Acknowledgments}

Mullen's $S^{*} P e R M * K^{*} T$, and Ron Silliman's Mohawk are reproduced by kind permission of their authors.

Robert Bly, “An Oyster” reprinted from What Have I Ever Lost by Dying: Collected Prose Poems, by Robert Bly, @ 1993, Harper-Collins.

Harryette Mullen, excerpts from Recyclopedia: Trimmings, $S * P e R M * K^{*} T$, and Muse \& Drudge, Graywolf Press, St. Paul, Minnesota, (C) 2006 Harryette Mullen.

Ron Silliman, excerpt from Mohawk (Doones Press, Bowling Green, Ohio 1973) () 1973 by Ron Silliman, used with permission. 


\section{Introduction}

From Plato's dismissal of food as a distraction from thought to Kant's relegation of the palate to the bottom of the hierarchy of the senses, the sense of taste has consistently been devalued by Western aesthetics. Kant is often invoked as evidence that philosophers consider taste as an inferior sense because it belongs to the realm of the private and the subjective and cannot claim universal validity. The prevalence of the sensual over the aesthetic, as well as of the particular over the universal, in gustatory taste would thus account, at least in part, for the neglect of the aesthetic potential of foodstuffs and commodities which, until the recent efforts of Carolyn Korsmeyer, Denise Gigante, and a few other "gastrocritics," had remained overlooked and undertheorized. In the field of philosophy, Korsmeyer's critique of the sense hierarchy in Making Sense of Taste, in particular, has provided invaluable insight into the language which governs discussions about food, art, and knowledge. One of the lessons to be learned from the history of Western philosophy from Plato to Hegel and beyond is that the supremacy of vision and, to a lesser extent, hearing among the senses has been legitimized by the idea that taste is one of the "lower" senses because it does not seem to be "required in the development of higher types of knowledge" (Korsmeyer 87), an idea promoted by Kant and eighteenth-century philosophy as a whole. As for the meal itself, it is more often than not regarded as a mere "vehicle" for a kind of "social enjoyment" that must imperatively transcend immediate, physical gratification and create a sense of "aesthetic unity" among the participants (Gigante 9). Unsurprisingly, Hegel's metaphysics also endorses the classic hierarchy of the senses and postulates that the bodily senses are irrelevant to the apprehension of works of art. For Hegel, art does not exist "merely for sensuous apprehension; its standing is of such a kind that, though sensuous, it is at the same time for spiritual apprehension; the spirit is meant to be affected by it and to find some satisfaction in it." Having defined art as an operation of the spirit becoming conscious of itself, Hegel concludes:

Consequently the sensuous aspect of art is related only to the two theoretical senses of sight and hearing, while smell, taste, and touch remain 


\section{Food, Poetry, and the Aesthetics of Consumption}

excluded from the enjoyment of art. For smell, taste, and touch have to do with matter as such and its immediately sensible qualities.... For this reason these senses cannot have to do with artistic objects, which are meant to maintain themselves in their real independence and allow of no purely sensuous relationship. What is agreeable for these senses is not the beauty of art. (cited in Korsmeyer 61)

Typically, the exclusion of taste from the realm of cognition, meaning, and representation is justified by the sheer physical proximity of the lower senses to their objects. For Hegel, the sense of closeness one experiences when tasting food abolishes the critical distance between the perceiver and the perceived, which allows objective pronouncements to be made. The idea that gustatory tastes and desires are self-directed, that "they don't seem to be about anything other than how things taste," and that food itself "does not mean anything" (Korsmeyer 110-11) because it does not seem to refer to anything beyond itself has remained dominant to the present day. As Korsmeyer has remarked, the central paradox underlying the lack of recognition of the aesthetic dimension of gustation is, quite paradoxically, that philosophies of aesthetic taste almost systematically resort to gustatory models but invariably assume that the private nature of taste impressions denies them any aesthetic pertinence:

The intimate acquaintance with the aesthetic object and the pleasure aroused in appreciation appear to parallel the pleasure response of gustatory taste. (As Luc Ferry put it, taste seems to be "the very essence of subjectivity; the most subjective within the subject.") Yet at the same time the subjectivity of gustatory taste appears to entail a degree of relativity inappropriate for comparison with judgments of beauty, and the classic problem of taste requires solution only for aesthetic taste. (Korsmeyer 111)

From a gastroaesthetic perspective, however, what Kant and Hegel perceive as a limitation becomes can be viewed as a new field of enquiry which investigates the dialectics of inside and outside, the personal and the communal, the natural and the cultural. The artists discussed in this book implicitly or explicitly reject the Kantian notion that gustatory appreciation is essentially passive, that it is entirely determined by the subject, and that it has no claim to aesthetic judgment. In a movement that alternates between introjection and introspection, the subjective interface by which "eat artists" experience the material world of sensory reality becomes an organ of physiological and psychological assimilation that reconsiders the Hegelian idea that digestion converts externality into a "self-like unity," thereby eliminating the other as other (Morton 221). In the context of the poetic experiments of the Modernist avant-garde (as evidenced in the writings of Gertrude Stein, F.T. Marinetti, Marcel Duchamp, James Joyce, and Wyndham Lewis) or the 
more recent performance art of Alicia Rios, Eleanor Antin, Vito Acconci, and others, the body itself is apprehended and represented as an unfinished, indigestible figure which hesitates between identification and rejection and, ultimately, between pleasure and disgust. As for the tongue, the organ of taste and self-expression, it becomes the site of aesthetic and philosophical negotiations in which bodily processes and self-consciousness run in parallel and interact with each other.

Because it constantly takes us to the body's direct confrontation with material reality, gastroaesthetics defeats all attempts at a purely discursive, analytical elucidation of the subject/object relationship. Foregrounding the fluidity of form, it also points to the inherent instability of the subject as body, begging us to ask ourselves the question that haunts Aesop's famous fable of the belly: how can the self possibly account for-and position itself towards- the precariousness of the digestive process, especially when it is perceived as a symptom of our failure to control our body's natural rhythms? As some of the more recent works analyzed in the following chapters suggest, the history of Eat Art has displayed different, sometimes antithetical ways of dealing with the irreducible otherness of ingestion and digestion. These ways range from a desire to explore the most uncomfortable contents of subjective experience (see, for example, my discussion of Kristeva's redefinition of aesthetics as a form of sublimated abjection) to various forms of "creative anorexia" whose close analysis casts unusual light on the goals and methods of minimalist art, a topic discussed at some length in chapter 4.

The close range within which the act of eating operates also discourages a reading based on the traditional mind/body duality and-in the more specific context of literary and artistic gastronomy-strong divisions between perception and ingestion, introjection, and identification. As we will see, one of the most interesting aspects of gastroaesthetic analysis is that it challenges conventional notions of subjectivity (by, for example, allowing the repressed animality of the subject to express itself with a vengeance) and examines the possibilities of alternative forms of "sensuous" knowledge. In different but related ways, the cooking experiments of the Italian Futurists and the literary still lifes of Gertrude Stein and Wallace Stevens indicate that the Modernists considered eating habits as a reflection of sociological, aesthetic, and psychosexual issues that clearly exceed the conventions of the traditional still life, with its highly codified rules and symbolic determinism. A quick look at Stevens's "Study of Two Pears" or Stein's Tender Buttons reveals that the contemporary literary still life, which parallels the development of post-impressionist aesthetics, is less interested in the emblematic meanings of objects ${ }^{1}$ than in the possibility of new experiments in light, color, and texture as well as new forms of spatial organization and Cubist-derived abstraction. Abandoning the poetics of the object-symbol, these works also approach food in ways that differ from the genre's more general preoccupation with inanimate objects 


\section{Food, Poetry, and the Aesthetics of Consumption}

(which has continued to extend to flowers, books, and clothing) and whose specific contribution to contemporary art and aesthetics this book proposes to discover and explain. But however abstract their discussions of the psychological and literary implications of food become, these works are always, by necessity, rooted in the tangible ingredients of cooking and recipes as well as in the language which conveys the complexities of gustative experiences and their psychological ramifications. Whereas Stein's "Food" section in Tender Buttons reveals the deep affinities between recipe and poetry writing, the actual conditions of food production and consumption, including the actual act of biting and chewing, are often at the heart of Francis Ponge's poetics as well as of the performance art analyzed in chapter 5 .

\section{FROM THE LITERARY STILL LIFE TO THE UNFINISHED BODY: CONSUMPTION, COMPOSITION, AND REPETITION}

Although it remains largely unexplored, the literary still life, to which the first two chapters of this study are devoted, has a rich history marked by the contributions of such major poets as Gertrude Stein, Wallace Stevens, Francis Ponge, Robert Bly, and Harryette Mullen. Detailed and extended discussions of specific texts reveal these writers' attempts to describe the avatars of a lyric self caught in a process that brings about a continuous alteration of the distinction between body and world, diet and discourse, self and matter, inside and outside, between what is I and what is not (or no-longer or not-yet) I. Writing about taste (a physical sense traditionally downplayed in Western literature), as well as smell, texture, and sight, these writers transcend the boundaries of the traditional still life in pursuing the consequences of the physical confrontation of the artist with the outside world. Addressing the materiality of composition (and de-composition), they also transcend the principle of "involuntary memory" that characterizes Proust's famous madeleine. Stein's and Ponge's poems about food, in particular, often bring the speaker's body into contact with the object described, inscribing it in a circuit of description and consumption, ingestion, and ex-pression. This results in a mode of writing that plays with both the physical and the metaphorical, the sensory and aesthetic dimensions of food.

As is well-known, one of the most characteristic features of Stein's work is her decision to incorporate repetition as a key structural feature of her poetry. This method would seem to confirm Fredric Jameson's thesis that one way of neutralizing the deadening effects of repetition is to incorporate it into the very texture of the writing. As Kenneth Rexroth has written, "Gertrude Stein showed, among other things, that if you focus your attention on 'please pass the butter,' and put it through enough permutations and combinations, it begins to take on a kind of glow, the splendor of what is called 'an aesthetic object'" (cited in Stein 1980: xv). For Stein, as for 
Ponge, this attention to everyday speech and everyday objects becomes a springboard for a study of the human character. As Stein herself confesses, she "began to get enormously interested in hearing how everything said the same thing over and over again with infinite variations but over and over again until finally if you listened with great intensity you could hear it rise and fall and tell all that there was inside them" (xvi). Her poetry thus appears as one example of how modernist aesthetics-despite its obsessive fear of repetition and its equally obsessive emphasis on formal innovationappropriated repetition (and reiteration) "as a kind of homeopathic strategy whereby the scandalous and intolerable external irritant is drawn into the aesthetic process itself and thereby systematically worked over, 'acted out,' and symbolically neutralized" (Jameson 1992: 18).

Although Stein's heavy administration of repetition in such works as Tender Buttons and "Lifting Belly" can hardly be described as "homeopathic," her repetition-with-variation techniques simultaneously anticipate and exceed the repetitions, replications, variations, and demultiplications displayed by the writings of Samuel Beckett, to whom a significant portion of chapter 4 is devoted, as well as by the art of Andy Warhol, Wayne Thiebaud, Claes Oldenburg, Daniel Spoerri, and Damien Hirst, whose visual works are examined in chapter 3 . Whereas Pop Art takes the viewer into a dimension where the use-value of food is divorced from the act of eating and transposed onto another, more abstract level (that of "pure" consumerism rather than that of consumption) the tableaux-pièges of Daniel Spoerri's Eat Art ironically mark a return to the "illusion of timelessness" conveyed by the classical still life.

\section{FOOD, POETICS, AND THE AVANT-GARDE}

In recent years, contemporary philosophy and cultural theory have displayed a growing interest in the conjunction of food and literary criticism. In the United States, the foundational works of Denise Gigante and Timothy Morton have provided a solid historical and theoretical basis for an investigation of the cultural and literary significance of foodstuffs in Western culture. This volume differs from its predecessors in that it concerns itself with both literary texts and visual/performative media from an interdisciplinary perspective and draws as readily on art history, philosophy, and cultural history as on textual analysis per se. The other specificity of this book is that it deals exclusively with contemporary works and therefore hopes to fill a gap in understanding further the development of a modern attitude to the intersection of art and food. ${ }^{4}$ The essays that follow examine the importance of food as a pivotal element-both materially and conceptually-in the history of the Western avant-garde from the early years of the twentieth century to the present day. From Gertrude Stein to Alain Robbe-Grillet, from F.T. Marinetti to Andy Warhol, from 


\section{Food, Poetry, and the Aesthetics of Consumption}

Marcel Duchamp to Alicia Rios, the examples chosen explore the connections between art and food in ways that address contemporary notions of the body, language, and subjectivity. Clearly, the choice of poetic texts as the main corpus of this study reflects the importance of food aesthetics in some of the most important currents of early Modernism (including Italian Futurism and literary Cubism), a tendency confirmed by the later experiments of Francis Ponge and their American extension in Robert Bly's "thing poems."

As the following chapters will make clear, this book was also inspired by the proximity of poetic practice to the works of the visual and performance artists who have continued to foreground the connections between food, language, and representation. As I have suggested, far from restricting itself to a description of the metaphorical uses of food, this book is largely devoted to the various ways of representing and apprehending the materiality of edible matter in contemporary art and literature. Unlike Marcel Proust's madeleine, whose chief function was to sustain the "immense edifice of memory" (Proust 51), most of the works examined here do not seek to apprehend food along the lines of memory and nostalgia. Proust's butter pastry itself cannot be reduced to its mnemonic presence as it insists on the physical persistence of taste, which gives the Proustian world its full-fledged "form" and "solidity" (52). As we will see, contemporary experimental art and literature have not ceased to reflect and theatralize the self's confrontation with foodstuff as material objects. More generally, the constructivist impulse behind the development of the Western avant-garde has remained central to any critical exploration of the world of objects-whether or not of the edible variety-preferring to dwell on process, movement, and method, rather than on structural and analytical description, a process that lends itself to an active engagement with the production and assimilation of both art and food.

Though the problem of defining the avant-garde surfaces throughout this book, my intention is not to add to the long list of monographs and essays dealing with the controversies surrounding the definitions and redefinitions of the historical and theoretical avant-gardes. Instead, I will try to explore the specific contribution of gastroaesthetics to twentieth century experimental art and underline its commitment to a poetics that aims to reintegrate art not only into the praxis of life (as Peter Bürger's definition of the historical avant-garde famously argued) but also into the very fabric of human physical existence, which is constantly stimulated by forms of oralities that address the complexities of the production and consumption of both food and meaning. My preference thus went to texts and performances that challenge and reorganize our "sense of reality," arguing, explicity or implicitly, that knowledge always necessarily involves a politics of the body, a politics controlled and regulated by discursive and performative models that numerous contemporary artists have sought to test and/or subvert. 


\section{FROM POETRY TO PERFORMANCE}

This book has no claims to exhaustivity as regards the uses of food in twentieth century experimental art. As I have just suggested, the examples I have selected offer unusual ways of looking at the process of art production and consumption, ways that do not seek to repress its inscription in the human/ social/political body's complete functioning. In doing so, I hope to have suggested a few alternate methods of reassessing the recent avatars of the still life (with its recent incursions into the performative) and of articulating the relationship of modernism and the avant-garde through the prism of the conjunction of diet and aesthetic discourse. More often than not even the nontextual (visual or performance-oriented) works discussed herein bear an intimate relationship with contemporary poetry "on and off" the page. In the same way as Stevens's literary still lifes can be considered as an ekphrastic exercise about how visual effects can be emulated by textual objects, performance artist Eleanor Antin has confessed to conceiving of her performance art as a form of "poetry" indebted to Diane Wakoski and Jackson Mac Low as least as much as to minimalist or conceptual art. In the chapters that follow, poetry and its visual and performative extensions into the art world appear as so many creative responses to philosophy's marginalization of the life of the senses. One thinks, here, of Giambattista Vico's distinction between metaphysics, which "detaches the spirit from the senses," and poetry that seeks instead to "plunge it into them" (Todorov 49), bridging the gap between knowledge and perception, the universal and the particular, through a process of constant defamiliarization and re/dis-figuration of linguistic and physical material. As the last two chapters of this book indicate, the "institutional" proximity of performance and installation art to poetry was recently strengthened by the works of Janine Antoni, Jana Sterbak, and Wim Delvoye who, in more ways than one, emerge as continuators of the earlier, equally visceral experiments of Carolee Schneemann, Vito Acconci, Karen Finley and other postwar poets turned "eat artists." The predominance and foundational character of poetic and para-poetic texts in the corpus I have covered is, of course, not coincidental: The dialectical affinities between consumption and lyric ex-pression build a natural alliance between eat art and poetic experiment as both genres have remained privileged channels for a critical investigation of mimesis, referentiality, poetic closure, and lyric subjectivity.

Roland Barthes's definition of gustatory taste as a perversion "built upon the dissociation of need and desire" (Barthes 1984: 304) provides an interesting ground for a further investigation of the avant-garde's relationship with food. Interpreting Brillat-Savarin's dictum that "the pleasure of eating depends on hunger or, at least, on appetite, the pleasure of the table [being] more often than not independent from both" as the expression of a bourgeois consciousness "unencumbered by social guilt," Barthes concludes that gastronomy theatralizes "the luxury of desire ... an unconditional loss, a 


\section{Food, Poetry, and the Aesthetics of Consumption}

kind of ethnographic ceremony by which man celebrates his own power, his freedom to burn his energies 'for nothing." What Barthes writes about gastronomy equally applies to the culinary arts. Indeed, the growing interest in food as art in contemporary Western culture presupposes an audience satiated and wealthy enough to have the leisure to contemplate foodstuff as conceptual, rather than nourishing, at a time when "knowing about food and being able to discourse about food ... [ [have become] desirable social attributes" and could be considered "'gastronomic capital,' a subset of Bourdieu's 'cultural capital'" (Santich 9). A consideration of the function of food in the literature of non-Western developing countries would reveal other cultural specificities and, in a majority of cases, a preoccupation with foodstuff as a vital necessity of life, rather than a springboard for conceptual language and performing games. But even though gastroaesthetic experimentalism, just like the avant-garde as a whole, can be accused of downplaying the differences between formal innovations and political progress, it has also produced works whose aesthetic and political relevance derives precisely from their tendency to urge us to privilege the social and ritual value of food over its material use. In the works of Joseph Beuys, Eleanor Antin, and Alicia Rios, Eat Art is still geared at a radical critique and transformation of society. As for the "anorexic art" of Eleanor Antin, it reminds us that the other side of the coin of overconsumption is the development of neuroses that arise precisely from the dangers and anxieties paradoxically generated by a world dominated by overabundance, saturation, and repletion. In a recent article on anorexia nervosa, Susan Bordo comes to a similar conclusion when she suggests that the "will to conquer and subdue the body" expresses "an aesthetic or moral rebellion" against cultures "characterized by gross excesses in consumption" (Bordo 237). As chapter 4 of this volume sets out to demonstrate, the story of minimalism itself-with its radical rejection of "rich" and complex compositional materials-is infused with a similar critique of overproduction, consumption, and waste. My reading of poetic and pictorial minimalism begins with extensive close readings of Beckett and Robbe-Grillet and proceeds to discuss Lucien Dällenbach's recent claim that most contemporary artists, being partisans of an aesthetic of "thinness" and frugality, tend to reject "the royal place which [traditional bourgeois gastronomy] reserves for the seamless and the unctuous," a cooking mode whose speciality is to "dissolve natural ingredients and thereby render them unrecognizable." Transposed onto the domain of writing, this cult of homogeneity is radically opposed to the avant-garde's emphasis on the material signifier ${ }^{2}$ rather than the parts, to the composition d'ensemble rather than the unit of composition. ${ }^{3}$

More generally, the texts and performances considered here remain faithful to the notion that, in the words of John C. Super, "food is the ideal cultural symbol" and it allows historians and art critics alike "to uncover hidden levels of meaning in social relationships and arrive at new understanding of the human experience" (cited in Santich 11). As suggested 
above, they also reject the traditional paradigms of lyric expression in the name of a concretist poetics which goes beyond the metaphorical appropriations of the language of eating and cooking that abound in countless "culinary" poems and stories. As the whole history of the avant-garde has taught us, any attempt to appraise the "poetic" function of these works can only be carried out through a confrontation with linguistic and concrete matter "as such," from the "body" of language to the actual bodies of performance artists. In the last analysis, Kate Linker's remarks that Vito Acconci's performances seek to replace "the space of the page for a place in which the body was assigned the task of going beyond the poetic function" (Dworkin 99) applies to all of the other writers and eat artists considered in this book. Lastly, the contemporary avant-garde's general shift in emphasis from product to method and process-illustrated by the prevalence of nonillusionistic and nonretinal art and the rejection of transparent modes of expression and representation-paves the ground for a systematic examination of the production of food and its symbolic and physical transformation within the human body, an examination which undermines the systemic unity of production, consumption, and regulation. As some of the most recent recent developments of Eat Art amply demonstrate, ${ }^{5}$ the avantgarde's physiology of taste favors an aesthetics that seeks to encompass the unfinished body in its totality, which includes not only the consumption but also the digestion and excretion of edible matter. As the mouth that speaks becomes the mouth that eats and participates actively in the dynamics of projection, introjection, and incorporation, the "embouchured self" (Cazé unpag.) brings about a continuous alteration of the distinction between self and world, production and consumption. In many ways, the performance artists discussed in the closing section of this study are the culmination of an aesthetics that investigates the intersection of art, food, and culture. In the works of Vito Acconci, Eleanor Antin, Carolee Schneeman, Karen Finley, Alicia Rios, and others, the manipulation and consumption of food-the primary act by which the child begins to relate to something outside himself, to the non-ego-develops both as a destabilizing and a liberating element in a process which nuances and complicates the relationship between diet and discourse. 


\section{Tasting is Believing A Few Thoughts on Still Life Poetics}

\section{GREENAWAY}

The main subject of Peter Greenaway's film, The Cook, The Thief, His Wife and Her Lover, is the relationship between political power ${ }^{1}$ and the imperatives of physical and sexual hunger. For Greenaway's dictator-thief, food is a way of asserting his authority over his wife and partners by stuffing them with delicacies in order to prevent them from mouthing the unpalatable truth. "A good cook puts unlikely things together," says the thief-like duck meat and orange or ham and pineapples. The oxymoronic potency of bittersweet food is equated with the apex of good taste. But it also signifies the ultimate form of violence, which lurks beneath the varnish of cultural refinement in a world in which every civilized gesture becomes an act of barbarism. The multiplication of foodstuff, the seemingly endless banquets, and the infinite refinement of the French chef's cuisine only build the aestheticized background against which the most atrocious crimes are perpetrated.

If we agree with Norman O. Brown that "eating is in the form of the Fall" (Brown 97), ${ }^{2}$ then the original separation between nature and culture can be seen to result from the primal scene of illicit eating. More often than not, the lives of Greenaway's characters are reduced to the mechanical transit between the dining room and the bathroom, which, incidentally, is where most of the illicit sex takes place in the film. The association of food, sex and scatology in The Cook, The Thief, His Wife and Her Lover reaches an intensity unparalleled since Rimbaud's "Young Glutton" (1871), a littleknown gem from the Album zutique. Like the greedy child of Erik Satie's "Almond Chocolate Waltz," ${ }^{3}$ Rimbaud's young glutton, who is seen sticking out his tongue at a pear like a chameleon trying to catch a fly, sums up the mysterious process which takes human beings into a dimension where the use-value of food is divorced from the act of eating and transposed onto another, more abstract level:

Cap of silk, ivory prick, very black attire, 
Paul stalks

the cupboard,

sticks out small tongue at pear,

prepares

wand,

and havoc. ${ }^{4}$

(Rimbaud 16)

The Cook, The Thief, His Wife and Her Lover is full of such poetic displacements that convert food into an intellectual or emotional fetish. About halfway through the movie, we learn, for example, that one of the reasons why the French cook's cuisine is so popular is because it includes all kinds of black ingredients. For Richard's clients, these "insatiable consumers of matter" (Feher 395), eating black food is like defying death by consuming the color of death ("I charge a lot for anything black-grapes, olives, blackcurrants. People like to remind themselves of death-eating black food is like consuming death-like saying-ha, ha, Death!-I'm eating you."). Greenaway's film culminates in a failed cannibalistic ceremony that attempts to combine the forces of Eros and Thanatos through the catalytic virtues of French cuisine. The ritual is interrupted by the execution of the thief, who is shot by his wife after trying to force her to eat her dead lover's roasted genitals. The eater and the eaten are caught in a vicious circle: a perverted narrative equivalent of Arcimboldo's "Cook" (ca. 1570), a visual palindrome which can be seen alternately as the cook's head and a plate full of roasted meat. ${ }^{5}$

The cinematic still lifes of Greenaway's The Cook, The Thief, His Wife and Her Lover seem an ideal introduction to the object poems I will examine in this chapter. All the examples I have chosen deal with the representation of foodstuff in contemporary poetry. Like Greenaway's film, they address the issue of the ontological instability of the ego by focusing on the avatars of a lyric self caught in a process which brings about a continuous alteration of the distinction between mind and matter, diet and discourse, inside and outside, between what is I and what is not (or no-longer or notyet) I. The central paradox in Greenaway's still lifes is that they cannot be completely still because the camera not only moves around the object but also registers the slightest changes produced by the play of light and shade as they happen. The cinematic still life cannot thus engage in the "illusion of timelessness" which characterizes the traditional still life; it cannot contain the message that "nothing changes," that "the instant described will remain as it is in the eyes of the beholder, the individual perceiving subject" (Stewart 29). Rather, it returns us to Cézanne's shrivelled lemons that for D. H. Lawrence proved the validity of our "intuitive feeling that nothing is really statically at rest" (Anderson 1).

For Christian Metz, one of most important problems addressed by film theory is that of the "impression of reality" experienced by the viewer. Film 


\section{Food, Poetry, and the Aesthetics of Consumption}

gives us the impression that we are "witnessing an almost real spectacle" to a much greater extent than does a poem or a painting. Film "speak[s] to us with the accent of true evidence" (Metz 4). When poetry strives to give an impression of reality, it has to rely on other means of actualization of the image, means that are necessarily more complex than in film, where "the image is always actualized" (67). As Paul Hoover writes:

In poetry, actualization occurs on many levels at the same time, including the sound of the words and phrases, the timing of the sentences, the formal relations of the parts, the intellectual demand placed by the poem as thought, and the obvious underlying fact that poems are in words, while films rely primarily on images. Because imagist poems are so constrained by phanopoesis, ${ }^{6}$ Pound's term, they are in the long run foreign to what poetry does best, which is to display the complex privacy of thinking, and the emotional announcement that is poetic rhetoric. Any movement which seeks to abolish rhetoric in poetry will ultimately fail, as it is central to the poem's emotional "push" even when that intention is ironic or muted. (Delville and Pagnoulle 12)

\section{STEIN}

As we will see in the next chapter, nowhere is this complex process of actualization of the poetic image more evident than in the work of Gertrude Stein, whose celebrated "repetition with variation" technique sought to emulate the dynamics of the moving image. Commenting on the literary portraits of The Making of Americans, Stein writes: "I was doing what the cinema was doing, I was making a continuous succession of the statement of what the person was until I had not many things but one thing" (Stein 1967: 106). Whereas in film the main technical concern is how to link one image to the next, actualization in Stein's cinematic prose poetry occurs at the level of the verbal elements of the poem which, read sequentially, are gradually perceived as a "continuously moving picture" (105). One of the main goals Stein set herself while writing Tender Buttons was indeed to write "portraits of things" without reducing them to static objects. The idea was, she claimed, to "include color and movement" in her prose miniatures (113). In a piece such as "Apple," the illusion of "movement" conveyed by Stein's prose, results, to a large extent, from the use of wordplay, multiple negations, and alliterations, all of which take the reader away from semantics and subordinate referentiality to the imperatives of rhythm (as we know, many of Stein's poems were inspired by the syncopated cadences of casual conversation and "kitchen talk"). Stein's use of repetition and reiteration produces more ambiguity as the repeated words grab different meanings from the neighboring words and sentences, refusing to become "useful" by becoming attached to the things they are supposed to designate: 
APPLE

Apple plum, carpet steak, seed calm, colored wine, calm seen, cold cream, best shake, potato, potato and no no gold work with pet, a green seen is called bake and change sweet is bready, a little piece a little piece please.

A little piece please. Cane again to the presupposed and ready eucalyptus tree, count out sherry and ripe plates and little corners of a kind of ham. This is use. (187)

But the overall effect of the still lifes of Tender Buttons is ultimately less verbal than "verbi-voco-visual," to use James Joyce's phrase. Perhaps more than any other poetic form, the object poem written in prose appears to hesitate between ekphrastic ${ }^{7}$ description and the creation of visual effects directed towards the presentation of the poem as object. Because of its justified margins, the object prose poem (especially when it consists of a single block of writing placed in the middle of the page) necessarily aspires to the condition of concrete poetry and the visual arts as the "framing" of the described object by the white margins almost inevitably evokes the concrete framing of the canvas. Typographically speaking, the objectification of the thing described is further underlined by the already reified en bloc composition of the paragraphs, which emphasizes the materiality of text.

As David Antin posits, Stein's prose poetry “is a kind of concrete poetry with justified margins" (qtd. in Perloff 2004: 14). And, indeed, the ability to see words and paragraphs, rather than read them, is not the privilege of concrete poetry as such. Even if one concurs with Marjorie Perloff that the conventional prose poem is "usually a block of print whose words, syllables, and letters have no optical significance" (177) and exhibits a continuity which "encourages an inattention to the right-hand margin as a terminal point," the object poem in prose seems a somewhat different entity in which the ekphrastic element is so marked that it invites, at least to some extent, a visual reading of its textual components. In Tender Buttons, the painterly impulse is immediately apparent in Stein's decision to write several sketches devoted to the same object, as in the "Potatoes" series, for example, where she allows herself to depict her subject from a variety of angles thereby emphasizing the affinities between her writing techniques and Cubist painting. As Rosmarie Waldrop explains, "[the] most obvious feature [of the concrete poem] is reduction. . . . both conventions and sentence are replaced by spatial arrangement" (qtd. in Perloff 2004: 175). In "Potatoes," the reduction of the poem to a short series of words undergoing various repetitions and variations precludes any attempt at a "normal," sequential reading of the piece. Such poetic prose is typical of a kind of writing that develops an aesthetics of permutation, substitution, and indeterminacy and enacts what Waldrop calls the "revolt against this transparency of the word" (175-76), the rallying cry of many poets associated with Language Poetry: 
14 Food, Poetry, and the Aesthetics of Consumption

\section{POTATOES}

Real potatoes cut in between.

\section{POTATOES}

In the preparation of cheese, in the preparation of crackers, in the preparation of butter, in it.

Roast potatoes for.

\section{ROAST POTATOES}

(Stein 1967: 189)

\section{STEVENS'S OBJECT LESSON}

For Wallace Stevens, another poet influenced by post-impressionist art, the main focus also seems to be on color and form rather than content or symbolism. After a mock-didactic opening ("Opusculum paedagogum" [Stevens 196]), Stevens's "Study of Two Pears" immediately proceeds to discuss what the pears are not, thereby emphasizing the unique, irreducible singularity of the object in a way that is reminiscent of Rilke's Dinggedichte. In many ways, Rilke's "thing poems" inaugurated the modern tradition of the object poem while marking the poet's turn from his early Neo-Romantic lyricism to a more objective mode inspired by Cézanne, one which sought to describe objects and animals with the detached eye of the painter. Like Rilke, Manet, and Cézanne before him, Stevens enjoys the physicality of composition. His "Study of Two Pears" is only the ekphrastic depiction of an imaginary painting representing an absent object (the poem does not describe a specific painting although its implied referent is clearly the post-impressionist painterly tradition). Still, the third stanza of the poem nonetheless insists on presenting real fruits to the reader, three-dimensional forms which seem to exceed the canvas of the printed page.

Whereas Rilke's poetics of "objective expression" ("sachliches Sagen") for all its apparent factuality and descriptive exactitude-still endeavors to reveal the essential nature of things and inevitably lends itself to metaphorical interpretations (e.g., the theme of death and rebirth in the "Blue Hortensia"), Stevens's "Study of Two Pears" insists on the object's resistance to the observer's gaze (the pears "are not seen as the observer wills") and precludes any attempt to read symbolic meanings into the text ("The pears are not viols, / Nudes or bottles. / They resemble nothing else"). The colors that dominate Stevens's still life ("yellow," "red," "blue," "citron," "orange," and "green") are abstracted from the fruit and turned into nouns (they are both substantivized and substantiated). As for the pears themselves, their shape may resemble that of a woman's body or a bottle but they are above all "Yellow forms / Composed of curves / Bulging towards the base ... They are not flat surfaces / Having curved outlines. / They 
are round / Tapering toward the top"). Impersonalized by Stevens's literal imagination, they recede to the background as the poet's attention becomes increasingly attracted by the play of light and shadow that blurs the outlines of the fruits. Because nothing seems to distinguish them from one another, they also acquire a generic quality. To paraphrase Georges Braque, "a pear beside a pear is no longer a pear ... it has become fruit." ${ }^{9}$

The compositional principles of Stein's Tender Buttons and Stevens's "Study of Two Pears" address questions of representation which exceed the limits of ekphrastic description. One of these questions once again has to do with the existence of the poem as a poetic object. Jack Spicer once wrote to Federico García Lorca: "I would like to make poems out of real objects. The lemon to be a lemon that the reader could cut or squeeze or taste ... live moons, live lemons, live boys in bathing suits" (Spicer 34). And according to Archibald MacLeish, "A poem should be palpable and mute, / As a globed fruit" (Charters 874). Reading and enjoying a mute poem means relying above all on the materiality of writing and the look of the poem on the page. It also involves a double form of transmutation: the transformation of the object into the written word followed by the latter's further integration into the poem or book as object. As Susan Stewart has argued, literary descriptions of material objects inevitably tend to be perceived according to a visual mode of apprehension of the page as canvas:

just as the still life is a configuration of consumable objects, so the book's minute description of the material world is a device which tends to draw attention to the book as object. The configurations of print and the configurations of context-as-décor bear an intimate relation which oral genres, pointing to the time and space of the body, do not partake of. Description of the material world seems self-motivated, seems to be directed toward a presentation without direction. (27)

The work of Bob Grenier, an American poet influenced by Stein and associated with Language Poetry in the 1970s and 1980s, oscillates between visual and textual representation in a way that returns us to Stewart's "self-motivating" description. His Sentences, published in 1978, is a boxed collection of 500 short poems printed on note cards that be shuffled and reshuffled into any order. By specifying the paper quality and typeface ("This work was composed on an IBM Selectric Typewriter, using a Courier 72 (10 point) ball. Card stock is $110 \mathrm{lb}$ index white" [Grenier unpag.]), Grenier inevitably draws the reader's attention to the words on the page, which become the main object of investigation. To quote Beth Anderson, the poetic still life here "extend[s] the category of objects to include words themselves" (Anderson 2). This aspect of Grenier's work was confirmed by his more recent works, which include handwritten and holographic poems that seek to preserve the "gestural" (in the Benjaminian sense) aspects of literary production. ${ }^{10}$ While Grenier's elliptical style distinguishes it from 


\section{Food, Poetry, and the Aesthetics of Consumption}

the blocks of prose of Tender Buttons, some of his "sentences" seem to hark back to Stein's culinary anti-descriptions:

arriving in potato

TWELVE VOWELS

breakfast

the sky flurries

\section{ROBERT BLY'S THING POEMS}

At the other end of the spectrum, which opposes the Language poets' poetics of abstraction and "radical artifice" 11 to the more traditional strategies deployed by poets who are committed to a poetry of direct statement which does not challenge the seeming "transparency" of the written word, we find the poetry of Robert Bly, one of the best-known practitioners of the American object or "thing" poem. Far from foregrounding the materiality and opacity of writing, Bly insists on the sense of transparency and immediacy one experiences when reading a poem composed "away from the writer's desk, and in the presence of the object" (Bly 1991: 201). In his work, the representation of objects, including foodstuff (Bly's collections abound in "edible" still lifes), is not reduced to the textual trace of an absent thing. Instead, it seeks to present the object as directly and naturally as possible in the seemingly unmediated, unpretentious, "artless" mode for which Bly has become famous:

The oyster looks impenetrable and thuggy, and is the size of a baby mountain-lion's paw. Its surface is flaky, breaking off, crazily staked with little abdominal errors. There are waves here, as on gypsy skirtsconcealing what?

Hands, as they move to open it, feel grainy, about to violate a privacy. Small flakes of subtle calcium fall away; they are the grief and surprise that come away from lips closed so long. We have to call for a knife, which is the gift of those who lived before us, a strong knife, the end simpleminded but without Puritanism; it arranges its hard-ended molecules so as to recapture the past. 
The oyster body wets the tip of the nose as one tries to gulp it up ... the lips feel satisfied, as if they deserve what they have received.

And when we see the two empty shells, we feel it is right to praise the naked life. The shells are ready now to be thrown away into gardens, or thrown back into the ocean, as simple plates of desire. (Bly 1990: 41)

While the closing paragraph of the poem testifies to Bly's interest in objects that, to quote his master Francis Ponge (Bly acknowledges the author of The Defense of Things [Le Parti pris des choses] as his "predecessor" in the "thing poem"), "contribute more for living than [they] offer[] for reflection" (Bly 1990: 27), the poem as a whole is typical of the author's desire to create a poetics of intimacy that investigates the dialectics of singularity and genericity. (Significantly, the titles of Bly's objects, unlike Ponge's, are almost always preceded by the indefinite article: "An Oyster" instead of its Pongean predecessor, "The Oyster.") Bly's poem begins by describing the eater's physical confrontation with the "impenetrable and thuggy" body of the oyster. Bly's mollusc, that "wets the tip of the nose as one tries to gulp it up" (41), produces oral pleasure (locutionary, gustatory, and erotic) while opening the possibility of both incorporation and introjection. The mysterious and potentially threatening quality of the "crazy" "abdominal errors" that cover its body are feminized and sexualized by the metonymical gypsy skirts whose "privacy" is about to be invaded by the eater's hands. The eater's guiltless gesture in opening the oyster's solid lips is mitigated by a sense of "grief and surprise." Ultimately, however, it results in a rather problematic mixed metaphor combining a feeling of sensory self-satisfaction in gobbling the mollusc's viscous content ("the lips feel satisfied, as if they deserve what they have received") with a desire to praise the oyster's "naked life" in a gesture that sublimates the physical violence perpetrated by the eater into an attempt to "recapture the past."

As we will see, the oyster's ambivalent status as a viscous entity protected by a solid shell points not only to Ponge's own "The Oyster" but also to the solitary snail of the Parti pris des choses, which is discussed below. The first sentence of Ponge's "The Oyster," which compares the mollusc with "a medium-sized pebble," also creates an intertextual reference to another poem of the same collection, "The Pebble," which is perceived, at a purely descriptive level ("if one limits oneself to a simple description") as an intermediary state "between the rock and the stone" (Ponge 49), a liminal object that the observer must to translate into a "notion," a conceptual form which contains a "stubbornly" ${ }^{12}$ self-contained microcosm ${ }^{13}$ :

The Oyster, about as large as a medium-sized [pebble] ${ }^{14}$, has a rougher look, and a less consistent color, whitish in a dazzling way. It is a world bull-headedly sealed. You can open it, however; you must hold it then in the deep fold of a napkin, use a knife notched and not too honest, and 


\section{Food, Poetry, and the Aesthetics of Consumption}

try more than once. Fingers that are curious cut themselves, break their nails: it's not an elegant task. The knocks you give it leave whitish rings on the shell, halos of some kind. (Ponge/Bly 23).

The clumsy, hesitant attitude of Ponge's oyster gobbler, with his failed attempts to open the shell with his bare fingers or with his notched knife, contrasts with the clinical efficiency of Bly's strong, "simpledminded" blade. Ponge's emphasis on the laboriousness of the process ("un travail grossier") preempts any culturally or historically specific reading of the poem, such as that suggested by Bly's reference to "the gift of those who lived before us" in "An Oyster." Ponge thus deromanticizes and literalizes the symbolic connotations of human intervention in the poem, focusing instead on the sense of wonder experienced by the viewer of the inside of the oyster, witnessing the slow collapse of the "upper heavens" onto the "lower heavens" of the world inside the shell. The poem's final image interrogates the ambivalent viscosity of the mollusc, which seems to fluctuate to the rhythms of the observer's attempts to apprehend it by smell or sight ("a pool, a viscous and greenish [bag] ${ }^{15}$ that rises and falls as you smell and look" [23]). Although the significance of Ponge's "halos" is difficult to ascertain and may or may not refer to the material and symbolic victimization of the "martyred" animal, the poem does not try to repress the violence inherent in the act of opening the oyster shell. Lastly, in the French original, Ponge's repeated use of the French accent circonflexe in words like "blanchâtre," "opiniâtrement," "verdâtre," and "noirâtre" (21) is, according the poet himself, "determined by the shape of the word "huître" (904) which turns the oyster into a textual object, a vector of ex-pression ${ }^{16}$ as tangible as the mollusc's shell.

\section{The Deep Image}

The popularity of Bly's "artless" mode is attested to not only by the success story of the "Deep Image" school (of which more will be said below) but also, in a more anecdotal fashion, by the following writing assignment I recently came across on the internet :

\section{The Object Poem}

1. Focus on a single object and meditate on the object.

2. Try to find unusual ways of describing this object that are not ordinary manners of describing it. Try not to approach the object in a purely rational descriptive fashion. Try to make unusual connections with the object's appearance with other objects via similes or metaphors.

3. Tie together a network of loose thoughts regarding the object, often providing the object with an otherworldly existence, a hidden life.

This assignment is worth 1 point. (Kahl unpag.) 
Whatever we may think of it, this creative writing exercise stresses three descriptive strategies which can be seen at work, to various degrees, in the long tradition of objectist poetry which runs from Rilke's Neue Gedichte to Bly's Morning Glory: (1) a focus on the irreducible singularity of the object described; (2) a desire to establish metaphorical relationships between the object and other objects or the world of human life; (3) a desire for a poetics of depth and inwardness capable of revealing the essential nature or "hidden life" of things. ${ }^{17}$

As I have just suggested, Bly's poetics of depth is generally indebted to the poetics of the "Deep Image," a term originally coined by Robert Kelly and Jerome Rothenberg in the early 1960s and which has been applied to the works of poets as diverse as Diane Wakoski, Clayton Eshelman, and Louis Simpson. In a 1960 letter to Robert Creeley, Rothenberg describes the practice of the Deep Image poem as follows:

So there are really two things here, conceivable as two realities: 1 ) the empirical world of the naïve realists, etc. (what Buber and the hasidim call "shell" or "husk"), and 2) the hidden (floating) world, yet to be discovered or brought into being: the "kernel" or "sparks." The first world both hides and leads into the second ... i.e., the phenomenal world is to be read by us ... and the deep image is at once husk and kernel, perception and vision, and the poem is the movement between them. (Rothenberg 301)

For Rothenberg, the Deep Image is essentially a process which encourages the reader to penetrate the shell of the real and acquire a deeper knowledge of the meaning and beauty of the "buried images" of the natural world. Such a process also evokes what critics George S. Lensing and Ronald Moran call "the Emotive Imagination," a mode of writing that seeks to "understand through feeling" (6) and endeavors to capture the "deep truth" of the "hidden (floating) world." Rothenberg's insistence on the movement between perception and vision seems a fairly accurate description of Bly's Deep Image poetics. Bly distinguishes the Deep Image from Ezra Pound's Imagism, which he claims "was largely Picturism." He argues that the superiority of the image over the picture lies in the fact that the former is "an animal native to the imagination" which cannot be "drawn from or inserted back into the real world" whereas the latter is drawn from the objective "real" world. Yves Bonnefoy's "interior sea lighted by turning eagles" is an image, he explains, whereas Pound's famous "Petals on a wet black bough" can actually be seen (Bly 1980: 26). ${ }^{18}$

Bly's combined aversions to mere picturism and rhetorical formalism as well as his commitment to a highly imagistic free verse are typical of his desire for a poetry of the unconscious, one which is likely to reveal the deeper, hidden motives of our actions and beliefs and "leap from the conscious to the unconscious and back again, a leap from the known part 


\section{Food, Poetry, and the Aesthetics of Consumption}

of the mind to the unknown part and back to the known" (Bly 1972: 1). When applied to the still life genre, Bly's Deep Image poetics is thus meant to lead to the discovery of some secret, deep, and resonant-but nonetheless ineffable-wisdom hidden beneath the phenomenal world. ${ }^{19}$ Like other like-minded American poets such as Louis Simpson, William Stafford, and James Wright (with whom he founded the poetry magazine The Fifties in 1958), Bly believes in the existence of a yet-to-be-discovered, primitive consciousness. Such a consciousness is grounded in the poet's felt encounter with the natural world as well as in the personal intuition of the universal in the particulars of experience. The Deep Image's body-centered immanentism usually delivers a moment of mystical enlightenment which is rooted in the poet's observation of his concrete surroundings but eventually emerges from the deepest recesses of the subconscious.

Bly's poetics of immediacy thus claims to center itself "not on story or image but on the object, and hold[] to its fur, so to speak" (Bly 1986: 199), which once again takes us back to Susan Stewart's "self-motivated description." For Bly, as for Charles Simic, a poet with whom he shares many features including an interest in the prose poem form, the question then becomes that of whether the poetic image can "afford us a glimpse of the world untained by subjectivity": "Is one an impartial witness, or is the object a mirror in which one occasionally catches sight of oneself imagining that impartiality?" (Friebert 96). As indicated by the opening comparison between the surface of the oyster and the waves of gipsy skirts ${ }^{20}$ in "An Oyster," Bly's project to create a poetic idiom which would respect the integrity of the object and advocate a self-forgetful, Taoist approach that "[lets] things live for themselves" (Bly 1975: 1) is, at least to some extent, defeated by his frequent use of anthropomorphic fallacies, which inevitably transform the object or animal described into a springboard for a reflection on human psychology and history. ${ }^{21}$

The assumptions of artlessness, naturalness, and immediacy that constitute the premises of Bly's Deep Image poetics-whose main purpose is to help to "heal to wound of abstraction" (Bly 1977: 61) — have been the target of much criticism. In his review of This Body Is Made of Camphor and Gopherwood (1977), sardonically retitled "This Book is Made of Turkey Soup and Star Music," Philip Dacey denounces Bly's use of an archaic vocabulary and a solemn simplicity of diction (as well as his consistent use of simple declarative present-tense sentences) as a particularly insidious form of literary demagogy. He argues that the claims to artlessness of his style paradoxically result in a rather high degree of affection and inflation. Although Bly "rails against artifice in poetry," Dacey writes, many of the poems in This Body are "more artificial-pieces clearly contrived in a language one is not likely to hear outside the poem - than virtually any of, say, Frost's poems in blank verse." Whereas "Frost and countless others achieve the natural or a semblance of it through the artificial," he continues, "Bly wishes to bypass the latter and ends up smack in the middle of it" (qtd. 
in Nelson 164). The most articulate objection to Bly's poetics of "naïve" directness and immediacy is raised by Robert Pinsky, who condemns Bly's reliance on a rather predictable lexical and visual decorum and chides him for his "more-imagistic-than-thou" attitude (Pinsky 77). More generally, Pinsky dismisses the simple, "archetypal" rhetoric of the Deep Image poem as a rather dull, hackneyed, and, ultimately, complacent form of neo-Surrealism: "One of the most contemporary strains in contemporary poetry is often interior, submerged, free-playing, elusive, more fresh than earnest, more eager to surprise than to tell. The "surrealist" diction associated with such writing sometimes suggests, not a realm beyond surface reality, but a particular reality, hermetically primitive, based on a new poetic diction: 'breath,' 'snow,' 'future,' 'blood,' 'silence,' 'eats,' 'water,' and most of all 'light' doing the wildly unexpected. ... This is a kind of one-of-the-guys surrealism" (162-63).

The implications of Pinsky's statements are twofold: (1) the codification of poetic language into a generic vocabulary can easily turn the "studied naturalness" of Bly's poems and prose poems into a new form of mannerism; (2) the sense of "authentic" "immediacy" created by Bly's poetry (which is allegedly written in some silent and secret place "with no one watching" [Bly $1975,20])$ always already depends on the existence of a "voice" which is certainly not that used by the poet in his everyday life. Despite its claim to lyric directness, Bly's poetry is never completely immune to a certain amount of "unspontaneous" contamination, if only in the form of the author's favorite pathetic fallacies. In this sense, Bly's search for an unmediated expression of the self and its relationship to a pristinely "natural" environment is itself a form of artifice, for it seeks to elude the necessary distance between the pre-verbal sensory experience and its elaboration into form.

According to Pinsky - who sees poetic language as the site of a permanent struggle not only between the imagistic and the abstract but also between artifice and artlessness-the kind of neo-primitivism advocated by Robert Bly and other Deep Image poets would seem to swing the pendulum too far away from what a poem is actually made of. Pinsky's "antidote" to the "forced spontaneity" of the Deep Image poem and its failed attempt to convey "immediate" experience in an unself-conscious way lies in a rejection of the Imagist notion that "a poet presents, rather than tells about, a sensory experience" (Pinsky 3). In his foreword to his more recent collection of prose poems, What Have I Ever Lost by Dying, Bly himself recognizes the impossibility of "describing an object or creature without claiming it, without immersing it like a negative in his developing tank of disappointment and desire" (Bly 1992: xv). "Our desires and disappointments," he writes, "have such hunger that they pull each sturgeon or hollow tree into themselves." "We usually work to keep the imaginative language spare, so that the being does not dissolve into human images," he concludes, "but I have learned to accept the fantasy that often appears toward the end of the poem" (xv). 


\section{Food, Poetry, and the Aesthetics of Consumption}

\section{PONGE'S DEVOURING MOUTH}

In order to explore the full implications of Stewart's definition of the still life as "a configuration of consumable objects," we must now return to the poetry of Bly's mentor, Francis Ponge. On a superficial level, Ponge's interest in the materiality of writing is reflected in his tendency to discover analogies between natural forms and forms of writing. One thinks, for example, of the "typographic bushes" described in his poem, "Blackberries," in which the description of the object becomes a kind of "linguistic event" where the written sign is endowed with mimetic value. This aspect of his work allies with the semantic and semiotic materialism of Tel Quel, whose inaugural issue, published in 1960 (the year of the publication of Philippe Sollers's essay "Francis Ponge ou la raison à plus haut prix"), promoted Ponge's poetry and established him as one of the magazine's spiritual fathers. As we will see, Ponge's work was itself inspired by the work of Paul Claudel, whose principle of "imitative harmony" Ponge appropriated and expanded, considering the poet's role as in many ways the opposite of the linguist's approach to language. Poetry, according to Claudel, demarcates itself from the arbitrariness of the sign in "acting as if the opposite principle, i.e. the adaptability of sound to sense, was an indisputable and absolute truth," one that is grounded in the poet's intention to create "occidental ideograms" (Gleize 316). As we will see in our reading of "The Glass of Water" and other poems considered below, Ponge shares Claudel's desire to discover phonemic and typographical anologies between words and things, with the essential difference that Ponge's poetry remains characterized by an awareness of the "miserable coincidence" and the "desperate approximation" (Ponge 1999: 807) of sound and sense. ${ }^{22}$

Another particularity of Ponge's object poems is that they go beyond those of his predecessors in the tradition of the literary still life in addressing the consequences of the physical confrontation of the artist with its subject. Ponge's poems about food, in particular, often bring the self into contact with the object described in a way that involves the speaker's own body and inscribes it in a circuit of description and consumption, ingestion and ex-pression. From "Bread":

The surface of bread is a marvel to behold, if only because of its quasipanoramic aspect: as if one had the Alps, the Taurus or the Cordillera of the Andes right at hand.... This loose cold subsoil we call crumb has a sponge-like tissue: its leaves or flowers are like Siamese twins soldered together at every angle. When the bread goes stale, these flowers wither and shrink: then fall apart, and the mass crumbles ... But let us break it now: for on the tongue bread should be less an object of respect than of consumption. ${ }^{23}$ (Ponge 22) 
Like "The (Dry) Fig," "The Olives," “The Potato," and many other still lifes contained in Le Parti pris des choses and Le Grand recueil, Ponge's bread becomes a "real" object of contemplation and reflection as soon as it becomes comestible. Although the poet expresses his refusal to grant the piece of bread a symbolic significance, ${ }^{24}$ his main concern is to investigate the sheer material texture of the bread and sing the praise of the "dreaming matter" as well as that of the various "textual projects of its prodigious imagination" (869). Exposing the hidden, viscous world that lies hidden beneath the reassuring near-symmetries of the loaf, projecting the piece of bread onto the future and envisioning its physical decay, the poem also prepares the reader for a full confrontation with the ultimate demise of matter, thereby reintroducing the memento mori theme of the traditional still life. The latter, however, is now placed in a materialistic context in which the poet's function is to use language in a way that allows him to "both name the objects of the world and express our innermost feelings" (869). And, indeed, the speaker's emotional response to the piece of bread is at least as ambivalent as the material structure of the loaf itself. In the middle section of the poem, the crust is unfavorably contrasted with the "sickening underlying mush" underneath. The poet's use of the word "sickening," which interrupts an otherwise factual description, is indicative of Ponge's ambivalent responses to intermediary states between the solid and the liquid, a preoccupation that also surfaces in "The Oyster," "The Orange," and "The Snail," of which more will be said below.

Ponge's distaste for the mushy insides of the loaf of bread extends to his more general anxieties about how the self can apprehend and represent the undifferentiated and the amorphous. As Ian Higgins has remarked, the "threat of the elemental" that traverses Ponge's whole work reflects a more general fear of the threat of "annihilation," which is the penalty for not attending to the "mute supplication" of things to be described for what they are ("la muette supplication, les muettes instances qu'elles font qu'on les parle, à leur valeur, et pour elles mêmes" [Higgins 12-13]). The punishment for failing to realise the thing in language is "a vertiginous sense of the absurd ... a loss of grip on the world and oneself" (13) that deprives the subject of an opportunity to define himself through his relationship with material objects. ${ }^{25}$ More than anything, it is the temptation to focus on one thing at a time which entails the collapse of the self ("The diversity of things is in reality what constructs me ... if I only consider one of them, I disappear: it annihilates me" [qtd. in Higgins 13]). Confronted with the endless variety and diversity of the natural world, the poet can only hope to describe objects in relation to other things or human beings in order to reveal their "differential quality[ies]" (Higgins 14)-hence the anthropomorphic tendency in many of Ponge's object-poems.

Ponge's disgust at the sight of the ignoble mush in "Bread" is thus only one manifestation of a systematic aversion to shapelessness, an aversion 


\section{Food, Poetry, and the Aesthetics of Consumption}

only partly alleviated by the possibility of comparing formless things with each other. Haunted by the amorphousness and spongiosity of bread mush, snails, sponges, mud, orange pulp, or even water, Ponge's poetic materiology aims to physically contain the shapelessness of things through language. In the long sequence "The Glass of Water," for example, the poet characteristically equates the title "VERRE D'EAU" with "the object it designates," the letters "V" and "U" evoking the shape of a vase (Ponge 1999: 586). Creating a pictorial and textual prism that "gives shape" to the amorphousness of matter, the poet praises the purity and sensuous limpidity of water ("Pureté, Limpidité, Fraîcheur, Lasciveté réunies" [Ponge 1999: 590]) while recognizing the danger of dissolving into an unstable, "vicious" element which, uncontained by the U-shaped glass, ${ }^{26}$ becomes corrupted by the passivity and cowardice of "what prefers to obey the law of gravity rather than preserve its form":

It is white and shiny, amorphous and fresh, passive and obstinate in its only Vice: gravity, which possesses exceptional means to satisfy this vice: circumventing, piercing, eroding, filtering ... it collapses ceaselessly, renounces every form, only tend to humiliate itself, lies on its stomach on the ground, almost like a corpse, like monks of certain orders. Always lower: such is its motto : the opposite of excelsior. ("Water"; Ponge 1999: 31)

Here, the threat of insanity ("one could almost say that water is mad, because of this hysterical need to obey its own gravity, possessed by her as by a fixed idea" [31]) succeeds that of the dissolution of the self into undifferentiated space. The final humiliation of a mind unable to impose order onto the diversity of things is partly redeemed by the capacity of the human imagination to ascribe structural and psychological qualities to the object, qualities that differentiate not only between different shapes but also between different kinds of shapelessnesses. The flabby amorphousness of the sponge ("a mere muscle" that fills up "with air, with water, clean or dirty: such gymnastics is ignoble" [20]), for example, differs as much from the ambivalent texture of the juicy pulp of the orange as from the fresh fig's "intolerable" softness and its "non-resistance" to the eater's teeth (Ponge 1977: 87). As for "The Washing Machine," "the greatest of all domestic vases" (739), it "experiences an idea or a feeling of diffuse filthiness" about "the jumble of ignoble tissues" inside of itself which "through emotions, boilings, and efforts, it manages to overcome-in separating the fabrics so well that, when rinsed in a catastrophe of fresh water, they will seem to be extremely white" (740).

The insistent "let us break it now" of the closing line of "Bread" confirms Ponge's interest in objects that "contribute[] more for living than [they] offer[] for reflection" (Bly/Ponge 27). Whereas "Bread" ends with the speaker's remark that "bread must be in our mouth less an object of respect 
than one of consumption" (Ponge 1999: 23), another, later poem ends with the poet's conclusion that the potato "serves life first before it lends itself to philosophy" (1155). As Marcel La Haye-one of the Belgian continuators of the Pongean still life-writes, in a poem composed some twenty-five years after Ponge's "Potato," the potato "feeds, sustains, refuses to study its own form"; its physiognomy is "sad and serious, her eyes are deep, her taste is bland, and it has no intention of being witty" (La Haye 62).

\section{Peeling and Defeating an Orange}

As the poems examined earlier suggest, Bly inherited from Ponge a preoccupation with process rather than product, activity rather than knowledge, as well as with the dialectics of inner and outer reality, an aspect of his work that often leads to a radical interrogation of the junction of body and world. As in Ponge's poem "Blackberries," in which the poet reflects upon the transit of the fruits "travelling through [the birds] from the beak to the anus" (Bly 1990:15), the focus, in Bly's poetry, is both on the material transformation of food within the consumer's body and on the ontological incompleteness of animal life. In Bly's "An Oyster" and other, related poems such as "Peeling An Orange" and "In Praise of a Grain of Rice," the poet's devouring mouth makes its physical presence felt rather than just heard, bringing about a resolution of the antinomies between separation and unification, expression and consumption. For the poet or reader who dares to eat a peach, or peel an orange, Bly's oyster, which "wets the tip of the nose as one tries to gulp it up" (Bly 1990: 41), produces oral pleasure (locutionary, gustatory, and erotic) and opens the possibility of both incorporation and introjection.

A comparison between Ponge's "The Orange" and Bly's tribute, "Peeling an Orange," reveals further similarities and differences between the French poet and his American disciple. As we know both writers tend to ground their poetics in a minute observation of the object's material structure, which often reveals a secret, hidden meaning. ${ }^{27}$ The mysterious qualities ascribed to Bly's objects systematically originate in the poet's delight in exploring their effects on the unconscious mind. Such an approach, Bly explains, is indebted to the "Romantic view of composition, which ... means that the poet asks ... the hidden man, or the hidden woman, or the latent intelligence, to enter the poem and contribute a few images that we may not fully understand and which are not entirely contained in human language" (Bly 1990: 9). In contrast, Ponge's poetry repeatedly attempts to assimilate the fruit to a textual object liable to be deciphered by the poet's intuitive imagination. ${ }^{28}$ In "The Orange," Ponge's substitution of the phonetic with the visual and the tactile results in an extended metaphor which likens the expulsion of the fruit's juice to verbal expression (in the second part of the poem it is the orange's phonetic density that becomes the real subject of the poem). Ponge's poetic textualization of the object is reinforced by the author's comparison of the 


\section{Food, Poetry, and the Aesthetics of Consumption}

fruit's skin with a "thick, moist, blotting-paper plug" (20) as well as by the ambivalent meanings of the words "aspiration," "countenance," and "consciousness" in the opening paragraph of the poem:

As with the sponge, there is with the orange an aspiration to recover countenance after submitting to the test of expression. But where the sponge is unfailingly successful, the orange never is: its cells have burst, its tissues ripped. As the rind alone gets back its shape, more or less, thanks to its elasticity, an amber liquid squeezes itself out along with, we grant you, refreshment and suave fragrances,-but also often a bitter awareness of having prematurely delivered its seeds. (19-20)

As Ponge's description gradually gives way to a parable for the violence made to things, the eater becomes the "tormentor" or "executioner" (bourreau) of the fruit, whose "fragrant sacrifice ... really submits too readily to its oppressor" (20). This suggestion is expanded by Bly's own fable of domination in "Peeling an Orange" (appropriately retitled "Defeating an Orange" in the later volume What Have I Ever Lost By Dying?), where the orange skin "reveals its white underside, as when citizens on the border lift their faces as the tanks approach" and the eater's lips "feel a sting for long afterward" (Bly 1990: 51). Ponge's eater, however, unlike Bly's, does not experience the sting of remorse (although the poem briefly compares the orange with the sponge, commenting that the former "has better taste, but is too passive,-_and this fragrant sacrifice ... really it submits too readily to its oppressor" [88]) and, instead, surrenders to the synaesthetic pleasure delivered by the ingestion of the fruit's juice and the sheer pronunciation of its name:

We must insist on the glorious colour of the ensuing liquid, which, better than lemon juice, causes the larynx to open as wide to pronouce the word as to ingest the liquid, without any apprehensive pursing of the mouth, whose taste buds do not bristle at it. (Ponge 1999: 20) ${ }^{29}$

In a recent piece about the potato, Eugène Savitzkaya also gives primacy to the physical transformation of the object in a way that stresses the vegetable's potential for (poetic) incorporation "into the very texture of hair, teeth and eyes" (Savitzkaya 90). Like Ponge's' orange, "whose extremely fine but highly pigmented, tartly tasteful epidermis is just rough enough to highlight the flawless form of the fruit" (Ponge 1999: 20), ${ }^{30}$ Savitzkaya's "whole, integral" potato emerges as an object of pure form and density. The ingestion and incorporation of food, a crucial element of what Ponge calls the "materialist consolation" provided by everyday objects ("The Fig"; 804), becomes a means of achieving understanding beyond the act of mere description and the desires and mental projections of the lyric self: "Examining a deforming mass does not teach us anything. It is only when you try to act on it and 
participate in its transformation that you can understand the modalities of its movement, that you can follow it until the end of its journey, with your fingers, your hands, your arms and your belly" (Savitzkaya 91). Savitzkaya's poetic persona resembles many of Ponge's I-speakers who, by touching and ingesting the foodstuff they set out to describe, also seek to eliminate the aesthetic distance that separates the observer from the observed, making us aware of the boundaries of self and world for the purpose of urging us to transgress those boundaries. Where Rilke and Stevens mainly present us with food for the eye in a way that is ultimately "self-motivated," Ponge's distrust of the conventional strategies of mental projection that preside over the poetic destinies of objects results in a mode of writing that plays with both the physical and the metaphorical, the sensory and aesthetic dimensions of food. Tasting becomes believing. "Dish of Fried Fish" ("Plat de poissons frits"), a poem that both extends and subverts the tradition of the classical still life from within, emphasizes the simultaneity of sensation and thought, vision and interpretation, in Ponge's food poetics:

Taste, sight, hearing, smell . . . it's instantaneous:

When the fried sea fish opens itself, a sunny day on the tablecloth, and the big swords of its body are ready to be scattered on the floor, when the skin detaches itself like a film pellicle comes off an overdeveloped plate (but everything here is much more delicious), or (what more can we say ?) ... No, it's too good ! It feels like an elastic pellet, a caramelized piece of fish skin stuck at the bottom of the frying pan. (Ponge 1999: 768)

Ponge's culinary narrative subordinates the description of the fish to the actual act of tasting the fish, an experience whose gustative complexity seems to exceed the poet's interobjective and anthropomorphic comparisons and metaphors, ${ }^{31}$ as indicated by the first interjection in parenthesis ("but everything here is much more delicious"). The use of the indefinite pronoun designating the experience of observing and inhaling the smell of the food ("it's instantaneous") prepares the reader for a synaesthetic sequence describing the disorientation of the senses confronted with the confusion of antithetical states, such as the sweet and the salty (the caramel-looking and -tasting fish skin), or the natural and the aesthetic. As the fish's skin becomes a photographic "pellicle" (a thin skin) whose function is to develop ("révéler") the intensity of the observer's gaze, Ponge's poem deliberately confuses sensory and representational categories, realizing the phonetic and semantic texture of the fish in an etymological pun that conflates aesthetic, linguistic, and sensory apprehension. Such a "revelation," of course, is more literal than it is symbolic, and the poem ends with a humorous, anticlimactic metaphor that precludes any allegorical reading of the poem. ${ }^{32}$ Ponge's mouth-watering presentation of the fried fish dish is brought to a close by an evocation of the French fishing port of Sète, ${ }^{33}$ with its fishing boats "vertiginously" rocking the waves, the bottle (or glass) of golden wine acting as an 


\section{Food, Poetry, and the Aesthetics of Consumption}

interface between the dinner table and the landscape that the eater observes through the window.

Meanwhile a small lighthouse filled with golden wine-posed vertically on the tablecloth—shines within reach. (768)

\section{Marianne Moore’s Carrots and Strawberries: A Short Parenthesis}

Marianne Moore's early poem, "Radical" (composed in 1919 but first published in the collection Observations, 1924) describes the "inner life" of a carrot. Unlike most contemporary practitioners of the literary still life, Moore's "Radical" clearly concentrates on the growth, rather than on the consumption, of food. The poet's materiologist vision of a "tail-like, wedgeshaped engine with the / secret of expansion, fused with intensive heat to / the color of the set- / ting sun and / stiff," producing and preserving its own vital energies against the forces of contingency and entropy, echoes the organic factory of Ponge's "Piece of Meat." Moore's carrot, which is "Tapering / to a point, conserving everything" is "predestined / to be thick," its material presence eclipsing "the outside world as "but a circumstance, a mis/ erable corn patch for its feet" (Moore 134). From the speaker's perspective, the vegetable's "physical consciousness" of the earth that surrounds it is determined by the need to release its pent-up, self-nurturing energies. The ragged stanzas of the poem reflects the movement of the carrot's "ambitious" growth, "tapering" downwards in a movement that enacts the "stiff," "belligerent" necessity to survive and expand its fibrous body, "with ambition, im- / agination, outgrowth, / nutriment, / with everything crammed belligerent- / ly inside itself, / its fibres breed mon- / opoly." Such a movement is mimetically reflected in the poem's lines, which also seem to "struggle" away from the in a "wedging" thrust towards the right-hand margin. Moore's later poem "Nevertheless" (1944) contrasts with "Radical" in its adherence to regular patterns (that of the eighteen-syllable stanza comprising three six-syllable lines), although the latter are undermined by unorthodox hyphenated enjambments which bear the mark of the poet's determination in dealing with the struggle and damages of WWII, a suggestion reinforced by the presence of the "barbed wire," the violence of the "ram's horn" and the koksaghyz, or the Russian dandelion, which was an important source of rubber production during the war ("you've seen a strawberry / that's had a struggle; yet / was, where the fragments met, / a hedgehog or a star- / fish for the multitude / of seeds. What better food / than apple seeds-the fruit / within the fruit-locked in / like counter-curved twin / hazelnuts?” [253]).

\section{Between Definition and Description: Ponge's Decentered Lyric}

Ponge's and Moore's object-poems invite a discussion of the poet's rejection of the traditional lyric mode in favor of a hybrid medium that hesitates 
between definition and description, a new kind of writing which "situates itself between the two genres (definition and description), would take from the first its infallibility, its indubitability, its brevity also, from the second its respect for the sensory aspect of things" (Ponge 1999: 516-17). According to Ponge himself, the object poem rejected the traditional, self-present lyric in favor of a decentered lyric born out of our encounter with material objects. In his poetic essay, "L'objet, c'est la poétique," Ponge captures the implications of an ontologically decentered subject and describes man as "a strange body which does not have its center of gravity within itself" and "needs an object which modifies it, like its direct complement, immediately" (Ponge 2002: 657). Ponge's objectist poetics thus emerges a continuation of Stein's use of the still life as a means of finding new ways of expressing the poet's emotional life (see our discussion of Stein's work in the next chapter). As Michel Collot recently remarked, Ponge's "objective" poetry paradoxically "aims at the regeneration of the subject and the renewal of the lyric mode." His rhetoric of objects undermines accepted distinctions between pure and open form at the same time as it defeats the speaker's aspirations to wholeness and totality. In the last analysis, human subjectivity, in the poet's eyes (and mouth)

is not equivalent to the pure interiority of the "spirit" or the "heart ... It is at once material and relational: "sub-jective" means "what pushes me out of myself, from beyond me, from beyond my body," to throw me outside. (qtd. in Rabaté 121)

Ponge's materialist definition of the sub-jective is at once confirmed and complicated in his poem "The Snail," which praises the interpenetration of the passive and active elements which unite the mollusc, its shell and its environment in a movement that emphasizes the "nobility" of the snail's slow movement through the earth itself:

... snails like moist earth. Go on, they progress glued to it with their whole bodies. They carry it with them, swallow it, excrete it. It passes through them. They pass through it. It's an interpenetration in the best of taste because it is, so to speak, tone on tone-with a passive element, an active element, the passive simultaneously bathing and nourishing the active-which moves at the same time as it eats. ... It is so well glued to nature, it enjoys it so perfectly and closely, it befriends the soil which it embraces with his whole body, and the leaves, and the sky toward which he so proudly raises his head, with its so sensitive eyeballs; nobility, slowness, wisdom, arrogance, vanity, pride ... (Ponge 1999: 25-26)

The image of the "wise" and "proud" gasteropod devouring the earth while being traversed by it-continually ingesting, digesting, and excreting 


\section{Food, Poetry, and the Aesthetics of Consumption}

the earth in an endless symbiotic embrace-embodies the utopian dream (from a gastrophilosophical perspective) of a disalienated relationship with food, a movement that allows the formless adaptability of the snail to secrete its own organic dining room. It is interesting to note that the latter develops from its own immediate edible surroundings ("Their very secretion produces itself in such a way that it shapes itself. Nothing external to them, to their necessity, to their need, is involved in their work" [27]), its "contractility" being one of its most admirable virtues, to paraphrase Marianne Moore's own tribute to the invertebrate's graceful "compression" in "To a Snail" (Moore 174). As soon as the mollusc comes out of its shell and "unveils its vulnerable form," its extensible body deploys itself in a continuous movement, which takes us back to one of the great obsessions of Romanticism: that which, via Schlegel and Coleridge, opposes mechanical form (the domain of alienation and imitation) to organic form, which itself allows the poet's creative imagination to develop from within, in its "snail-like," innate self-motivatedness. ${ }^{34}$ Ponge's assimilation of the snail's body to an uninterrupted, self-motivated movement of pure, unalienated sensuousness (as indicated by the bilingual pun on "Go on" which playfully inscribes the very nature of the "escar-got"'s movement in its very name) is further sexualized by the verbs "jouir" (25), "baiser" and "honorer" 35 (Ponge 1999: 26), which characterize the snail's physical penetration of the earth. Ultimately, the snail, which traverses the poetics of Ponge, ${ }^{36}$ is, as the author explains in "The Mollusc" (which immediately precedes "The Snail" in Le Parti pris des choses), almost as much a "quality" as a living "being" (24). Poised between penetration and interpenetration, the snailwhose self-secreted shell is at once an integral part of and a "monument" (27) to its own being ("their shell, which is simultaneously a part of their being and a work of art, a monument")—exists both within and outside the traditional limits of subjectivity and selfhood. This special feature, as Ponge himself concludes, is shared by the artist and the saint ("Saints, they turn their life, their self-perfection into a work of art"), ${ }^{37}$ both of whom "nourish" their respective selves, discretely and stoically "trac[ing] man's duty for him," despising the "necessary" and the obligatory," "their very secretion produc[ing] itself in a way that permits its convertion into form" (27).

\section{CLAUDEL'S PIG AND THE KNOWLEDGE OF RICE}

In one of the middle sections of "The Snail," the slow, noble, methodical stoicism of Ponge's mollusc is contrasted favorably with the behavior of the pig, whose interaction with the earth is characterized by an unrestrained and capricious greediness (26). For Ponge, the pig's "mean little feet" and his "fearful scurrying" are the antithesis of the snail's "perfect slide" and its unashamed way of "honoring" the earth. More than anything, it is the pig's eating habits that Ponge finds repellent on the grounds that they are dictated 
by the animal's hurried fear of "missing or losing something." It has been suggested by Bernard Beugnot (Ponge 1999: 907) that the irruption of the swine in Ponge's object poem may be a response to Paul Claudel's 1896 "The Pig," which is in the poet's first published collection, Connaissance de l'est. ${ }^{38}$ The following passage from Claudel's poem compares the pig with a ploughshare penetrating the soil:

It is a solid, monolithic piece; jointless and neckless, it rushes forward like a ploughshare. Trundling around on its four stocky hams, it is a walking trunk collecting food, ingurgitating every smell into its pumplike body. Once it finds the right hole, it wallows in it with enormity. It is not the duck's impatient wriggling, it is not the dog's sociable exhilaration; it is a deep, solitary, conscious, integral delight. (Claudel 67)

The morphology of Claudel's pig evokes that of a walking stomach: the pig is literally a "gastero-pod," a "stomach on foot" whose "jointless and neckless" body, "solid and all of one piece," "pump[s]" the food out of the fresh mud. Like Ponge's snail, who "does not have many friends" and "does not need them to be happy" because "he is so well stuck to nature, and he so perfectly and closely enjoys it" (Ponge 26), Claudel's pig is essentially a solitary eater. Its instinct drives it to "two fundamental things: earth and filth" (Claudel 67). The conflation of earth and dirt into a single, undifferentiated substance, which is both nutritive and excremental, is paralleled by the ambivalence of the pig's ingestion of edible matter ("It snorts, sips, samples, and one does not know if it is drinking or eating; round-shaped, it quivers forward and dives into the fat heart of the fresh mud"). It also attributes a positive value to the collapse of the solid and the fluid into a muddy, intermediary state which, unlike the Sartrian viscous (to which we will return in the later chapters of this book)—or, to some extent, Ponge's "sickening" bread mush-does not entail the risk of "losing" oneself in ambivalent compromise between self and object, being and consciousness, action and passivity. On the contrary, far from being disparaging, the speaker of Claudel's poem implicitely envies the pig's "deep, solitary, conscious and integral joy" in surrendering to the joys of the earth and ends on an optimistic, possibly redemptive, note with the promise of a material and spiritual transsubstantiation ("I do not forget that pig blood serves to fixate gold" [68]). ${ }^{39}$

A consideration of "Rice," another poem from Connaissance de l'Est, reveals more affinities between Ponge and Claudel's respective poetics of consumption. "Rice" (1903) begins with a comparison between the act of biting into a piece of bread and that of laboring the earth, a comparison that extends to the slicing of the bread crust at the end of the first paragraph. But what makes this comparison rather unusual is less the physical resemblance between the knife and the ploughshare than the suggestion that the bread itself (or, rather, the wheat seed which will be cooked into bread) "eats" the 


\section{Food, Poetry, and the Aesthetics of Consumption}

earth "in the manner in which we will eat it," thereby reversing the activepassive relationship that unites the eater and the eaten:

It is the tooth which we plant in the soil with the ploughing iron, and our bread is already eating from it in the same way as we will consume it. In these parts the cold northern sun sets its hand to the plough; it nurtures our field, just like the naked fire which cooks our bread and roasts our meat. We plough the solid earth and open the furrow which gives birth to the crust which we slice with a knife and crush between our jaws. (136)

The second, and last, paragraph of Claudel's poem takes us to its real object, which is not rice itself but the opposition between East and West seen through the prism of food (the various pieces in Connaissance de l'est were composed between 1895 and 1909, at a time when the author was working as a diplomat in China and other Far Eastern countries). The rice plantation emerges as a space in which the act of growing food departs from the strong, masculine, and potentially sacrificial violence of the ploughman's gesture. In place of the rapid, dividing movement of the ploughsare, we are introduced to a very different art of growing epitomized by the Chinese peasant's patient, endlessly repeated gestures as he "attends to the kitchen of his rice field like a housewife to the steaming dinner." And to the solid "crustiness" of the Western soil, the poet opposes "the menstruations of the virgin earth," an ill-defined, uncontainable landscape, "ill-separated from the sea" and which "the rain saturates without flowing out," a "sauce" which needs, paradoxically, to be nourished with the peasant's own bare hands ("And the village's task is to enrich the sauce with tubs of water: on all fours the peasant mixes it from within and stirs it with its bare hands"). The Chinese peasant, immersed in a fluid element he cannot fully embrace, only "stir up and mix," also differs from his Western counterpart in that he "does not bite into the bread" but "snaps it up with his lips," "gobbl[ing] up" the semi-liquid food without altering its form ("he gulps down a semiliquid food without fashioning it in its mouth"), the grain of rice remaining intact, "unworked" ("non-façonné"). Claudel's tendency to describe food from the inside and emulate the Japanese art of landscape painting, in which "the artist ... instead of copying nature, imitates and borrows the very elements ... to build his forgeries" (Claudel 85), exerted a considerable influence on the author of The Defense of Things. Not unlike Ponge's snail traversing the earth, the Chinese peasant-a reptilian priest ("in his black soutane with its little tortoise-like, mustard-yellow"), toothless and unencumbered by ploughing tools-crawling through the vaporous rice field embodies "the passive immersed in and nourishing the active" (Ponge 25). In different but related ways, Ponge and Claudel once again conceptualize the ontology of an intercorporeal giving and receiving, a process which interrogates the material, esthetic, and phenomenological status of an object 
whose vaporous state hesitates between the solid, the liquid, and (in the case of Claudel's vaporous field) the aerial. The sense of ambivalence and in-betweenness produced by Claudel's grain of rice and Ponge's snail will continue to haunt the poetic writings and performances described in the next chapters. The following sections will show how contemporary food poetics departs from established traditions of the still life while remaining faithful to some of their original impulses in attending to the movements of the poet's mind when confronted with objects that require more than merely visual scrutiny. 


\section{On Tender Buttons and Brussels Sprouts The Modernist Still Life and the Aesthetics of Consumption}

The pancakes will be soft as fine linen.

—Eugène Savitzkaya, Alive

In his recent book on the poetics of the mosaic, Lucien Dällenbach suggests that one way of understanding the birth of modernism is to consider it in the larger context of the "visceral fight which has opposed the fat and the skinny since the beginning of time":

One could legitimately expect the Moderns to side with thinness. Unconditional partisans of the frugal, of the unadultarated and of a mode of preparation which treats a meal's individual ingredients and exalts their gustatory singularity, which is reflected in their discrete arrangement on the plate, those small eaters could only ally themselves with the New Cuisine against the traditions of French gastronomy. The bourgeois cult of the copious, the unequaled science of table dressing: this was already enough to make them take a dislike to it. (115)

For Dällenbach, the quarrel between the Ancients and the Moderns thus boils down to "la querelle des gras et les maigres." What strikes me in this passage is less the historiographical dimension of Dällenbach's claim than its suggestion that modernism can be seen and redefined through the lens of the conjunction of food and discourse. In addressing the relationships between the dynamics of the material signifier and the consumption of material goods, Dällenbach refers to the process which takes us into a space where the conjunction of words and foodstuff provides us with a useful tool for a reappraisal of modernist notions of the body and subjectivity.

Gertrude Stein's Tender Buttons is arguably the most famous example of the poetic still life written and published during the modernist period. Critics who have so far attempted to define Stein's specific contribution to American modernism have tended to underline her peculiar use of repetition-with-variation, her "poetics of indeterminacy," and her subversion of the patriarchal order. ${ }^{1}$ Still, even though Tender Buttons remains her most widely discussed work after Three Lives and The Autobiography of Alice 
$B$. Toklas, very little attention has been paid to her use of the still life and, more particularly, of the "edible" still life which is the subject of this chapter. Part of this neglect is stems from the fact that the still life itself was until recently an underestimated and undertheorized genre which is now gaining the attention of scholars in the field of literary studies and art history. As I have suggested in chapter 1 , an essential aspect of the "edible" still life lies in its capacity to encourage viewers and readers to dissociate food from eating and/or eating from nutrition. Whereas the culinary experiments of the Italian Futurists took food into the domain of the performative and the theatrical-a tendency which prefigured the later experiments of performance artists such as Alice Rios and Karen Finley-the literary still life encourages a further dissociation of the senses whereby the visual spectacle of food has to be conveyed through an ekphrastic description which needs to be processed into imaginary sense impressions in order to truly "make sense." It stimulates the reader's appetite for things that are neither completely inside us nor completely outside us and therefore address a number of fundamental issues related to the boundaries of the lyric self and its discourse. As we will see, it would be pointless to try and understand the literary still life outside the context of what can be called the twentieth century's preoccupation with objects, a tendency reflected in art works as diverse as Ponge's Defense of Things, Wallace Stevens's Cubist object poems and, of course, Stein's prose poems.

\section{GERTRUDE STEIN'S NAKED BREAKFAST}

Tender Buttons is divided into three sections. The first two, "Objects" and "Food," contain 108 short prose entries whose length ranges from a single line to a little more than a page. "Rooms," the third part of the collection, is a long, uninterrupted prose sequence consisting of relatively autonomous paragraphs. Whereas the titles of the still lifes of the first section prepare the reader for a description of Victorian interiors and domestic items (such as a carafe, a cushion, a box, a piece of coffee, a red stamp, a cloak, a red dress and an umbrella), the titles of the entries collected in the "Food" section range from simple ingredients and recipes ("Roastbeef," Mutton," "Breakfast," "Sugar," "Cranberries," "Milk," "Salad Dressing and an Artichoke") to eating actions and rituals ("Dinner," "Dining," "Eating"). As we will see, these recipes exist mainly as a springboard for the observer's reflections on a variety of subjects that range from cooking to clothing to gender relationships to sexual intercourse, not to mention Stein's more general preoccupation with the workings of the phenomenological subject.

As Stein herself repeatedly insisted, the prose poems of Tender Buttons were the result of her investigation not of descriptive prose but of poetic language and what she perceived as poetry's reliance on "nouns." In a 1934 lecture entitled "Poetry and Grammar," Stein commented that "in coming 


\section{Food, Poetry, and the Aesthetics of Consumption}

to avoid nouns a great deal happens and has happened. It was one of the things that happened in a book I called Tender Buttons" (Stein 1967: 136):

In The Making of Americans a long very long prose book made up of sentences and paragraphs ... I said I had gotten rid of nouns and adjectives as much as possible by the method of living in adverbs in verbs in pronouns, in adverbial clauses written or implied and in conjunctions.

But after I had gone as far as I could in these long sentences and paragraphs that had come to do something else I then began very short things and in doing very short things I resolutely realized nouns and decided not to get around them but to meet them, to handle in short to refuse them by using them and in that way my real acquaintance with poetry was begun. (136-7)

This passage is representative of Stein's distrust in the referential power of words ("the sign that means that really means a necessary betrayal" [168]). As for her "refusal of nouns," it parallels her pessimistic view of the evolution of poetic language, which she sees as a gradual process of erosion of its capacity to represent reality adequately or, at least, establish fixed relationships between signifier and signified. "When the language was new," she claims, "as it was with Chaucer and Homer, the poet could use the name of a thing and the thing was really there" (7); "the completeness was in the use" (41). Whatever we make of Stein's view of the Cratylean dream supposedly embodied by the language of Chaucer and Homer, Stein remained convinced that the ensuing "long period" that followed was characterized by an increasing amount of "confusion" which signalled the progressive separation of poetic language from the reality to which it is striving to refer, a period in which writers started to "confuse what they [were] saying with the words they [were] choosing" (44). For Stein the advent of modern poetry meant that the power of words to summon reality into being, what she calls "the excitedness of pure being" of language, was irremediably lost. As a result of the failure of language to create one-to-one relationships between signifier and signified, the name-giving, reality-defining function of words is precisely what the contemporary poet should strive to question and subvert ("poetry is doing nothing but using losing refusing and pleasing and betraying and caressing nouns" [138]). Because poetry, however, is "entirely based on the noun," this can only occur if one decides to "refuse nouns by using them" in order to meet them on their own ground and question their usevalue. The best example of this is Stein's famous line "A rose is a rose is a rose is a rose," whose main purpose was to avoid losing "the enjoyment of naming" (139), which disappears as soon as you know a thing by its name. Poetic language therefore becomes a means of disrupting reified relationships within so-called referential or utilitarian language in order to revitalize it and "make it new": Stein's ambition, so she claimed, was to make the rose appear "red for the first time in English poetry for a hundred years" (7). 
Transposed onto the domain of culinary ekphrasis, this ambition finds its full expression in a poetics that purports to attend "the daily life the complete daily life and the things shut in with that complete daily life" (35). In Stein's project to encompass the total habitus of our everyday lives by attending to the world of objects (such a claim to absolute comprehensiveness is diametrically opposed to the perspectival pessimism and relativism which was to pervade the whole history of Modernist aesthetics), food occupies a transitional status between self and object, a position reflected in its central position within the collection.

Unlike, for instance, Rainer Maria Rilke's Neue Gedichte (1907)—which contain some of the first modern and fully developed occurrences of the socalled "object poem"-Stein's still lifes do not seek to represent the object in a pure state of being and, to cite Rilke's own words, "separated from chance and time" (Preminger 194). On the contrary, Stein's still life poetics is founded on a recognition of the inevitable mutability of the thing observed. In "Breakfast," as in many other pieces of the "Food" section, the vocabulary of cooking and dining provides her with ways of describing the physical alteration of matter within and without the human body. Characteristically, "Breakfast" subordinates description not just to an analysis of medium and perspective (as Stein's Cubist influences indicate) but also to the manipulation of edible matter and its potential for psychological integration:

\section{BREAKFAST}

A change, a final change includes potatoes. This is no authority for the abuse of cheese. What language can instruct any fellow.

A shining breakfast, a breakfast shining, no dispute, no practice, nothing, nothing at all.

A sudden slice changes the whole plate, it does so suddenly.

An imitation, more imitation, imitation succeeds imitations.

Anything that is decent, anything that is present, a calm and a cook and more singularly still a shelter, all these show the need of clamor. What is the custom, the custom is in the centre. (182-83)

"Breakfast" contains in nuce the most important characteristics of Stein's still lifes. These include her distrust of transparent, unproblematic mimesis (the accumulation of "imitations" devalues their relationships to the original object), her desire to "de-center" the traditional lyric subject, and her faith in a "final" and "sudden" "change" of perspective likely to upset traditional ways of representing domestic relationships. Hence, perhaps, Stein's assertion of "the need of clamor," which may refer to her subversive treatment of the "shining" aseptic "decen[cy]" and "custom" of Victorian interiors. As for her denial of an authority for "the abuse of cheese," it may signal the possibility of breaking through the barriers of Victorian decorum. Lastly, the "sudden slice [that] changes the whole plate" in the third sentence anticipates a similar 


\section{Food, Poetry, and the Aesthetics of Consumption}

passage from act 3 of What Happened, a very short "five act play" which first appeared in the volume Geography and Plays (1922). According to Ulla Dydo, the play was an attempt to account for what had actually "happened" at a dinner party for the birthday of British painter Harry Phelan Gibb in April 1913 (Dydo 268):

\section{ACT THREE}

Two.

A cut, a cut is not a slice, what is the occasion for representing a cut and a slice; what is the occasion for all that.

A cut is a slice, a cut is the same slice. The reason that a cut is a slice is that if there is no hurry any time is just as useful.

\section{Four.}

A cut and a slice is the any question when a cut and a slice are just the same.

A cut and a slice has no particular exchange it has such a strange exception to all that which is different.

A cut and only slice, only a cut and only a slice, the remains of a taste may remain and tasting is accurate.

A cut and an occasion, a slice and a substitute a single hurry and circumstance that shows that, all is so reasonable when everything is clear. (271)

The vocabulary used by Stein in What Happened is remarkably similar to that of Tender Buttons, with its obsession with taste and its "Cubist" disruption and distortion of temporal and spatial categories. Still, the strange polyphony that emerges from the play distinguishes it from its predecessor which, for all its experimental qualities, still assumes the presence of an authorial voice which sounds alternately descriptive and self-referential. Because the centered numbers, which conventionally indicate the names of the characters, also indicate the number of paragraphs contained in their section, it is unclear whether the opening "statement" that "a cut is not a slice" is spoken by "two" characters who would then immediately contradict themselves by declaring that a cut is a slice. In the "Four" section, however, the implication seems to be that the slice and the act of cutting cannot be separated from each other, a recognition derived from a constructivist understanding that process and product, the cooking and the cooked, the method and the writing, cannot be considered outside the totality of (physical/ideological) production and consumption.

In other texts, the author's fusion of culinary metaphors are more openly and explicitly critical of sexual politics. Stein's more explicit and, some would 
argue, more confrontational engagement with patriarchal culture in "Patriarchal Poetry" contains the following litany-like list of culinary precepts:

Patriarchal poetry and not meat on Monday patriarchal poetry and meat on Tuesday.

Patriarchal poetry and venison on Wednesday Patriarchal poetry and fish on Friday

Patriarchal poetry and birds on Sunday Patriarchal poetry and chickens on Tuesday

patriarchal poetry and beef on Thursday. Patriarchal poetry and ham on Monday

patriarchal poetry and pork on Thursday patriarchal poetry and beef on Tuesday

patriarchal poetry and fish on Wednesday Patriarchal poetry and eggs on Thursday

patriarchal poetry and carrots on Friday patriarchal poetry and extras on Saturday

patriarchal poetry and venison on Sunday Patriarchal poetry and lamb on Tuesday

patriarchal poetry and jellies on Friday patriarchal poetry and turkeys on Tuesday. (111)

Stein's style here emerges as an extreme, compulsive version of her habitual use of repetition-with-variation discussed above and elsewhere ${ }^{2}$ in connection with the author's early portraits and still lifes. As Krzysztof Ziarek suggests, "the repetitiveness of grammar, its insistence on following rules," may reflect for Stein "the cultural order which links stability with the figure of the father and with patriarchal power-the order of sameness, repetition, and predictability that erases difference." For Ziarek, this would seem to indicate that one of Stein's concerns is to combat the "phallocratic complicity of traditional grammar with the grammar of culture," using the list as a means both to expose the arbitrary nature of hierarchical rules of representations and undermine it from within. "The end result," Peter Quartermain concludes in his own exegesis of "Patriarchal Poetry," is that "the hierarchies are ironed out, and we read the language paratactically, nonpatriarchally" (Quartermain 36).

Quartermain's equation of parataxis and repetition with the language of resistance to authority is not without relevance to a study of Stein's literary still lifes whose commitment to a poetics of physical and semantic mutability undermines the general atmosphere of Victorian cleanliness and propriety that ironically pervades the whole collection. But it is above all the semantic indeterminacy of Stein's descriptions which distinguishes them from the more traditional, metaphorical uses of the genre. Far from ascribing specific connotations to food ingredients, Stein opts for a radically antirealist take on the world of objects, letting meaning arise not from the 


\section{Food, Poetry, and the Aesthetics of Consumption}

accumulation of "meaningful details" but rather from a complex network of sonic and semantic echoes, correspondences and repetitions, the sum of which consolidates the collection's "internal" logic. Besides a number of physical or geometrical elements (such as lines, curves, blank spaces, and "color") linked with Stein's interest in post-impressonist painting, these unifying factors include the idea of "change" and the notion of "spreading," a culinary-sexual pun used repeatedly in Tender Buttons. ${ }^{3}$

\section{A Democracy of the Senses}

Volumes and Pigs,

Razors and Figs,

Set him a jigging

and see how he jigs!

—Edward Lear, "Teapots and Quails"

Tender Buttons has often been interpreted as a poème à clef giving euphemized expression to the author's relationship with Alice B. Toklas. Stein's tendency to use the still life as a means of finding alternative ways of expressing the complexities of her sexual and emotional life is reflected in the following excerpt from her poem "Orange In," where the bilingual pun on "pain" (the French "pain" becomes the English "pain") establishes a set of correspondences between the material and the psychological without resorting to the more traditional mental projections and "pathetic fallacies" which abound in many contemporary object poems. By equating physical with emotional discharge, Stein's poem also becomes a way of ex-creating ${ }^{4}$ a form of suffering which can only be expressed negatively ("a no since"):

Cocoa and clear soup and oranges and oat-meal.

Pain soup, suppose it is question, suppose it is butter, real is, real is only, only excreate, only excreate a no since. (195)

Through its exploration of the senses of smell, touch, and taste, Stein's idiosyncratic use of abstraction in Tender Buttons challenges the then dominant visual and auditory modes of poetic expression, which of course included Imagism-which was at its heyday when Stein began to work on her collection-and the more radical "verbi-voco-visual" experiments of the modernist avant-garde. As Stein reminds us, "a clatter is not a smell" (Stein 1967: 179) and "Roastbeef" pronounces itself in favor of a kind of writing which seeks to capture the synaesthetic metamorphoses of objects and recognizes that the reality-defining function of language is in constant motion so that "no name is signed and left over, not any space is fitted so that moving about is plentiful" (200). The real "point" of Tender Buttons is thus not the description of the objects themselves 
but the changing complexities and mutabilities which constantly interfere with the act of naming:

Why is the name changed. The name is changed because in the little space there is a tree, in some space there are no trees, in every space there is a hint of more, all this causes the decision. ("Rooms" [202])

The exact nature of "the little space" mentioned here remains unclear. Is it the space in which the word "tree" is printed on the page? Is it the window that frames the tree seen from the inside of the house? Be that as it may, Stein's (non-)description of the tree returns us to her fascination with names and her lifelong attempt to discover "a way of naming things that would not invent names, but mean names without naming them" (141). When she started to work on Tender Buttons, Stein claims that one of her main sources of inspiration was Shakespeare's "tree-less" description of the forest of Arden in As You Like It:

I had always been impressed from the time that I was young by having it told me and then afterwards feeling it myself that Shakespeare in the forest of Arden had created a forest without mentioning the things that make a forest. You feel it all but he does not name its names.

Now that was a thing that I too felt in me the need of making it be a thing that could be named without using its name. After all one had known its name anything's name for so long, and so the name was not new but the thing being alive was always new. (142)

Readers familiar with Shakespeare's As You Like It will immediately object that the Bard's description of the forest is far from being "tree-less" (in fact, the Duke Senior's first encounter with the forest in act 2, scene 1, starts with the promise of a "life exempt from public haunt / Finds tongues in trees, books in the running brooks, / Sermons in stones and good in every thing"). Still, one guesses how the Duke's animist celebration of life in the forest as a place of spiritual elevation and linguistic play must have appealed to Stein's imagination. The very language and imagery used by the Duke-one thinks especially of the pun on "books" and "brooks"-is eminently Steinian in its interest in linguistic displacements which suggest ways of exploring transitional states between the fluid and the solid. For the rest of her writing career, language itself became Stein's "forest of Arden," a magical place, where strange linguistic and imagistic coincidences occur, and where ordinary objects are transformed through a kind of language which is "not imitation either of sounds or colors or emotions" but "a real thing" and "an intellectual recreation" (142). Such a ludic exercise, however, requires heightened attention to semantics and rhetoric as well as to the emotional properties of objects ("of course you all do know that when I speak of naming anything, I include emotions as well as things” [142]). 


\section{Food, Poetry, and the Aesthetics of Consumption}

Stein's food poetics, by undermining the taken-for-granted syllogistic and mimetic transparency of the descriptive and definitional still life (Stein's vignettes often read like parodies of dictionary entries), prepares the ground for a creative investigation of the conditions that allow the observer/smeller/ taster/listener to relate to things which can only acquire nonpermanent sensory features and identities. Indeed, Stein's objects exist in a playful "system to pointing" (161), which can only ascribe provisional material and spatial qualities to objects. This is particularly true of foodstuff, whose physical integrity is subjected to crushing, cutting, squeezing, heating, melting, chewing, and other forms of physical manipulations. In the same way as two identical windows can be distinguished from each other by the length and positions of their respective curtains, a piece of meat, a plum, and a gallon of milk cannot be differentiated outside a conceptual framework that enables difference to "spread" (161) and examines the very process of "change" (a recurrent word in Tender Buttons) and mutability, which preconditions any "meaningful" description and analysis:

Why is there a difference between one window and another, why is there a difference, because the curtain is shorter. There is no distaste in beefsteak or in plums or in gallons of milk water, there is no defiance in original piling up over a roof, there is no daylight in the evening, there is none there empty. ("Rooms" 201)

In Stein's "Rooms" the poet's "democratization" of the world of things seems indebted, at least in part, to the Cubist experiments of papier collés mixing and juxtaposing language with the physical world, in the absence of a fixed centre of referentiality ("act so there is no use in a centre" [196]):

A tribune, a tribune does not mean paper, it means nothing more than cake, it means more sugar, it shows the state of lengthening any nose. (201)

A close reading of Stein's Tender Buttons reveals how useful the "inferior" senses of smell and taste are to the apprehension of objects, including the sensuous connotations of the colors, textures, and flavors of food. The sheer wealth of references to gustatory and olfactory impressions in Tender Buttons makes it impossible to agree with any analysis of Stein's collection as a text which considers sight as a privileged faculty. Although some of these ocularcentric interpretations tend to overemphasize the influence of the visual arts, and Cubism in particular, on Stein's style, other critics, such as Christopher Knight, have contended that her prose largely follows the "classical premises of perception," an "episteme which privileges analysis and discrimination" as well as a three-dimensional view of space and a linear view of time (Knight 35). But Although Tender Buttons is indisputably a product of nineteenth century culture (as evidenced by her constant pursuit 
of the "thing-in-itself"), Stein's poetry, rather than representing "the culmination of the classical episteme," would seem to represent its twilight, a twilight resulting from a recognition of the necessity to attend to the fluidity and mutability of things, a paradox which constantly undermines what I have discussed elsewhere as Stein's postessentialist poetics. ${ }^{5}$ The main textual "evidence" provided by Knight to support the privileging of looking in the book is the special status it bestows upon "appearance and color"(36):

Repeatedly, Stein ... speaks of things as being seen. For example, in "A Piece of Coffee," she writes, "The Sight of a reason, the same sightslighter, the sight of a simpler negative answer, the same sore sounder, the intention to wishing, the same splendor, the same furniture" (36)

Surely one would expect ocular perception to play an important part in a collection essentially devoted to the "observation" everyday objects. But a closer look at this passage from "A Piece of Coffee" suggests that the poem, far from privileging visual perception to the detriment of other senses, shows that any attempt to separate vision from other ways of apprehending the world is, as Stein herself might have put it, "useless." ${ }^{6}$ Only a "sightslighter" (the word would seem to suggest an indifferent or careless observer) would separate sight from reason because perception is always already an act of interpretation leading to more or less simple or complex "answer[s]." In the same passage, this recognition of the necessary interaction between the senses extends to the senses of touch and hearing (at least if we assume that the words "answer" and "sounder" refers to the production of sound). The establishment of such a democracy of the senses in Stein's Tender Buttons is strengthened by the use of multiple puns and alliterations which tend to mix and "level down" the different sense levels and registers. It emerges as the opposite of the hierarchical system promoted by the classical episteme Knight defines, via Foucault's The Order of Things, as "a space of order" (35) in which sight is "the means to an analysis partes extra partes acceptable to everyone" (46).

\section{Pink Melon Joy}

It was a peculiar bin a bin fond in beside.

$$
\text { —Gertrude Stein, "Salmon" }
$$

As the readings above amply demonstrate, what is even more problematic about Knight's ocularcentric theory is the unusual wealth of references to smell, taste, and touch which traverses the whole book, an aspect of Stein's work that distinguishes her from contemporary avatars of the literary still life. For, despite the importance she gives to "appearance and color" (36), Stein never neglects other perceptual dimensions of objects such as 


\section{Food, Poetry, and the Aesthetics of Consumption}

weight and texture or the semantics associated with touch, smell, and gustatory experience. Whereas the pithy "A Time To Eat" reduces eating to "a pleasant simple habitual and tyrannical and authorised and educated and resumed and articulate separation" (Stein 1967: 171), "A Sound" is a short but eloquent tribute to the synaesthetic pleasures of candy chewing based on vaguely eroticized childhood reminiscences reinforced by the fetichist pun on "chews" and "shoes":

\section{A SOUND}

Elephant beaten with candy and little pops and chews all bolts and reckless reckless rats, this is this. (174)

As Elizabeth Fifer has convincingly argued, one of the specificities of Stein's poetry lies in its fusion of oral and genital imagery that largely "borrows from Alice Toklas's sphere of influence, the domestic" (Fifer 480). She adds that Alice's cooking and sewing ${ }^{7}$ activities "offered particularly available sources for sexual imagery and (and indeed always have been part of sexual lore in folk and popular literature)." The sewing and threading metaphors identified by Fifer are mainly taken from more "lyrical" pieces, such as "Pink Melon Joy," "Painted Lace," "Lifting Belly," and "Possessive Case." As for "Breakfast" and the other pieces contained in the "Food" section of the book, they provide ample evidence that the poet's appetite and her pleasure in eating rather than merely looking at food remains at the center of her linguistic and phenomenological preoccupations:

What is a loving tongue and pepper and more fish than there is when tears many tears are necessary. The tongue and the salmon, there is not salmon when brown is a color, there is salmon when there is no meaning to an early morning being pleasanter. There is no salmon, there are no tea-cups, there are the same kind of mushes as are used as stomachers by the eating hopes that makes eggs delicious. Drink is likely to stir a certain respect for an egg cup and more water melon than was ever eaten yesterday. Beer is neglected and cocoanut is famous. Coffee all coffee and a sample of soup all soup these are the choice of a baker. A white cup means a wedding. A wet cup means a vacation. A strong cup means an especial regulation. A single cup means a capital arrangement between the drawer and the place that is open. ("Breakfast"; Stein 1967: 183)

Although the mushed eggs of "Breakfast" can both signify an intermediary state between fluid and solid and the "mushy" sentimentality inherent in the use of culinary metaphors to convey sexual relationships, the anachronistic "stomacher" (the ornamented triangular section of the bodice covering the stomach or chest, worn by both sexes until the eighteenth century), added 
to the symbolic transformation of the simple egg cup into a white "wedding cup," considers the physical and cultural limits and "regulations" imposed upon the eating body by clothing and convention. The salmon evokes the "shocking pink" of female genitalia, ${ }^{8}$ and Stein's innuendo-saturated description refuses to separate the tongue from the flesh, or the lips from the cup, in a gesture that combines the pleasures of gustative pleasure and oral sex.

Similarly, "Roastbeef," the opening, programmatic text of the "Food" section, conveys different levels of proximity of sensual apprehension while enacting the proximity of gustatory and aesthetic taste. Characteristically, the act of visual dissection of the object is subordinated to the actual carving and cooking of the meat, a ritual which testifies to Stein's hope of discovering a "stouter symmetry" within a changing and unstable world, a world in which the tender and the poisonous, the cultural and the natural, occasionally coexist in a transient and "lovely" harmony:

Lovely snipe and tender turn, excellent vapor and slender butter, all the splinter and the trunk, all the poisonous darkening drunk, all the joy in weak success, all the joyful tenderness, all the section and the tea, all the stouter symmetry. (178)

The examples I have discussed show the centrality of taste to Stein's project to represent nothing less than the process of representation itself in a way that does justice to the immediacy of sensory apprehension. They also show that Stein resists the temptation to surrender to the primacy of vision heralded by classical philosophy and attend to the materiality of language as well as things ("Celery tastes tastes where in curled lashes and little bits and mostly in remains" [190]). In order to achieve these goals, Stein develops a micropoetics of sensory experience that investigates the very fabric of edible objects. Once the inanimate becomes animated, the relation between materiality and meaning becomes a relation in movement, a system of "spreading," a description in the act of becoming meaningful, poised between an atomist view emphasizing the irreducible integrity of matter and a metapoetic stance which confers meaning to things through their physical interaction with the observer/feeler/smeller/taster. Stein's vignettes thus focus on the physical properties of objects at the same time as they insist on their potential for being ab-stracted from the world of matter and transformed into sense impressions. In Stein's poetry, the unstable, liminal quality of food questions the limits of the body which, in turn, tends to be perceived as a precarious, unfinished entity, an organic factory ingesting, processing, exuding and excreting substances which are alternately inside and outside.

\section{Walking on the Wild Side of Modernism}

Considered in the context of the development of a modern tradition of the literary still life, one of the particularities of Stein's Tender Buttons is 


\section{Food, Poetry, and the Aesthetics of Consumption}

that her still lifes only exist only in and through time and movement and are therefore far from being "still" (or dead, if one refers to the French "nature morte"). Playing upon the tension between painting (a spatial art) and literature (a time art) and aspiring to the condition of film, a medium that conveys both time and space, Stein seeks to create a polymorphous zone which is no longer subject to such a distinction. ${ }^{9}$ Stein's penchant for sexual innuendoes further complexifies the process of the sensory dissociation that characterizes her "moving" still lifes. Although it has been suggested that Stein's "tender buttons" were a euphemism for a woman's nipples," there is, according to Virgil Thomson, "another erogenous zone in female anatomy that could just as easily be called a tender button." James Laughlin, for his part, reports that it was "a common name for the vegetable Brussels sprouts in the days when Gertrude and Alice were growing up." "Gertrude explained this to me herself," Laughlin writes, "many years ago when I was visiting at her place near Bilignin, and I always assumed that she was not pulling my leg, for the title seems to me very natural and suitable for that particular book, seen in that light of what the words could mean." Whatever we make of Laughlin's anecdote and Thomson's speculations, my readings of pieces such as "Breakfast" and "Salmon" evidence the strong conceptual link that unites food and sex in the whole collection. In many other pieces contained in the "Food" section of the collection, Stein uses the vocabulary of cooking to give euphemistic expression to her lesbianism. Milk, potatoes, cabbage, butter, and other culinary ingredients evoke various erogenous zones in female anatomy:

\section{MILK}

A white egg and a colored pan and a cabbage showing settlement, a constant increase.

A cold in a nose, a single cold nose makes an excuse. Two are more necessary.

All the goods are stolen, all the blisters are in the cup.

Cooking, cooking is the recognition between sudden and nearly sudden very little and all large holes.

A real pint, one that is open and closed and in the middle is so bad. (Stein 1967: 186)

As Marjorie Perloff has remarked, Stein's "Milk" creates sexual innuendo "by what the Russian formalists called "orientation toward the neighboring word'" (Perloff 1985: 190), which makes us wonder whether we are "hearing about milk or about female parts and liquids" (191). In Stein's collection, this piece is immediately followed by another, onesentence "Milk" poem in which the pun on "in sight" and "inside" also expresses the intermingling of erotic and gustatory pleasure ("Climb up 
in sight climb in the whole utter needles and a guess a whole guess is hanging. Hanging hanging" [Stein 1967: 186]). As for the cavities and containers (boxes, bottles, bins, etc.) which abound in "Milk" and the whole collection, they implicitly reduce the act of eating to the fundamental action of "filling holes," an action defined by Jean-Paul Sartre as the primary function underlying both the acts of eating and of copulating. ${ }^{11}$ But what Stein's "Milk" even more fundamentally describes is a liminal substance which, like the "white egg" and the "cold in the nose" mentioned in the first and second paragraphs, respectively, is secreted by the body and destined to be eaten-an ambivalent matter that interrogates the limits of the self and is reminiscent of conflicting emotions and sensations surrounding the nourishing maternal body. ${ }^{12}$ In a piece such as "A Brown," contained in the "Objects" section of Tender Buttons, Stein's scatological humor adds another, more playful twist to her poetics and politics of corporeality as the sentence "a news is pressing" can be understood as a pun on "anus" and/or to the act of pressing a scrap of newspaper against the body, a piece of paper which would then undergo "its own surprising change from reading matter into material for the sewer" (Ruddick 236):

\section{A BROWN}

A brown which is not liquid not more relaxed and yet there is a change, a news is pressing.

\section{WYNHAM LEWIS’S UNHUNGRY ITCH}

He seemed to find analogies for his repeating habits in pictures provided by the human digestion.

$$
\text { —Wyndham Lewis, Tarr }
$$

As we have seen, Stein's "Naked Lunch" is far from enacting what Dällenbach diagnoses as the "nutritive nightmare" of the Moderns (Dällenbach 119), a condition marked by various "aversions and phobias rather than the pleasures of the table and a happy appetite" (116). In English modernist letters, nowhere is this tendency more manifest than in the personality of Wyndham Lewis's Frederick Tarr, whose claim to be immune to the physical claims of sex and appetite is best expressed in the central lunch scene of the novel, where he attempts to resist both the pleasures of food and his girlfriend Bertha's sexual appeal:

To cover reflection, he set himself to finish lunch. The strawberries were devoured mechanically, with unhungry itch to clear the plate. He had 


\section{Food, Poetry, and the Aesthetics of Consumption}

become just a devouring-machine, restless if any of the little red balls still remained in front of him. (Lewis 68)

The mechanical hurriedness with which Tarr proceeds to eat his meal is symptomatic of what Lucy Ricaud recently described as his tendency to oppose "negative values such as meat, sex, women, emotions and positive ones such as anorexia, emotional or physical frigidity and indifference" (Ricaud 218), a tendency which reveals the links established between misogyny and anorexia, a term which Tarr extends to "loss of appetite both for food and sex and aesthetics" (213). As For Lewis's third-person narrator, he concludes that Tarr's refusal to let his passions and appetites express themselves is rooted in a "Puritanical and uncivilised" way of life, "the result of solitary habits" and "morbid English shyness, that cannot tolerate passion in its nakedeness" (Lewis 12-13). In the context of his relationship with Bertha-a relationship he regards as a foolish attempt to "have the apple and eat it too" (26)-Tarr's insistence on the necessity to preserve his creative vitality and channel it fully into art leads him to condemn greed in all its forms. Animated by the Nietzschean dream of a new, unconditional vitalism in life as well as art, he is desperately looking for a creative space unencumbered by the morality and sentimentalism of the masses. His emphasis on detachment and control in artistic as well as dietetic matters causes Tarr a lot of anxiety regarding both women and food. Tarr ultimately feels threatened by the prospect of being literally devoured by Bertha who jokingly nicknames him "Sorbet," the French for "Sherbet," which becomes Tarr's "love name" and "a perversion of his strange second name Sorbert" (47)..$^{13}$ Lastly, Tarr's declaration that "man is the opposite of his appetite" also makes him a precursor of the anorexic artists and characters analysed in chapter 4.

Later in the novel, Tarr's neurotic relationship with food climaxes in his affair with Anastasya, a woman whose aristocratic cosmopolitanism (her parents are Russian, was born in Berlin and raised in America) transcends the narrow artistic and ideological confines of his own "Englishness." The nature of their confrontation is epitomized in another dinner scene in which Tarr finds himself overwhelmed by the sheer energy of the woman's forceful, life-affirming appetite. Tarr, the ascetic vegetarian, finds himself in a difficult situation when Anastasya tries to make him eat oysters, a delicacy Tarr confesses to never having eaten before:

They ordered oysters: they would be his first, he had never before dared to eat an oyster, because it was alive.

When he told her that it was his first oyster she was exultant.

"You perfect savage-your palate is as conservative as on ox's. Kiss me Tarr-you have never done that either properly."

The use of his gentile name was a tremendous caress. She presented her salt wet eating lips, he kissed them properly with solemnity, adjusting his glasses afterwards. 
"Why have you never eaten oysters?"

"The fact that they were alive has so far deterred me but I now see that I was wrong."

"You are afraid of everything that is alive" she assured him with a portentous nod. (Lewis 310)

In the argument that follows, Anastasya accuses Tarr of having "a marked prejudice in favour of what is dead" (310). She concludes that his failure to become a great artist is due to his incapacity to "hunt and kill his material so to speak just as primitive man had to do his own trapping butchering and cooking"; "it will not do to be squeamish," she concludes, "if you are to become a great artist, Mister Tarr!" (311). Tarr is both defeated by his own gustative and sexual impotence and terrified by the viscous sexuality embodied by the mollusc (the visual pun here is on the oyster's likeness to female genitals). His culinary humiliation consolidates his belief that an artist must realize himself in art, not in the life of the senses. ${ }^{14}$ Indeed, Tarr holds on to his belief that, unlike the common people, whose vitality "goes into sex if it goes anywhere" ("during their courtship they become third-rate poets, all their instincts of drama come out freshly with their wives" [20]), the artist must have a "more discriminating" sex instinct and develop a severe, "ascetic rather than sensuous" character which is "divorced from immediate life" (21).

Clearly, Lewis's difficult relationship with food comes closer to Eliot's, for whom "eating and drinking rituals are always associated with the futility and false consciousness of modern social life" (one thinks, for instance, of the "cups, the marmalade, the tea," the "cakes and ices" and "coffeespoons" of "Prufrock") than to Stein's, which is "regularly associated with pleasure, especially the sexual pleasures of women" (Perloff 2002: 66). As she herself puts it, in "Roastbeef," "the result the pure result is juice," and one may venture to suggest that its is the sensuous "juiciness" of Stein's prose-not its alleged abstractness or conceptuality—which has ensured its continuing popularity with scholars of the avant-garde over the last thirty years or so. As Perloff remarks, "Prufrock's question 'Do I dare to eat a peach?' has no place in the world of Tender Buttons, where indeed one dares to eat a peach and where, in any case, the issue is not conformity to this or that social norm, but the nature of peachness itself. Potatoes and cranberries, eggs and milk, carafes and boxes-to meditate on these ordinary things is to refigure one's place in the world of objects" (66-67).

Whereas Eliot, Lewis, and Joyce, to name but three major representatives of high modernism, have tended to use food to convey the ungodly condition of man in terms that evoke the peristaltic doom of a creature whose life is controlled by chemical and mechanical processes over which it has very little control ("and we stuffing food in one hole and out behind: food, chyle, blood dung, earth, food: have to feed it like stoking an engine" [Joyce 145]), ${ }^{15}$ Stein takes us into the direction of a poetics of objects that is akin to what Michel Onfray has described as "materiology," a discipline which allies gastronomy 


\section{Food, Poetry, and the Aesthetics of Consumption}

and aesthetics in their relationship to formal experimentation. ${ }^{16}$ The functional principle that combines cooking and poetry in Tender Buttons is precisely the desire to describe the process of transformation/alteration of linguistic and edible matter. In many ways, Stein's "materiology" is the exact opposite of Marinetti's futurist banquets, which are discussed in the closing chapter of this study. Instead of transforming actual foodstuff into discursive dishes and culinary narratives liable to be consumed as works of art, it manipulates the very fabric of discourse in order to foreground its status as object and create polysemic vignettes which abstract and multiply the formal and sensorial vectors of material consumption.

\section{DUCHAMP'S SUGAR CUBES}

In order to further place the importance of Stein's still life poetics in the context of the emergence of an alternative form of American modernism, one must turn to Marcel Duchamp's ready-made Why Not Sneeze Rrose Sélavy? (1921/1964), a bird cage containing 152 marble cubes in the form of sugar cubes, a thermometer and cuttlefish bone. As Duchamp himself explained, "This little birdcage is filled with sugar lumps ... but the sugar lumps are made of marble and when you lift it, you are surprised by the unexpected weight./ The thermometer is to register the temperature of the marble" (qtd. in Mink 7). In a 1956 interview, Duchamp goes on to argue that:

It was naturally, in trying to draw a conclusion or consequence from the dehumanization of the work of art, that I came to the idea of the Ready-mades. That is the name, as you know, that I gave to those works which in effect are already completely made. Let me show you: this is a Ready-made bird cage with, if you see me, I am having a hard time because this is not sugar, that is marble, and it weighs a ton, and that was one of the elements that interested me when I made it, you see. It is a Ready-made in which the sugar is changed to marble. It is sort of a mythological effect. (Sanouillet and Peterson 135)

As Janis Mink points out, the title of the piece can be seen as "a proposition. Why not do something like sneezing, that cathartic reaction that grows from a tickle to a climactic explosion, leaving only runny traces behind?" (Mink 7). Once again the poetic still life takes us in the direction of a possible eruption of the senses, one which is undermined, at least to some extent, by the unexpected weight of the sugar lumps that defeat the promise of sweetness delivered by the ready-made. The coldness of Duchamp's use of marble creates ironic tension (the thermometer will never erupt) while being suggestive of an earlier, pre-modern aesthetic that relied on the use of noble, expensive material, a suggestion which is invalidated by the fact that the cubes bear the mark of mass production (they are stamped "Made in France"). Part 
of the "sort of a mythological effect" of the piece (the transmutation of sugar into marble) thus depends on the sense of anxiety created by an object which hesitates between the nonorganic and the organic (suggested by the thermometer and the cuttlebone that metonymically evokes the absent bird) while simultaneously pointing in the direction of sexual innuendo ("Eros, c'est la vie").

Two earlier works by Duchamp, the "Chocolate Grinder" (1914) and the "Bottle Hanger" (1914) deal with food-related subjects. The "Chocolate Grinder" is a painting designed as preparatory material for inclusion in his later installation "The Large Glass" and in which the artist's use of a "direct perspective" and "well-defined" geometrical contours made him feel "free for ever from the straight jacket of Cubism" (Duchamp 224). ${ }^{17}$ As for the "Bottle Hanger," it has been hailed by many as signaling the emergence of a kind of art (three years before Duchamp's urinal) that-besides being one of the earliest examples of the "anorexic" art analyzed in chapter 4-sets the tone for a gradual desacralization of the artwork and a poetics of the commonplace which has since then dominated the subsequent history of the avant-garde, in America and elsewhere. In the words of Duchamp, the choice of the ready-made was "never dictated by aesthetic delectation" but, rather by "a reaction of visual indifference with at the same time a total absence of good or bad taste ... In fact a complete anaesthesia" (Stiles and Selz 820). In order to qualify as a ready-made, the "found object" has to become an-aesthetic, tasteless, and, above all, completely useless. Duchamp's self-attested aversion to the work ethic is indeed indicative of an art which cannot have "any social importance whatsoever ... a work which is inscribed nowhere, which is neither visual nor cerebral. It's a sort of constant euphoria" (quoted in Erickson 115).

Duchamp's ready-mades are often regarded as a kind of work that abolishes the separation of art of life, which includes such banal activities as eating a chocolate bar and drinking a glass of wine. And still, nothing seems more remote from everyday life than Duchamp's bottle hanger. The absence of bottles encourages the viewer to forget the theme of wine consumption and concentrate on the shape and structure of the object (which may in turn encourage a symbolic reading of the spiky, phallic shape of the rack). Duchamp's bottle rack is literally "stripped bare" of its utilitarian function, that of facilitating the storage and drying of empty wine bottles in the same way as the "Chocolate Grinder" was abstracted from its instrumental destiny to become a conceptual part of the "Large Glass." Duchamp's readymades have encouraged thousands of artists to experiment with everyday objects and material, including foodstuff, and exploit their aesthetic and philosophical potential. But such decontextualized, abstract objects are no longer objects in their own right. They have become generic things whose structural properties (and their metaphorical extensions) are emphasized to their physical impact on the life of the senses. For Octavio Paz, Duchamp's ready-made is "not just a dialectical game; it is also an ascetic exercise, a 


\section{Food, Poetry, and the Aesthetics of Consumption}

means of purgation" which results in "a nihilism that gravitates on itself and refutes itself ... the enthroning of a nothing and, once it is on its throne, denying it denying oneself" (Paz 29). For Paz, one of the biggest supporters of Duchamp's aesthetics, such a poetics of (double) negation amounts to "an art of interior revelation" similar to the blessed state of Bodhisattva," a "non-entity" which Duchamp once described as "the beauty of indifference" (29). Duchamp's food aesthetics, as displayed in "Chocolate Grinder" and "Bottle Rack," is once again emblematic of Dällenbach's ascetic modernism, with its antibourgeois rejection of the seamless, instrumental transparency of artworks and objects alike. More importantly, such an aesthetics excludes the body who manipulates the utensil and prepares to savor the result of his preparation. The radical, "an-aestheticized" autonomy of Duchamp's ready-mades also conceal the social relations that underlie the concrete conditions of production and use of the object. In the last analysis, Duchamp's bottle rack no longer belongs to anyone or any particular context, the ultimate goal of the ready-made being to convey a sense of nonpossession and "noncontemplation" (Paz 29).

\section{On Creaminess and Totality}

All belly belly well.

$$
\text { —Gertrude Stein, "Lifting Belly” }
$$

The superiority of the generic over the singular, as well as of structure over use and labor, in Duchamp's peculiar appropriation of manufactured objects anticipates certain features of the Pop Art works considered in the next chapter. Seen from the angle of Dällenbach's gustatory aesthetics and his appraisal of the modernist cult of thinness, the modernist opposition to "creaminess," seamlessness, and its assumptions of totality, continuity and narrative is logically reflected in its penchant for an aesthetics of juxtaposition, disjunction, and collage. As for Stein's still lifes, they have been widely interpreted as the nearest literary equivalent to Cubist painting, which itself often resorts to collage and seeks to persuade its viewers that an object or landscape is "possessed of an infinite number of perspectives, all equally veracious and authentic" (Ortega y Gasset 92). Such is the essence of Stein's now famous "composition as explanation," a mode influenced by Cézanne, who was among the first to reject the notion that composition consists "of a central idea, to which everything else was an accompaniment and separate but which was not an end in itself" and embrace a new method which was based on the recognition that "in composition one thing was as important as another thing. Each part is as important as the whole" (Stein 1971: 19).

Parallels have been drawn between Why Not Sneeze ... and Stein's long poem "Lifting Belly" (1917), ${ }^{19}$ a poem that explores the erotic potential of food and consumption and contains explicit references to sneezing and 
sugar. Unlike Duchamp's installation, however, Stein's poem is deeply rooted in the body's drives and appetites. In many ways, nothing is further from Duchamp's (literally) disincarnated ready-made sculpture than Stein's juicy, visceral prose poetry:

All belly belly well (4) . . . Did you say, oh lifting belly. / What is my other name / Representative. / Of what. / Of all the evils of eating. / What are they then. / They are sweet and figs. / Do not send them. / Yes we will it will be very easy. (5) . . Sneeze. This is the way to say it (9) . . . Lifting belly is a picnic. On a fine day. / We like the weather it is very beautiful (12) . . . Strawberry. / Lifting beside belly. / Lifting kindly belly. (20) . . Did she say jelly. Jelly my jelly. Lifting belly is so round (22) ... And then there was a cake. Please give it to me. She did (37) . . . The Jew lady. How do you do. She is my wife. / Can you accuse lifting bellys of extras. / Salmon is slamon. Smoked and the most nourishing. / Pink salmon is my favorite color (39) . . Fairy ham / Is a clam. Of chowder ... Lifting belly is famous for recipes. / You mean Genevieve. / I mean I never ask for potatoes. / But you liked them then. / And now. / Now we know about water (46) ... Lifting belly is sugar. Lifting belly to me (52) . . Dear Daisy / She is a dish. (53)

The examples I have just cited undergo permutations and transformations throughout the poem. They use the vocabulary of food to describe the energies of homoerotic sexual hunger. Mixing fragments of ordinary conversation and "kitchen talk" with food euphemisms for sexually aroused body parts, "Lifting Belly" delights in the accumulative effect of culinary badinage, double entendres, and sexual innuendoes, assessing the dangers and attractions of food sex, autophagy, and cannibalism, while speculating about the proximity of the pleasures of reading and the "evils" of eating ("Do you like ink. / Better than butter. / Better than anything. / Any letter is an alphabet. / When this you see you will kiss me" [48]).

"Yet Dish," a lesser know piece published in 1913 (the title can be heard as "Yiddish" and point to somewhat different, more cultural influences), displays a rather different interest in the phonemic and physical textures of food ingredients and body parts, one which comes closer to the pun-ridden anti-descriptions of Tender Buttons:

Cousin coarse in coarse in soap.

Cousin coarse in soap sew up. Soap.

Cousin coarse in sew up soap. (55)

In the later sections of the poem, the puns on "soap" and "soup" and "coarse" and course," which set the tone for the whole poem, give way to a constellation of motifs that blur the boundaries between inside and outside, 


\section{Food, Poetry, and the Aesthetics of Consumption}

the eater and the eaten, the container and the contained, meat and flesh ("never a single ham" [57]; "pet soap" [58]), food and identity ("Lessons lettuce. / Let us peer let us polite let us pour, let us polite" [59]; "Pale eaten best seek" [61]), as well as the consumption and excretion of fluids and liquids ("peace while peace while toast" [57]). "Yet Dish" culminates in complex, synaesthetic, and unusually anxious kaleidoscopic visions of the pregnant contradictions of the unfinished body:

Meal dread.

Meal dread so or.

Meal dread so or bounce.

Meal dread so or bounce two sales. Meal dread so or bounce two sails. Not a rice. No nor a pray seat, not a little muscle, not a nor noble, not a cool right more than a song in every period of nails and pieces pieces places of places. (58)

\section{SUGAR AND KIDNEYS: JOYCE'S PERISTALTIC POETICS}

As in Willie Dixon's standard "Spoonful"20_a masterpiece of equivocal blues flirtation that seems an unlikely candidate for an examination of American modernism-Stein's food poetics leaves us wondering whether we are dealing with a spoonful of sugar that stands for the metaphorical sweetness of love relationships. Stein's celebration of the sweet-sexy in "A Substance in a Cushion," begins with the recognition that "sugar is not a vegetable." As always, the precise meanings and "buried narratives" of Stein's serial abstractionism remain inscrutable, but one of the implications of this sentence may be that the ignorance or lack of taste that can lead us to confuse sugar with a vegetable is also liable to reduce our aesthetic, culinary, and sexual options. In the following excerpt from "Breakfast," the rhythms of Stein's prose convey the pleasures of ingestion at the same time as they attempt to pump all the jaded "wornout literary words" (Stein 1967: 7) out of the reader's stomach and rinse the poet's mouth of the unpleasant taste of stale poetic images and postromantic decorum:

A breeze in a jar and even then silence, a special anticipation in a rack, a gurgle a whole gurgle and more cheese than almost anything, is this an astonishment, does this incline more than the original division between a tray and a talking arrangement and even then a calling into another room gently with some chicken in any way. ("Breakfast" 183)

Clearly, Stein's approach to food, unlike that of Eliot or Lewis, remains consistently optimistic and hedonistic. My intention here is not to ask whether her food fetishism and gourmet eroticism is representative of a 
dominant or subversive trend in the modernist approach to food and food art. The examples I have selected suggest that in modernist poetry and the visual arts, food often remains an object of poetico-conceptual investigation, not a springboard for a critique (or celebration) of commodification and consumer fetishism. A rather different story (and a rather different book) could account for the various uses of food displayed by the dystopian tradition upheld by Upton Sinclair's The Jungle or, for that matter, Charlie Chaplin's Modern Times, whose memorable eating machine (which is meant to minimize lunchtime on the job and maximize the workers' output) remains a powerful metaphor of the death of the subject crushed under the weight of the mechanization of modern urban life. But these examples, like Eliot's "Prufrock," far from making foodstuff the essential, material foundation of their aesthetic, tend to use it primarily as a metaphorical element of a larger social and political critique. In the context of modernist poetry, Elizabeth Bishop's sestina "Miracle for Breakfast" embodies such a socially conscious approach to food (and hunger). Bishop herself described the piece as her "Depression poem ... written shortly after the times of souplines and men selling apples, around 1936 or so" (cited in Schwartz 297). The poem depicts a crowd of starving citizens who are "waiting for coffee, / waiting for coffee and the charitable crumb / that was going to be served from a certain balcony" (Bishop 20). In place of a loaf of bread and a cup of coffee, they only receive a literal crumb and only a drop of coffee and start longing for divine intervention. The perspective then shifts to the first person singular, and the speaker eventually escapes into a dream world where nature itself can provide her with a comfortable house built "through ages, by insects, birds, and the river." In a poignant, surrealist image, the crumb, with its implicit reference to the Eucharist, becomes the opaque mirror in which this dreamworld is paradoxically reflected (the speaker sees the bounteous villa "with one eye close to the crumb"). The piece ends with a return to the communal "we" and a recognition that the miracle has not occurred and that the social subordination of the starving mass to the "charitable" "kings of old" will never be eradicated ("We licked up the crumb and swallowed the coffee / A window across the river caught the sun / as if the miracle were working, on the wrong balcony" [21]). ${ }^{21}$

Unlike Bishop's starving dreamer in "A Miracle for Breakfast," Stein's gastropoetics, despite the radicalism of its sexual politics, is less geared towards social criticism, direct statements, and practical changes than towards the development of unusual forms of consumption (often of a fetishistic nature) which effect the gradual abstraction and dissociation of food from its usevalue. A detailed comparison between Stein and Joyce would probably reveal more similarities and dissimilarities between the former's culinary innuendoes and the latter's poetic peristaltics. Joyce's Ulysses, in particular, offers another useful model for an understanding of the totality of literary production and consumption. Like Stein's "A Brown," Ulysses considers the writer's creative practice as fundamentally excremental. By likening the 


\section{Food, Poetry, and the Aesthetics of Consumption}

movement of food down the oesophagus and, by extension, the entire digestive process, to the workings of narrative fiction in the "Lestrygonians" chapter, Joyce sets the tone for many later attempts to pursue analogies between diet and discourse in order to illuminate the tensions between physical and mental pleasures. Of this chapter the author declared:

"Among other things," he said, "my book is the epic of the human body. The only man I know who has attempted the same thing is Phineas Fletcher. But then his Purple Island is purely descriptive, a kind of coloured anatomical chart of the human body. In my book the body lives in and moves through space and is the home of a full human personality. The words I write are adapted to express first one of its functions then another. In Lestrygonians the stomach dominates and the rhythm of the episode is that of the peristaltic movement."

"But the minds, the thoughts of the characters," I began.

"If they had no body they would have no mind," said Joyce. "It's all one." (Budgen 21)

Joyce sees the body as the supreme maximalist receiver and generator of meaning, rhythm and being. Although Bloom insists on the simultaneously enjoyable and disturbing sensations afforded by food and sex, ${ }^{22}$ Joyce's peristaltic prose argues for a kind of interpretive reading, which causes his writing to inflate with unexpected meanings that exceed the sum of its individual parts. In Ulysses, this strategy takes the form of a compulsive cycle of consumption and excretion that is perhaps best exemplified by the beginning of the "Calypso" chapter, which pictures Leopold Bloom eating "with relish the inner organs of beasts and fowls":

He liked thick giblet soup, nutty gizzards, a stuffed roast heart, liverslices fried with crustcrumbs, fried hencods' roes. Most of all he liked grilled mutton kidneys which gave to his palate a fine tang of faintly scented urine. (Joyce 2000: 65)

Later, in "Calypso," this circular peristaltic metaphor is extended to textual consumption as he sits on the toilet seat reading the newspaper, the rhythms of reading varying with the syncopated cadences of excretion:

Quietly he read, restraining himself, the first column and, yielding but resisting, began the second. Midway, his last resistance yielding, he allowed his bowels to ease themselves quietly as he read, reading still patiently that slight constipation of yesterday quite gone. (78)

As the rhythms of Bloom's defecation begin to interfere with his reading speed, Ulysses stages the uneasy interaction of body and mind, investing the "other end" of the digestive tract with a meaningful capacity which 
exceeds its primary physiological function. Here, the simultaneous consumption of textual matter and expulsion of fecal matter is still linked to a model of subjectivity that, unlike Stein's Tender Buttons, separates inside from outside. But the subject's vulnerability to constipation also underlines the potential dangers of a dysfunctional exchange between self and world, a failure of digestion described in Coleridge's notebooks as "the endless Flatulence, the frightful constipation when the dead Filth impales the lower Gut" (qtd. in Morton 243), a humiliating condition which suppresses the pleasure of release and condemns the digestive tract to laborious contractions. The metafictional and metapoetic implications of Joyce's description of the labor of the guts convey his ambition to pass "that last frontier of novelistic realism-beyond a character's palate and down inside his digestive track . . . collaps[ing] ingestion with the very end of the digestive process" (Bénéjam 26). Joyce's short-circuiting of the digestive process, like Stein's gourmet aesthetics, returns us to Barthes's definition of taste as a perversion "built upon the dissociation of need and desire," a space in which the mouth and the teeth emerge as the organs of speaking, consumption, and sexual intercourse and contribute to the expression of a self "unencumbered by social guilt" (Barthes 1984: 304), exalting the need to combat the forces of convention and habit and celebrate the raw, unconditional energies of bodily labor. 


\section{Pop Serialism \\ Soup Cans, Pie Counters, and Things That Look Like Meat}

\section{HARRYETTE MULLEN'S $S^{* P E R M *}{ }^{* * T}$}

Harryette Mullen is one of the very few African-American writers whose works have been associated with Language Poetry. ${ }^{1}$ Trimmings, her second collection-appropriately published in 1991 by Lee Ann Brown's Tender Buttons press-is inspired by Stein's use of the still life. The collection, which investigates the cultural values and mannerisms associated with feminine clothing, mixes references to Stein's "cubist" prose sketches with elements of Black dialect and fragments of blues songs in a way that alternates between the literal and the metaphorical, the philosophical and the erotic. In her third book, $S * P e R M *{ }^{*}{ }^{*} T$ (1992) (pronounced as both "supermarket" and "spermkit"), one of Mullen's main targets is what she describes as "the erotics of marketing and consumption" which transform foodstuff into culturally-charged commodities. Not only are we the products of what we eat (the missing letters of the collection's title happen to be U-A-R-E, which almost reads as "you are what you eat."), but the very language of commodity production and advertising reveals the status of food as "a system of communication, a body of images, a protocol of usages, situations, and behavior" (Barthes 1997: 22). More specifically, Mullen's prose poems stage what Jean-François Lyotard described as the power of commodity capitalism to "derealize familiar objects, social roles, and institutions to such a degree that the so-called realistic representations can no longer evoke reality except as nostalgia or mockery" (Lyotard 14). Still, for all their debased and "derealized" nature, the objects described in Mullen's poetry point to the potential for cultural identification and uniformization embodied by supermarket goods. In the following poem from $S^{*} \mathrm{PeRM}$ * $\mathrm{K}^{*} T$ (all the poems in the collection are untitled and unpaginated), Mullen describes the pink, blonde, and blue-eyed babies that appear on baby food cans:

Ad infinitum perpetual infants goo. Pastel puree of pure pink bland blue-eyed babes all born a cute blond with no chronic colic. Sterile eugenically cloned rows of clean rosy dimples and pamper proof towhead cowlicks. Adorable babyface jars. Sturdy innocent in the pink, 
out of the blue packs disposing durable superabsorbent miracle fibers. As solid break down, go to waste, a land fills up dead diapers with funky halflife. (unpag.)

Throughout the collection, Mullen's use of the literary still life remains rooted in an attempt to investigate the cultural significance of food and expose the class, gender, and racial stereotypes inscribed in the familiar codes of the advertising industry. Like Mullen's earlier collection, Trimmings, $S^{*} P e R M^{* *}{ }^{*} T$ thus enacts "a kind of prose-poetic social semiotics which draws as much on the early Roland Barthes-especially the Barthes of Mythologies - as on Stein" (Monroe 137). It does so in a way that oscillates between an ironic indictment of the predictable associational logic of commercials ("What's brewing when a guy pops the top off a bottle or can talk with another man after a real good sweat. It opens, pours a cold stream of the great outdoors. Hunting a wild six-pack reminds him of football and women and other blood spoors" [unpag.]) to more farcical détournements of advertising slogans ("Scratch and sniff your lucky number. You may already be a wiener"; "A box of blue movie equals smurf sex" [unpag.]) that, to quote Mullen's comments on her grandfather's art of preaching, allow the culture itself, rather than the lyric I, ${ }^{2}$ to speak and sing "with both meat and gravy" (Frost 404).

Elsewhere in $S * P e R M *{ }^{*}{ }^{*} T$, Mullen's interest in the psychosexual uses and abuses of food leads her to explore the theme of anorexia. But in Mullen's vision of fast-food society, the all-engulfing power of consumer culture is by no means challenged by the anorexic's refusal of food. On the contrary, this refusal is recuperated in the form of sugar-free lite mints or diet pills "prescribing themselves" over counter:

How anorexics treat themselves. Sucking slim mint for the breathless, rationed yet tingling indulgence. Over-counters prescribe themselves slighter than any other lifetime of fractioned unburned energy hands down all ads up. How fresh in your mouth to eat a sweet thought minus the need to work off guilt, to amortize the cost. (unpag.)

In another piece, the angle shifts to the point of view of the anorexic child's parents. Here, Mullen's decision to examine the dyamics of consumption in terms of power relationships extends to the family where the child's “crisp image" gradually disappears from sight, resisting her mother's "nurturant murmur" which, like the words of love she chokes upon, painfully compares the mouth that eats with the mouth that speaks. Mullen's depiction of the "torn hostage ripening out of hand" is unusually moving and made more urgent by the poem's direct address to the reader:

A daughter turned against the grain refuses your gleanings, denies your milk, soggy absorbency she abhors. Chokes on your words when asked 


\section{Food, Poetry, and the Aesthetics of Consumption}

about love. Never would swallow the husks you're allowed. Not a spoonful gets down what you see of her now. Crisp image from disciplined form. Torn hostage ripening out of hand. Boxtop trophy of war, brings to the table a regimen from hell. At breakfast shuts out all nuturant murmurs. Holds against you the eating for two. Why brag of pain a body can't remember? You pretend once again she's not lost forever. (unpag.)

Because more will be said later of the theme of fasting as a means of (de)constructing cultural and sexual identity and containing the excesses of the body, I will not dwell on the psychosexual implications of Mullen's poetic appropriation of anorexia. Suffice it to say at this stage that the proximity of anorexia, identity, and abjection in Mullen's work echoes some of the most important performance artworks discussed in the closing chapter of this book, most of which share a tendency to allow female subjectivity to make its mark in the body's very materiality. As indicated by the preceding excerpts, the most interesting poems of the collection go well beyond the theme of nutritional and cultural standardization that has inspired hundreds of American artists from Andy Warhol to Wayne Thiebaud-they stage, instead, what Barthes described as the "malaise of matter" (Barthes 1982: 137), a principle which transgresses the separation of the synthetic and the organic, the animal and the human, the solid and the fluid, the living and the dead. In the following piece, Mullen confronts us with the repressed materiality of the meat industry, forcing us to contemplate a narrative of regression and animality that lurks beneath the impeccable, hygienic cleanliness of meat packaging (the book itself contains two black and white reproductions of meat shelves whose amateurish, unadorned quality echoes and accentuates the literal rawness of Mullen's still lifes):

It must be white, a picture of health, the spongy napkin made to blot blood. Dainty paper soaks up leaks that steaks splayed on trays are oozing. Lights replace the blush red flesh is losing. Cutlets leak. Tenderloins bleed pink light. Plastic wrap bandages marbled slabs in sanitary packaging made to be stained. A three-hanky picture of feminine hygiene. (unpag.)

The constant references to the human body interfere with the description of the cutlets and meat slabs and creates an uncanny effect, which results from the reader's confrontation with things that resemble us a little too much and a little too little to qualify as "real" objects, things that are likely to be considered as separate from our own physical, "meaty" selves. The final "punchline" of the poem creates an analogy between the "leaking" blood of the packaged meat and the sense of abjection elicited by menstrual flow while pointing to the cheapness and "three-hanky" sentimentality of advertising imagery (elsewhere in the collection, the author writes about "the eternal raw ingredients for programmed microwavering halfbaked expressions of family love" [unpag.]). ${ }^{3}$ The proximity of the feminine hygiene 
shelves to the meat products in the supermarket, the physical presence of bodily discharge, the semantic ambivalence of the word "bandage," which can describe alternately the packaging and the act of protecting and compressing an injured part of the body, all these features of $S * P e R M *{ }^{*}{ }^{*} T$ contribute to a global vision of the world of food production and consumption which creates an ever-growing amount of frustration and disappointment due to the failure of commercial goods to live up to their own promises of emotional and material gratification :

Seeds in packets brighter than soup cans, cheaper than lottery tickets, more hopeful than waxed rutabagas, promising order in alphabetized envelopes, dream startled gardens one spring day tore open. Sown in good dirt, fingered tenderly. (unpag.)

\section{AN ORGANIC FACTORY: THE RETURN OF PONGE'S “PIECE OF MEAT”}

The shortest and most Steinian piece of $S * P e R M * K^{*} T$, Mullen's "toejam" poem, envisions the body's capacity to secrete its own food in a way that borders on the abject. As for the pun on "mink chocolate," it can be interpreted as the experience of eating a milk chocolate bar and/or to the "melting" sensation of sexually-aroused female genitals ("mink") following the foot licking and toe sucking foreplay implicitly described in the first sentence:

Toejam must cause jelly don't. Mink chocolate melts in you. (unpag.)

Once again, the work of Francis Ponge comes to mind when considering Mullen's oblique presentation of the body as an organic factory. Like Ponge, Mullen describes less what the self ingests and digests than the process of disgestion itself. Ponge's "Piece of Meat" (1942), a companion piece to Mullen's own poems about industrial food, also places the body in a closed circuit of production and consumption where "every piece of meat is a kind of factory, blood mills and presses" and where "tubulures, furnaces and tanks are placed side by side with power hammers and rolls of fat" (Ponge 1999: 32). Revealingly enough, Ponge's "Piece of Meat" is directly followed by three poems dealing not with objects but with human beings. In one of them, "R. C. Seine No," the poet describes the sorry fate of a multitude of workers entering the buildings of the Messageries Hachette, where Ponge worked from March 1931 to December 1937. (The title of the poem was inspired by the letterhead of the Messageries, the letters "R. C." standing for "raison commerciale.") The state of alienation of the workers is described in terms that evoke the processing 


\section{Food, Poetry, and the Aesthetics of Consumption}

of foodstuff into consumable products and its subsequent transformation into excrement. After comparing himself and his colleagues with coffee beans about to be poured into "the grinding machine," Ponge likens the building itself to a "sphincter" from where "everyone is expelled, shamefully safe and sound, and yet depressed, through tubes that are lubricated by wax, fly tox and electric light" (34). Here, Ponge, who was a member of the Communist Party from 1936 to 1946, denounces the objectification of thousands of isolated selves forced to worship "the noise of the sacred machines" and who, "for the most part are deprived of speech, as mute as the carps or the pebbles" (685). His imaginative engagement with takenfor-granted objects paves the way for a more oblique critique of reification which perceives the necessary mediation of human relationships by what the poet calls elsewhere the "shameful order of things" ("Les écuries d'Augias" [191]).

Mullen's $S * P e R M *{ }^{*} T$ alerts us to the disappearance of both the butcher and the cook in pre-packaged meat, which results in the elision of the slaughtering process that turns flesh into meat. But instead of focusing on the theme of reification and the fate of the factory workers, ${ }^{4}$ Mullen's poetry explores the ways in which packaging turns meat into a consumable fetish, unrecognizable as what it is, transforming animal flesh into a clean commodity ("Meat is real. Clean meat. Trimmed, not bloody" [Mullen unpag.]). Mullen's alliterative, pun-ridden prose-which creates phonic correspondences between the sanitary control of menstruation and the mechanisms of meat processing-underlines the incapacity for the observer to determine the exact nature, origin, and ultimate destination of both the processed food and its packaging (is it made of paper or plastic?; is it biodegradable?). The material ambiguity of Mullen's still lifes gets more acute (and potentially threatening) as the reader-viewer realizes there is nothing more terrifying than an object without form, a "thing" that defies definition and interpretation and brings about a continuous alteration of the distinction between body and world. But what is at stake here is not just the horror of what has neither a clear form nor a definite name but, rather, the threat of the dissolution of the body-self into the realm of the undifferentiated and the amorphous. Like the piece of cheese in Louis Zukofsky's Mickey Mouse poem in A-8, which "shows eyes in the cut" (Zukofsky 64), Mullen's still lifes destabilizes the intimacies assumed between the eater and the eaten by looking back at their potential consumers who find themselves suddenly exposed to the ambivalent "gaze" of dead matter.

I would like to conclude this subchapter by suggesting that Mullen's $S * P e R M *{ }^{*}{ }^{*} T$, like most of the other "edible" still lifes we have examined so far, would seem to confirm Jean-Michel Maulpoix' suggestion that lyricism is not merely the expression of personal feelings, that it "does not represent the full expression of the (poetic) subject, but rather its being devoured " ("sa dévoration" [cited in Cazé unpag.]). Building upon 
Maulpoix's proposition, Antoine Cazé defines the lyric as a mode that underlines the physicality of utterance, a phenomenon that constantly destabilizes the lyric self, making it "[lose] its ideality" by privileging its "'physicalities' or physical embodiments":

A self does not get so much expressed thanks to its voice as it is chewed to pieces-dismembered and dis-figured-in the devouring mouth of the poet; mouthed rather than voiced (as Whitman's “omnivorous lines" would have it, which ardently desire to "fetch you whoever you are flush [i.e. flesh] with myself"); a self is "embouchured" (canto 18) in what Steve McCaffery has so graphically described as "a polis of mouth, lips, teeth, tongue, tonsils, palette, breath, rhythm, timbre and sound.” (Cazé unpag.)

By placing the emphasis on the materiality of expression, $S * P e R M * K * T$ enacts such a dis-figuration of the lyric mode, one that constantly destabilizes an "embouchured" self that enacts the conjunction of diet and discourse. As the mouth that speaks once more becomes the mouth that eats, Mullen's food poetics whets our appetite for things that resemble us or what we would like to be, objects whose forms and textures are liable to surrender what Ponge once enthusiastically described as "the infinite resources of the thickness of things rendered by the infinite resources of the semantic richness of words!” (Ponge 1999: 203).

\section{“Biotoniques”: Frozen Moments and Technological Reliquaries}

If one had to look for visual correspondences to Mullen's poetic take on mass food production and consumption, one would be tempted to turn to Andy Warhol's Campbell's Soup cans, Wayne Thiebaud's pastry paintings, or the more recent post-hyperrealist still lifes of Florent Mattei's "Biotoniques" series (1997-2005), in which images of actual food products are rendered "unreal" through computerized treatment. Mattei's original intention was to respond to advertising images and messages that ascribe a "near-cosmetic" virtue to foodstuffs (the word "Biotoniques" itself sounds like a mock-advertising slogan), one which bears the promise of a better, healthier life liable to deliver material success and increased performance (Mattei unpag.). One of the most striking pieces of the "Biotoniques" series is a photograph entitled "Roastbeef" (1999) in which every trace of "real" blood seems contained by the packaged form in which it finds itself tied up and contained. The seductive power of the perfect smoothness that characterizes the contours and surfaces of Mattei's piece of meat-which makes it resemble the fake food replicas that used to adorn old-style restaurant and shop windows-also emerges as a logical visual extension of Mullen's meat poem in erasing the "meatiness" and the natural "leakage" of the joint of beef. 


\section{Food, Poetry, and the Aesthetics of Consumption}

Like Mattei's “Biotoniques," the still lifes of photographer Irving Penn, far from replicating Warhol's serial pastiche, also play with the formal and ideological implications of food packaging. Penn's photographs reduce the organic complexities of the asparagus tips, corn grains, and blueberries to simple, square, and rectangular shapes that betray their earlier packaged condition. They also implicitly point to the traditional art of the metaphysical still life as they play with the dialectics of permanence and impermanence, time and timelessness. In the "Frozen Foods (with String Beans)" (1977), the very stillness of the vegetables and fruit placed on a glass table (the frozen condition of Penn's vegetables reads like a visual pun on the "frozen" moment captured by classical food paintings) is at least potentially undermined by the idea that the inconsumable beauty of frozen goods will thaw and turn to mush under the effect of room temperature.

Like the computerized photorealism of Mattei's "Biotoniques," Irving Penn's frozen sculptures are clearly indebted to Pop Art and its by now familiar representation of commodity and consumer culture. Still, these artists' attempts to confront the viewer with the disturbing materiality of meat has very little in common with Warhol's food art, which generally avoids the realm of the flesh in order to concentrate on simulacra produced by mechanical reproduction and or the depthless surfaces of industrial packaging. Rather, they return us to the work of the underrated and unjustly forgotten "anti-Pop" artist Paul Thek, whose sculptures and ready-mades collected in "Technological Reliquaries" (1966) featured realistic wax and resin replicas of human tissue (including hair, teeth, and bone) encased in plexiglass showcases. The somatic, carnal knowledge afforded by Thek's feeds the viewers' anxieties about their own mortality and physical decay. The fact that some of the sculptures are covered with the artist's own hair adds another twist to the memorial significance and mystic potency of the relic tradition. Thek's reliquaries point to the end of man's life as a man of flesh while simultaneously combining "real," and potentially decaying organic material with synthetic, physically unadulterable replicas of flesh that look like real human or animal tissue. It is in the replica's molecular stability-which resists the physical decomposition and oxidation of matter-that the most disturbing aspects of Thek's still lifes lies. Thek's treatment of the dismembered body rejoins the traditional function of reliquaries while marking the artist's diffidence to the power of science and "technology" to combat the physical corruption of flesh and postpone the final demise of the body as self. A devout Catholic, like Warhol, Thek creates "meat sculptures" which remain rooted in an investigation of the psychological and philosophical potency of religious imagery and thus anticipates by more than two decades the religious art of Andres Serrano and Olivier Richon ${ }^{5}$ - to cite but two younger artists who show a fascination with the interplay of the sacred and the bodily in religious iconography-while pointing in the direction of Damien Hirst's 
Turner-Prize winning bisected cow and calf ("Mother and Child Divided"; 1993) and Matthew Barney's thermoplastic fantasies in the recent "Occidental Guest” (2006).

\section{FOOD AND POP ART}

Since Jameson's memorable discussion of Andy Warhol's "Diamond Dust Shoes" (1981), Pop Art objects have often been received and described as fetishes "in both the Freudian and the Marxist senses" (8). Although Warhol's fixation on shoes is well-attested in both his life and art, ${ }^{6}$ Jameson argues that the "Diamond Dust Shoes" are also Marxist fetishes in that they conceal social relations that underlie the material conditions of production and consumption of the object (8-9). The transformation of a utilitarian object into a fetish presupposes an aesthetic that emphasizes the object's exchange value to the detriment of its use-value. In this respect, one of the most obvious limitations of the representational strategies of Pop Art and its more recent avatars stems from the fact that their works confine themselves to altering the color, size, or texture of the object so that its initial, useful function finds itself diminished or impaired, but not transformed. ${ }^{7}$ For some of its detractors, the subversive or confrontational potential of Warhol's art can only arise from the fact that it allows "the pictorial slang of popular culture images" to enter high art (Kuspit 32) or, to put it in Arthur Danto's more positive terms, that it renders "the eye so prized as an aesthetic organ when it was felt that the difference between art and non-art was visible ... physically of no use whatsoever when the differences proved to be invisible" (cited in Yau 24). ${ }^{8}$ The objects manipulated and "disfigured" by Warhol and the continuators of the Pop Art tradition of the still life do not take on new (utilitarian or nonutilitarian) functions. The "transformation" they effect is of an altogether different nature, one which reduces an already commodified object to a onedimensional or spectral image, an effect best expressed by Warhol's use of photographic negatives. As Fredric Jameson famously wrote, the "glacéd Xray elegance," of Warhol's shoes "mortifies the reified eye of the viewer" and gives us the impression that "the external and colored surfaces of thingsdebased and contaminated in advance by their assimilation to glossy advertising images- has been stripped away to reveal the deathly black-and-white substratum of the photographic negative which subtends them" (Jameson 1991: 9). ${ }^{9}$ Commenting on the incapacity of Warhol's paintings to function as critical political statements, Jameson concludes that:

Andy Warhol's work in fact turns centrally around commodification, and the great billboard images of the Coca-cola bottle or the Campbell's Soup Can, which explicitly foreground the commodity fetishism of a transition to late capital, ought to be powerful and critical political statements. If they are not that, then one would surely want to know 


\section{Food, Poetry, and the Aesthetics of Consumption}

why, and one would want to begin to wonder a little more seriously about the possibilities of political or critical art in the postmodern period of late capital. (19)

If one refers to Jameson's now famous comparison between Van Gogh's 1887 "A Pair of Boots" and Warhol's Diamond Dust Shoes, Pop Art also signals the emergence of a new kind of flatness or depthlessness, "a new kind of superficiality in the most literal sense" whose main subject becomes the commodification of perception itself. Whatever we make of Jameson's reluctance to see in Warhol's paintings any (intentional or unintentional) critical statement about the social relationships they describe and (dis)embody, Diamond Dust Shoes remains faithful to one of the traditional functions of the still life, that of reminding us of the transiency of things and the certainty of decay and death (although Jameson's interpretation implies that Warhol's print is less about death itself than about the death of the referential function of mass-produced images). And, indeed, if Warhol's image has a political dimension, it probably lies in the tension created between the "original," glossy commodified image (as is well-known, Warhol began his career as an illustrator designer for shoe fashions) and the flat, disincarnated black-andwhite deadness of the empty shoes.

This being said, the mortifying X-rayed coldness of Diamond Dust Shoespoised as they are between reification and the critique of reification-is by no means representative of Warhol's more general aesthetics of commodification. In his most famous "edible" still lifes, which as we know include soup cans and Coca-Cola bottles, Warhol is generally interested in the mass-produced, impersonal packaging of food rather than the food itself or its metaphorical and emotional connotations. This feature echoes the preoccupations of Mullen's $S^{*} P e R M^{* *} K^{*} T$ and, in particular, her desire to "let the culture itself [rather the lyric, expressive "I"] speak" (Frost 404). Warhol's "Apples" (which is included in a 1979 portfolio of six screenprints) are an interesting exception to this rule and a relatively unknown example of Warhol's relationship with "raw," nonpackaged food. Even though it shares the same techniques as the artist's more famous still lifes, "Apples" seems remote from the logic of consumerism and commodification that characterizes Warhol's more familiar work, which tends to delight in celebrating and duplicating the glossy surfaces and free-floating, impersonal signifiers of advertising culture. What happens to taste in this shallow, "depthless" world of colors and shadows parallels the process of an-aesthetization of the viewer confronted with simulacra of dead things, ghostly images of "real" objects expressing resilient traces of physical presence which preclude any form of interpretation or emotional identification. Seen from the perspective of a mind-machine that "duplicates without the awareness of the original identity" (Bergin 359), Warhol's disincarnated still lifes, in their inaccessible and "untouchable" two-dimensionality, do not only neutralize the sense of taste by deprogramming the viewer's appetite. They also illustrate Jameson's theories about the "waning 
of affect" (Jameson 1991: 10) of postmodern culture, concealing all marks of subjectivity, objectivity, and "carnality" involved in the act of tasting and consuming food.

Paradoxically enough, Warhol's "Fruit Series," for all their "postmodern" appearance, also point to an earlier still life aesthetics, that of the twodimensional fruits of Cézanne and the post-impressionists. My intention is not to claim that Warhol's "Apples" is merely a nostalgic, technologically updated pastiche of the still lifes of Matisse and Cézanne. But in what way then do Warhol's "Apples" differ, say, from the "depthless" surfaces of Matisse's "Peaches" (1920)? Clearly, part of the answer lies once again in the complete denial of subjectivity which seems to characterize Warhol's serigraph. Another essential difference is that the degree of depthlessness of Matisse's peaches is inferior to that of Warhol's apples as the former still derive part of their immediate presence from the shadows and reflections they project on the silver plate, although a closer look at those shadows and reflections reveals that they are far from being "realistic" as they are incompatible with each other and defy the laws of perspective. In the last analysis, however, if Warhol's apples do not "speak to us," it is not because they deliberately fail to create the illusion of three-dimensionality, but because they appear in a depthless world which seems devoid of a concrete background or surrounding (by contrast, Warhol's earlier still life, Flowers [1964], for example, was still "glued" to a background of grass). The mechanical, nongestural modes of production of Warhol's serigraph work accentuate this impression, as does the absence of a plate or basket which would refer to a concrete space in which to consume the fruits. It is therefore less the disappearance of the "human" element than the absence of context that confers to Warhol's apples the status of abstract icons that fail to refer to anything but "dead," intangible, and inconsumable objects.

The transformation of an object into pure form (or pure color) in Warhol's work also leads to a further dissociation of the sense whereby the observer, much like the speaker of Stevens's Cézanne-inspired "Study of Two Pears," is forced to look at the shape of objects to the exclusion of almost everything else, whether it be their nutritive, anthropomorphizing, or allegorical potentials. The serigraphed shapes of Warhol's apples and their green shadows only serve to enhance this impression, an effect somewhat mitigated by the black lines which do not match the contours of the colored fruits. Such is, perhaps, the essence of Warhol's "camp sublime," which Jameson defines as the loss of self and the sense of euphoria resulting from the world's dissolution into "a stereoscopic illusion, a rush of filmic images without density" (Jameson 1991: 34).

\section{Bananas and Brown Sugar}

Warhol's oft-discussed tendency to dwell on the surfaces of objects can also be attributed to what John Yau has identified as the artist's "aversion to both 


\section{Food, Poetry, and the Aesthetics of Consumption}

dirt and his body" (Yau 69). And, indeed, Warhol—unlike Stein, Mullen, and most representatives of the twentieth-century avant-garde-seems reluctant to depict or refer to filth, bodily juices, and secretions. In fact, Warhol rarely deals with the materiality of body, and when he does so he tends to resort to visual euphemisms, such as his 1967 "Banana," whose most famous avatar appeared on the cover of The Velvet Underground and Nico's eponymous album. On the album's sleeve, the words "peel slowly and see" are printed directly to the left of the banana. In the first edition of the album, the instructions were printed on a sticker that peeled off to reveal the pink insides of the phallic fruit on the record sleeve. From the Velvet Underground's peelable banana to the workable zipper sewn into the front sleeve of the Rolling Stones' 1971 Sticky Fingers LP (this time, what lies beneath the zipper is a large unerect penis wrapped in a pair of white underwear), Warhol's penis jokes once again confirm the importance of the joint aesthetics of the sexy and the sugary in the contemporary still life, a tradition which stretches from Stein to Mullen, Karen Finley, and beyond. Ironically enough, the Stones' album contained two songs whose titles resemble the titles of still lifes: the macabre "Dead Flowers" and the infamous "Brown Sugar" which, despite its racist and sexist overtones, remains one of the most popular avatars of the sweet-sexy in rock culture.

Unlike the Velvet Underground's "Banana," Warhol's earlier "210 Coca-Cola Bottles" (1962) is typical of the serialist strategies that underlie Warhol's best-known works. The wealth of studies dealing with the artist's serial techniques dispenses us from the need to describe them in detail. The principle of repetition-with-variation that characterizes Warhol's serigraph foregrounds the consumer's compulsive attraction to fast food Although converting the packaging itself into a reassuring fetish and a form of potential entertainment. A Coca-Cola bottle, just like a Brillo box or a soup can, is always already an aesthetic object whose carefully designed, streamlined shape seeks to convince potential buyers that they will experience a sense of fulfilment and order. To acknowledge the familiar shape of the bottle 210 times in a row (at least if one opts for a linear "reading" of Warhol's serigraph) really amounts to surrendering to the seductive and appeasing power of "an item that been packaged as an absolute necessity in the fight against entropy; and it is said to be the perfect aid for consumers in their unending battle with the forces of disorder" (Yau 25). Like the Campbell's Soup cans, the Coca-Cola bottles primarily reflect Warhol's interest in machine food, a kind of food that is untouched by human hands and whose availability "in such a sterile, inviolate form is in itself," as Paul Bergin reminds us, "an eloquent expression of the mechanistic trend which had made it possible to satisfy all our material needs with the products of machines" (Bergin 360).

If one had to address the eternal question of whether Warhol's art ultimately exposes and/or celebrates the emptiness of consumer culture, one would be tempted to conclude, rather predictably, that Warhol's serial 
repetition both recognizes and trivializes the power of mass-produced images. (Answering the question "What does Coca-Cola mean to you?," Warhol once disarmingly replied "Pop" [Goldsmith 5]). Be that as it may, Warhol's "art factory," like any other attempt to "express the machine in the machine's own term" (Bergin 359), seeks to (re)present the images of the Coca-Cola bottles (or their brands in the case of other "Coke" prints produced by Warhol) rather than the bottles themselves. By doing so, Warhol's serialized pattern renders each individual bottle literally "meaningless" (in terms of, for instance, its potential emotional or metaphorical or nutritional content) by repeating its literal value ad nauseam. And, indeed, one of the inevitable effects of (verbal or visual) repetition on the viewer/reader is to gradually erase meaning and alter our relationship to space and time. As John Yau puts it, in a discussion of the "universality" of Warhol's work: "It is not Coca-Cola and Campbell's soup cans that we have in common; it is that we are all stuck in time" (Yau 65). This being said, it is above all the prominence of (packaged) food in Warhol's work that lends itself to such a recycling of the classical still life and implicitly reduces the traditional memento mori and tempus fugit themes to the trivial, repetitive gesture of checking the package's contents, weight, and expiry date. The sanitary conditions in which packaged food is produced and sold also underlines the artist's desire to control the body's fuel supply in a way that seeks to repress or at least conceal its actual conditions of production behind the reassuring glossiness of the boxes and cans. The Campbell's Soup cans and the Coca-Cola bottles are so many examples of how food can be rendered uniform and uncontingent, protecting the viewer from a full confrontation with the actual processes of producing, buying, or eating (fast) food and claiming that "in the end we do have control over our bodies and environment, and that we can live in a house without dirt and death" (Yau 27), a concern which is also reflected in the primary, repressed utilitarian function of the Brillo box, which was derived from a carton containing scouring pads.

A more conventional, literal reading of " 210 Coca Cola Bottles" as a work based on the alternately deadening and exhilarating effects of sameness and repetition could lead us to regard Warhol's serigraph as a visual representation of the artist's apocryphal statement that "a Coke is a Coke is and no amount of money can get you a better Coke than the one the bum on the corner is drinking." ${ }^{10}$ But the other side of the coin whose obverse is the comforting, normalizing repetitions of Warhol's still life is of course the realization that the bottles do not look the same. Such a realization, which is further investigated in my examination of Robbe-Grillet's tomato quarter in the next chapter, weakens the notion that culture must necessarily triumph over nature in a space dominated by machine-produced aliments. And, indeed, the stitching together and the ensuing alteration (by means of the silk-screening process) of 210 near-identical mass-produced photographs of mass-produced objects arranged in seven rows of 30 


\section{Food, Poetry, and the Aesthetics of Consumption}

bottles each results in a composition which paradoxically foregrounds the details that distinguish the bottles from each other. Inspired by the infinite reproducibility of images and objects, the myth of Warhol's "unviolated" food becomes questionable as soon as the viewer recognizes that the "art factory," for all its apparent denial of individuality, nonetheless confronts us with the irreducible singularity of every single bottle (some of them are more blurred than others, and although most of them seem full and intact, others seem nearly empty or half-full). The bottles' imperfections and alterations thus reintroduce an element of subjectivity and materiality into Warhol's work by bearing the traces of the absent consumer's physical manipulation and ingestion of the drink.

Interestingly, Warhol's general aversion to the representations of real bodies (or bodily functions) in his still life does not apply to his film work, which he himself considered as an extension of his "still portrait variations" of Marilyn Monroe, Natalie Wood, and others (Goldsmith 186). Warhol's silent film, Eat (1964), in which his fellow Pop painter and sculptor Robert Indiana ${ }^{11}$ relishes a mushroom for 39 minutes, offers another interesting variation on the theme of serial repetition. The film consists of nine 3-minute rolls of film which are assembled out of sequence so that it is impossible to determine what portion of the mushroom gets eaten at any moment of the "script." Defeating the narrative linearity of the traditional filmed meal scene, the focus remains on the act of munching and swallowing the food, unencumbered by considerations of temporal progression. Although Warhol's "Eat" seems to run against the artist's general reluctance to represent the physicality of consumption, it is significant that such a performance was enacted by an actor and that Warhol's role remained confined to "directing" his "moving-picture portrait" (186). Warhol's last complete series of paintings and serigraphs, The Last Supper, takes on an ironic undertone towards the artist's earlier food aesthetics. The full series was first exhibited in Milan in 1987, at a time when Warhol's health was increasingly threatened by the stomach pains resulting from the wounds inflicted by feminist militant Valeria Solanas, who shot Warhol in 1968. Intriguingly, Warhol, who was a devout Catholic all his life, ended his career with a series of manipulated religious icons (copied not from the original but from cheap commercial reproductions) including a serigraph of Leonardo da Vinci's canonical painting "stamped" with a Wise Potato Chip logo which adds a final ironic twist to his ambivalent attitude to the aesthetics and politics of food and (self-)consumption. ${ }^{12}$

\section{BEBA COCA-COLA: CONCRETE POETRY AND ADVERTISING}

In the field of (concrete) poetry, the actual act of drinking coke as well as its ideological and cultural implications is the subject of Brazilian poet Décio Pignatari's "beba coca cola” (1957): 
beba coca cola
babe cola
beba coca
babe cola caco
caco
cola c lo a c a

(Solt 108)

Perhaps more than any other poetic genre, concrete poetry is a form of writing that, not unlike Warhol's art factory, shares affinities with the language of advertising and mass media. For Eugene Gomringer, one of the main contemporary representatives of the genre, concrete poetry-with its reliance on quick, direct, and concentrated verbo-visual messages liable to be "perceived visually as a whole as well as in its parts" (Gomringer, unpag.)-is only one manifestation of a general movement towards the "formal simplification" (unpag.) of private and public languages, of which the direct, visual poetics of advertising and industrial design is the logical culmination. ${ }^{13}$ One of the risks involved in such a project is of course that Gomringer's concrete poetry, which is supposed to be "as easily understood as signs in airports and traffic signs," should result in poems that are airport and traffic signs (Perloff 1991: 120). Gomringer's claims are by no means shared by all concrete poets and certainly do not apply to Pignatari's "beba coca cola." Indeed, far from enacting such a conflation and mutual co-option of advertising and poetry, Pignatari's poem enacts a critique of consumption in alluding to the process that transforms consumers into drooling, automated creatures (the word "babe," which means "drool" in Brazilian, could also refer to the presence of a sexy female actor promoting the drink on the advertising poster). As for the word "cola" ("glue") itself, it resonates with the urgency of a manifesto promoting the lettrist collages and juxtapositions of Pignatari's concretism.

The digitally animated and "spoken" version of Pignatari's poem, which appeared in 1992, is performed against a dark red background adorned with a white wave that evokes the original Coca Cola logo. It also features a polyphonic musical rendition, composed by Gilberto Mendes, which parodies the rhetoric of TV commercials and culminates in a belching sound that stresses the physicality of the drinking process. The poem's final belch is immediately followed by a round of applause, which suggests that an uncritical audience is "watching" the spectacle of advertising and relishing in the theatrical display of immediate gratification generated by mass food production. ${ }^{14}$ Pignatari's concretism turns the poem itself into a digesting machine, transforming the drink ("beba") into excrement ("cloaca"). The word "caco," which can mean either "shard" or "head," can be seen as either another reference to the garbage culture brought about by U.S. exportations (symbolized by a shard of broken glass) and/or to the more general 


\section{Food, Poetry, and the Aesthetics of Consumption}

brainwashing of consumers by advertising slogans. Opting for a poetics of ambivalence and ambiguity, rather than the "transparent" language lauded by Gomringer, "babe coca cola" confirms the status of the concrete poem as a kind of "antiadvertisement," a form where brevity and concision "combines high-speed communication with maximum information" (Perloff 1991: 93). The multiplication of the vectors of meaning effected by the lettrist permutations of Pignatari's poem expresses the social conscience and the potential for resistance of the written word to visual culture. Pignatari's concrete poetry is an art that seeks to subvert the public language from within and, to use the words of David Colòn, "expresses a disenchantment that pervades much Latin American literature from the mid- to late-twentieth century: the protest and anxiety of living in the specter of the American economic empire" (Colòn 58). Such a criticism of U.S. imperialism is embedded in the poem's structural arrangement: As Rosmarie Waldrop has remarked, in the line that immediately precedes the word "cloaca," "caco" and "cola" are included in the "beba" column, "negating the spatial separation that seemed to separate the product from the consumer. The sides are interchangeable; those who drink are no better than those who manipulate them into drinking" (cited in Perloff 1991: 118).

\section{THE ART OF CLAES OLDENBURG}

This survey of American "pop" food art cannot leave out the work of Claes Oldenburg, one of the last living and active representatives of the first generation Pop artists whose food sculptures display a direct and confrontational approach to consumerism. "Sculpture in the Form of a Fried Egg" (1966), one of his earliest food installations, is typical of the basic treatment undergone by Oldenburg's objects, which are almost systematically endowed with monumental proportions (the egg's diameter reaches 122 inches). Oldenburg's trademark is indeed the changes in scale and texture undergone by his favorite objects, which include various kinds of foodstuff and kitchen utensils. Critics who, like Donald Kuspit, opt for a political reading of his work have tended to describe it as an exposition of consumerism's tendency to overgrowth and autophagy: Oldenburg's food images would thus aim to show "that anything consumable becomes a gross object of appetite which calls for a 'consuming' relation with itself" (Kuspit 37). But what first catches the eye is the texture of Oldenburg's fried egg, in that it does not strive to create the illusion of a "real" (albeit gigantic) egg. Its sewn cotton and muslin texture undermines any "hyperrealist" reading of the piece, eliciting a different response in the viewer, one that capitalizes on the confusion of the soft and the viscous and creates a feeling of inbetweenness which defeats our expectations of how the sculpture should "feel." "Green Beans" (1964), another work from the same period, is not a sculpture in the form of green beans but an installation that foregrounds 
its own artificiality while playing on similar material/textural ambiguities. The visual effect of the vinyl and painted formica used in "Green Beans" is akin to that which is produced by "Sculpture in the Form of a Fried Egg" and other works of the same period. The overall impression drawn from the sculpture is all the more perplexing as its appeal is, by necessity, strictly visual, at least in the context of a museum in which visitors are not allowed to touch the beans or the egg. Ironically, Oldenburg's fake beans, with their shining vinyl surfaces and sewn contours, both echo and sabotage the equally fake and "unreal" glossiness of advertising images. Oldenburg's sculptures and installations thus seem to confirm E. H. Gombrich's intuition that one of the chief vocations of the traditional still life was its investigation of material texture: "still life could never have come to existence but for the surprise the early collectors experienced in seeing a painting transcend the expected limitations of the craft and conjuring up (or, in the case of "Green Beans" defamiliarize) the very texture of objects" (177). Regrettably, this dimension is lost in Oldenburg's later monumental works, such as Spoonbridge and Cherry, 1988 (w. Coosje van Bruggen) and Dropped Bowl with Scattered Slices and Peels (1990), which merely perpetuate his now-familiar play on dimensions, the choice of the material (stainless steel and aluminum painted with polyurethane enamel) being dictated by material (the sculptures, which are located outside in public places, must be weather-resistant), rather than aesthetic imperatives.

For all their differences, Warhol and Oldenburg, like many other lesserknown artists influenced by the Hyperrealist and Pop Art take on food, share a desire to isolate the object in a frozen moment of decontextualized ambivalence. Oldenburg's sculptures, like most of their Pop Art antecedents and successors, display no interest in conveying the peculiar texture, taste, or smell of the objects described. The relationship between the artist (or the viewer) and the work remains based on a very cold and distanced approach that recalls the traditional still life practiced by seventeenth-century Dutch painters. This results in a frozen tableau that no longer bears any visible mark of the artist's work or engagement with its models. As in the case of Cézanne's fruits, discussed in the first chapter of this study, the fruits and vegetables have become a generic emblem of consumerism.

\section{DAMIEN HIRST AND THE RETURN OF THE “LAST SUPPER”}

Amongst the most recent manifestations of neo-Pop Art, the work of Damien Hirst stands out. His 1999 series "The Last Supper" 15 is a portfolio of thirteen screenprints depicting pharmaceutical boxes labeled with chemical products and the names of a number of essential ingredients of British food culture. Hirst's installation builds upon a food metaphor to express his ironical stance towards the traditional notion that art can serve to heal as well as to please the senses. The artist's obsession with the collusion of 


\section{Food, Poetry, and the Aesthetics of Consumption}

art, illness, science, religion, and consumerism is here put to the service of what appears to be a critique of our faith in the power of drugs and medical paraphernalia to improve our lives. His altered labels, which bear the artist's personal insigna (Damien \& Hirst) seem to alert us to the dangers of corporate logos and language that conceal the traces of production and the actual nature of food and medicinal products. Ultimately, one of the meanings conveyed by Hirst's works is that we are bombarded with commercials advertising products which seek to convince us that we can live for ever. It is to be noted that, even though Hirst's work has often been compared with Warhol's, the studied sobriety of the Damien \& Hirst labels is so realistic that the boxes-which are completely devoid of the manipulated and aestheticized surfaces of Warhol's soup cans and Coca-Cola bottles-could be mistaken for real pharmaceutical products. Hirst's concentrated food boxes (A Futurist culinary dream come true) thus look more "real" than Warhol's or Thiebaud's still life series, and their presence in an art gallery is suggestive of significantly different social and cultural negotiations, some of which are more sinister than others. A closer look at the concentrated "Chicken" oral solution, for example, reveals that it contains 20 mgs. of "morphine sulphate" per ml., perhaps to suggest that one of the most fundamental methods used by the food and pharmaceutical industries alike is to keep the masses "asleep" and ignorant of their respective hazards.

As the penultimate chapter of this book will show, at the other end of the spectrum, which opposes Pop Art's distanced aestheticism to the more radical, visceral engagement of the artist with living matter, we find the performance art of Alice Rios, Eleanor Antin, and Karen Finley. Between theses extremes, we find a whole range of artistes-bricoleurs whose work with various forms of collage aim to create artifacts that either incorporate real bits of food and/or reflect the artist's struggle with the material conditions of the work's coming into being. As we have seen and will see, this process comes close to the emphasis on the material signifier, which has been the leitmotif of a whole generation of twentieth-century avant-gardists, from Gertrude Stein to Carolee Schneemann and beyond.

\section{WAYNE THIEBAUD, MARCEL BROODTHAERS, AND WILLIAM SWEETLOVE: MORE ALTERNATIVES TO POP FOOD SERIALISM}

Before we turn to Belgian "bricoleurs" Marcel Broodthaers and William Sweetlove, we must consider the work of Wayne Thiebaud, an artist who has often been compared to (and sometimes assimilated with) Warhol, especially in his treatment of the cultural and aesthetic implications of repetition and standardization. Much less has been written about the essential differences between the two artists' respective uses and representations of foodstuff. One significant exception to the rule is a 1985 essay by Karen Tsujimoto which, commenting on Thiebaud's famous rows of near-identical 
painted pies, argues that Warhol "documented standardization" whereas Thiebaud "explores the ideas of repetition and variation-the duality between the conceptual notion of conformity in the rows of pies and what is actually perceived" (Tsujimoto 44). An even more obvious difference between Warhol's and Thiebaud's respective uses of the still life is that the latter does not resort to the mechanical reproduction of images. Instead, he uses real paint whose material irregularities and singularities on the canvas reveal the differences and "accidents," which can be gathered by a close scrutiny of the works. Another, even more fundamental distinction must be made between the fast, mass-produced food Warhol was fond of observing and reproducing and the more "gestural" quality of Thiebaud's series, which invests every single object described with an aura of "presence" that transcends the banality of its original context. This quality of Thiebaud's work is also acknowledged by Tsujimoto, who concludes that "conceptually the serial format suggests uniformity and predictability" but that "in reality, each slice of pie can be perceived as slightly different; one slice is more squat than another, the meringue of one pie is fluffier than its twin." It is thus "the juxtaposition of similarities and dissimilarities and the ability to discriminate between the two[that] fascinated Thiebaud" (44). And, indeed, one of the effects of Thiebaud's still lifes is to deconstruct the illusion that serial food production creates identical dishes (an illusion also deconstructed by Robbe-Grillet's tomato quarter, discussed in the next chapter). In "Pies, Pies, Pies" (1961), "Pie Counter" (1963), and other paintings of the same period, the arrangement of the slices in parallel rows placed on a table immediately evokes the context of a small-town bakery whose homemade culinary compositions represent the opposite of the world of the mass-produced that was celebrated and disfigured in Warhol's art factory. The focus here, rather, is on the absent whole to which the slices implicitly refer: that of the perfect, round shape of the complete pie. Thiebaud's 1962 painting "Around the Cake" captures this aesthetic eloquently by presenting a full pie surrounded by eight slices, which anticipates the division of the round pastry into triangular parts and its subsequent alteration and consumption through time; the verbo-visual pun, of course, is based on the analogy between the arrangement of the slices and the figures "around a clock." "Around the Cake" reconciles Stein's repetition-with-variation techniques with an awareness not of the deadly effects of repetition but of the possibility of the object's resistance to the uniformizing powers of commodification. In this respect, Thiebaud's appropriation of the banal and the commonplace shows only superficial affinities with the dominant paradigms of Pop Art; in contrast, his fascination with simple round and triangular forms allies him with some aspects of minimalist art. More importantly, perhaps, Thiebaud's creative negotiation with the repetitive banality of food is not incompatible with a genuine delight in the sensory dimensions of culinary composition. Unlike Warhol (and the rest of Dällenbach's ascetic Moderns), Thiebaud is an artist whose relationship to food seems completely devoid of irony. Thiebaud, 


\section{Food, Poetry, and the Aesthetics of Consumption}

who uses painting like frosting, slathering it in creamy strokes, clearly loves food. His position is that of the cook and/or the gourmet, not that of the fetishistic consumer.

Unlike Warhol and Thiebaud, the Belgian artist William Sweetlove shows a complete disregard for the aesthetics of repetition and serialization. Rather than placing Sweetlove's work in the legacy of Pop Art, Achille Bonito-Oliva-who wrote the preface to Sweetlove's catalogue of Still Lives (1997) — relates his work to the emergence of postwar movements which purported to return to representation. This tendency, which culminated with the Italian transavanguardia championed by Bonito-Oliva himself, logically led some contemporary artists to exploit the literal potential of the still life to create representations that seem devoid of any metaphorical content. The "depthless" models of postmodern pastiche are of course influential on Sweetlove's work, as are the equally superficial and glossy surfaces of Pop Art. One could also add that the objects and dishes depicted in his paintings also share the unbearable glossiness of Thiebaud's iced cakes. But the main difference between Sweetlove and Thiebaud is that the former tends to select and isolate a very limited number of discrete, unrepeated "food units," drawing attention to their singular and imperfect nature. The fact that Sweetlove almost systematically chooses subjects that are related to his own food culture (that of the Belgian seaside) is indicative of his interest in the "local color" and cultural value of common, popular food. What is especially striking is the mixture of the sweet and the salty that characterizes many of the paintings he produced in the 1990s. A mussel or a raw steak set beside a piece of cake evokes a very ambiguous form of abjection, one which draws its disturbing effects not only from the combination of the real and the fake (some of his sculptures resemble the fake plastic sculptures displayed in pastry shops) but also from the seamless juxtaposition of the raw materiality of animal flesh and the more savory, sophisticated sight of pastries and dairy products (as well as the proximity of sugary and salty items, like meat and sweets) within the same picture. Finally, the firm delineation of the objects (which is sometimes reminiscent of the ligne claire school of Belgian comic art) and the use of white background in Sweetlove's paintings accentuates the radical separateness of the ingredients, thwarting any attempt at a synthetic or symbolic interpretation of the overall painting.

In the context of Belgian post-Surrealist food aesthetics, the literal "meaning” of Sweetlove's paintings harks back to Broodthaers' famous eggshells and mussel sculptures, which were were built in the 1960s and were recently hailed by Bernard Marcadé as "the ironic and provincial antidote to the Campbell soup cans and coca cola bottles of American Pop Art" as well as "the emblem of the European rejection of all forms of artistic heroism and imperialism” (Marcadé 248). Unlike Sweetlove's paintings, however, Broodthaers's still lifes partake in the art of collage and bricolage. His "Mussels in White Sauce" is a glued assemblage of real mussels contained in a real casserole. The artist's intervention is limited to the paint that covers the heap 
of mussels and trickles down the casserole, resembling white wine sauce. Denying his three-dimensional collage any symbolic or cultural significance, Broodthaers once declared that "a mussel conceals a volume. When the mussels overflow the pot, they are not boiling over in accord with a physical law, but follow the rules of artifice whose purpose is the construction of an abstract shape" (Broodthaers 1987: 41). The pun here is on the French "moule," which can mean either "mussel" or "mold." Broodthaers's fascination with the "concealed form" of the mollusc (which reaches an aporic climax in the "Jellyfish" poem discussed in the next chapter) stresses the centrality of pure form and artifice to the artist's practical and theoretical models. Rather than a Belgian or European/Continental alternative to Pop Art, his work emerges as a continuation of the semiotic, metarepresentational surrrealism inaugurated by René Magritte and which purported to investigate objects that "function[] as zero word[s]" and "carry the marks of language." For Broodthaers, the "poeticity" of these objects lies in the fact that they are "guilty in the sense of 'art as language' and innocent in the sense of language as art" (39). An odd fish in post-Surrealist and postmodern waters, Broodthaers's food poetics is committed to an art that does not limit itself to examining text-image relationships but considers, instead, the very texture of language at the same time as it interrogates the nature of the linguistic traces attached to things. 


\section{Minimalists and Anorexics}

\section{BECKETT'S POETICS OF TASTE-LESSNESS}

I had neither taste nor humour, I lost them early on.

—Samuel Beckett, Molloy

What's that?

An egg?

By the Brothers Boot it stinks fresh.

Give it to Gillot.

-Samuel Beckett, "Whoroscope”

After his arbitrary arrest at the beginning of Samuel Beckett's novel, Molloy is taken away to the guardroom and offered some bread and tea by "a big fat woman dressed in black, or rather in mauv." This episode, which is central to Beckett's poetics of taste, deserves to be cited at some length:

I still wonder today if it wasn't the social worker. She was holding out to me on an odd saucer, a mug full of a greyish concoction which must have been green tea with saccharine and powdered milk. Nor was that all, for between mug and saucer a thick slab of dry bread was precariously lodged, so that I began to say, in a kind of anguish, It's going to fall, it's going to fall, as if it mattered whether it fell or not. A moment later I myself was holding, in my trembling hands, this little pile of tottering disparates, in which the hard, the liquid and the soft were joined, without understanding how the transfer had been effected. Let me tell you this, when social workers offer you, gratis and for nothing, something to hinder you from swooning, which with them is an obsession, it is useless to recoil, they will pursue you to the ends of the earth, the vomitory in their hands. The Salvation Army is not better. Against the charitable gesture there is no defense, that I know of. You sink your head, you put out your hands all trembling 
and twined together and you say, Thank you, thank you lady, thank you kind lady. (Beckett 1976: 235)

The ambivalent description of Molloy's rejection of the food ("I threw it to the ground, where it smashed to smithereens, or against the wall, far from me, with all my strength" [236; my emphasis]) foregrounds the indeterminacy of Beckett's apparently factual narrative, which had already been adumbrated by the indeterminate color of the woman's dress as well as that of the "greyish concoction" of the meal itself. Molloy's decision to throw the food away seems paradoxically motivated by the fear of failing to maintain its equilibrium and letting it fall onto the ground (the more general fear of collapse is emphasized throughout the book and extended to his incapacity to ride his bicycle or even remain seated for long periods because of his "short stiff leg" [234]). More importantly, perhaps, it expresses Molloy's urgent need to put an end to the unbearable noise of "chattering teeth" produced by the wobbling cup, which stands as a reminder of his own toothless mouth. But, above all, it is the liquid's overflow that prompts Molloy's violent rejection of the food the social worker offers him. ${ }^{1}$ His anguish reaches a climax when he realizes that the tea is threatening to sog the bread and mix all the ingredients of his "meal" together. Given the wealth of religious and theological allusions in Beckett's drama and fiction, it is impossible not to see in the image of sogged bread a reference to the Eucharist. A narrative of failed transubstantiation, Molloy oscillates between absence and presence, the literal and the symbolic, plunging Beckett's anti-hero into anxiety and confusion.

Molloy's perception of food as "something to hinder you from swooning" is indicative of his aversion to food as a means of sustaining the body and keeping the senses awake, a prospect directly opposed to his oblomovian determination to savour the pleasures of "resting" (230), "forgetful of recent cares, indifferent to those at hand" (232). As for Beckett's description of the meal as a "little pile of tottering disparates, in which the hard, the liquid and the soft were joined," it clearly echoes Dällenbach's above-discussed account of the culinary aversions of the Moderns, according to which the discrete ingredients of a dish may be joined and juxtaposed but not mixed, for fear of their becoming part of a single, monstrously homogeneous preparation which conceals the actual conditions of its making.

In Watt, Beckett's description of Mr. Knott's meal emerges as an extreme variation on Molloy's culinary nightmare, which here returns with a vengeance in the form of a list of ingredients that are boiled together for four hours in a pot and eventually produce a grey preparation which is served to Mr. Knott twice a day:

The dish contained foods of various kinds, such as soup of various kinds, fish, eggs, game, poultry, meat, cheese, fruit, all of various kinds, 


\section{Food, Poetry, and the Aesthetics of Consumption}

and of course bread and butter, and it contained also the more usual beverages, such as absinthe, mineral water, tea, coffee, milk, stout, beer, whiskey, brandy, wine and water, and it contained also many things to take for the good of the health, such as insulin, digitalin, calomel, iodine, laudanum, mercury, coal, iron, camomile and worm-powder, and of course salt and mustard, pepper and sugar, and of course a little salicylic acid, to delay fermentation. (Beckett 1970: 84)

Beckett's maximalist "recipe" blends the ingredients of Mr. Knott's dish into a creamy, undifferentiated mixture which comprises drugs and additives as well as various kinds of food and beverages. Mr. Knott's meal emerges as caricature of nourishment, a monstrous amalgam which echoes Molloy's confrontation with the "greyish concotion" described above (in Molloy as in Watt, the color grey stands for the epitome of tastelessness and conveys the uncomfortably bland and unrecognizable synthesis which results from the mixture of differently colored ingredients). Mr. Knott's unsavory mixture, which turns out to be as "unknowable" as Mr. Knott himself, also points to the substory in Beckett's Watt in which Mary, a former servant at Mr. Knott's house, conjures the threat of culinary amalgamation by eating her onions and peppermints one by one and separately, "first an onion, then a peppermint, then another onion, then another peppermint" (49-50). It is also reminiscent of the central (and most hilarious) eating scene in Murphy, where the protagonist describes his "fourpenny lunch" as "a ritual vitiated by no base thoughts of nutrition," privileging the philosophical potential of food over its use-value, allowing the meal's symmetry to alleviate his sense of confusion and isolation. That the perfect symmetry of Murphy's lunch extends to its price ("'A cup of tea and a packet of assorted biscuits.' Twopence the tea, twopence the biscuits, a perfectly balanced meal" [Beckett 1993: 49]) gives him an opportunity to consider it from an economic point of view. Murphy's reduction of the meal to a business exchange is immediately followed by its conversion into a psychosexual transaction beginning with his acknowledgment that "he had only fourpence worth of confidence to play with" and ending with a successful attempt to swindle some extra hot water from Vera, the waitress, so that he ends up "paying for one cup of tea and consuming 1.83 cups approximately" (51). Having been offered a second fresh cup after complaining that the first one was Indian and that he asked for China, Murphy, "the seedy solipsist," decides that Vera is "incapable of betraying the slogan of her slavers, that since the customer or sucker was paying for his gutrot ten times what it cost to produce and five times what it cost to fling in his face." He is determined to "defer his complaints up to but not exceeding fifty per cent of his exploitation" (50):

With the fresh cup of tea Murphy adopted quite a new technique. He drank not more than a third of it and then waited till Vera happened to be passing.

"I am most fearfully sorry, " he said, "Vera, to give you all this trouble, but do you think it would be possible to have this filled with hot?" 
Vera showing signs of bridling, Murphy uttered winningly the sesame.

"I know I am a great nuisance, but they have been too generous with the cowjuice."

Generous and cowjuice were the keywords here. No waitress could hold out against their mingled overtones of gratitude and mammary organs. And Vera was essentially a waitress. (50-51)

In Murphy's mind, which is dominated by the psychological theories of the Külpe school, applying the right verbal or gestural stimulus allows him to have his lunch and eat it too. Whatever we make of Murphy's alleged verbal manipulations of the waitress, the chief function of Beckett's ritualistic meals (as will become clearer from my reading of "Dante and the Lobster" below) is to rescue the self from the threat of the indistinguishable and the unquantifiable. Applied to Beckett's own "minimalist" style, this strategy accounts, at least in part, for the author's gradual abandonment of the Joycean idiosyncracies of his early works and his decision to write a "lean," literal prose (as the closing sentence from Watt makes clear: "No symbols where none intended"), a style characterized by short, simple sentences and incremental repetitions, rebeginnings, alternations, and permutations that test the limits of the language of logic and, ultimately, undermine them from within. The effect of this writing style is perhaps best summarized by Celia who, listening to Murphy's voice, feels "spattered with words that went dead as soon as they sounded; each word obliterated, before it had time to make sense, by the word that came next; so that in the end she did not know what had been said. It was like difficult music heard for the first time" (23). Such passages exemplify the "self-obliterating" quality of Beckett's writing, of which the "impossible" descriptionthat brings Molloy to a close is another, more famous example ("Then I went back into the house and wrote, It is midnight. The rain is beating on the windows. It was not midnight. It was not raining"). Celia's analogy with "difficult" (by which she probably means atonal) music serves to remind us that the story of atonality itself was a story of exhaustion, that of major-minor keys and tonal hierarchies, whose demise parallels that of the hierarchized relationships between words within the sentences and paragraphs of Beckett's prose. Beckett's decision to deconstruct the sentence in his later work (added to his choice to write in French "because in French it is easier to write without style" [Beckett 1976: xxxiv]) led to an increasingly dislocated syntax culminating in the elliptical monologue of Not I and the unpunctuated blocks of prose of How It Is, where food and orality remain central to Beckett's narratological and philosophical preoccupations.

\section{Muddy Mouth}

In How It Is, an unnamed narrator is seen dragging himself through the mud whilst carrying a sack of canned food. The narrator's body crawling 


\section{Food, Poetry, and the Aesthetics of Consumption}

in the mud is gradually reduced to a mouth filled with mud, hesitating between ingestion and expulsion, abandoning itself to mute matter, struggling with the question of nourishment but still hoping to envision "a fine image fine I mean in movement and colour blue and white of the clouds in the wind" (527):

the tongue gets clogged with mud that can happen too only one remedy then pull it in and suck it swallow the mud or spit it out it's one or the other and question is it nourishing and vistas last a moment with that

I fill my mouth with it that can happen too it's another of my resources last a moment with that and question if swallowed would it nourish and opening up of vistas they are good moments (528)

From a syntactic point of view, it is as if the narrator's "muddy speech" could only spit out "incomplete" and repetitive statements whose accumulative effect embodies the process by which, in Mary Ann Caws's words, "definite statement is reduced to qualified determination, ... the easiest clichés of natural speech to linguistic fumblings ... [and] [t]he most frantic cries diminish in tone to a helpless polite monotony" (cited in Brienza 40). The reduction of Beckett's "narratives of consciousness" to a "diminished but not finished" form of expression ultimately efface the resilient traces of the speaker's subjectivity. To quote Texts for Nothing, "the subject dies before it comes to the verb" (Beckett, 1967: 76).

A detailed examination of Beckett's use of repetition in the unpunctuated blocks of prose of How It Is, as well as of its capacity to neutralize traditional categories of causality and temporality, would lie outside the scope of this chapter. Suffice it to say that here as elsewhere in Beckett's fiction, repetition and reiteration undermine the linear sequentiality of the narrative as a repeated word constantly refers back to its earlier avatars, cancelling them out at same time as it creates the expectation of more repetitions. Steven Connor has written that "repetition can sometimes involve the attempt to efface the signifier, so as to collapse the distinction between it and the signified. The compulsive repetitions of the child's demands for food, or of the language of pornography, both testify to the desire to make of the sign a substance, identical with what it signifies . . . repetition can often be read as an attempt to close the gap between word and thing, even though it is repetition which insistently opens up that gap" (33). By likening the compulsive repetitiveness of Beckett's style to the child's nutritional demands, and by emphasizing its role in conceptualizing the relationships between signifier and signified, Connor unwittingly summarizes Beckett's poetics of hunger in a way that establishes him as an important representative of modernist gastroaesthetics. As the mouth which speaks becomes the mouth which eats its own speech, it is only after breath and voice have been partially taken from him that Beckett's narrator is paradoxically in a position to choke off his desire 
for unmediated subjective ex-pression and confront the enigma of a selfconsuming, self-cancelling language.

\section{Dante and the Lobster}

To return to Molloy and its gastrosophical considerations, the existential anguish experienced by Beckett's protagonist in front of the meal offered by the social worker principally stems from his fear of seeing the precarious separation between solid and fluid collapse into the viscous, a state Sartre describes as an "aberrant mixture" which is "the revenge of the in-itself on the for-itself," and of which more will be said in the following sections of this book. ${ }^{2}$ This aspect of Beckett's culinary metaphysics has so far received very little consideration on the part of critics, with the notable exception of Denise Gigante's recent essay "The Endgame of Taste," which considers the Romantic legacy of taste in Molloy and Sartre's Nausea (1938). Gigante's ingenuous thesis is that Beckett revisits Sartre's nauseating pebble (a symbol of the existential disgust experienced by Antoine Roquentin in the opening pages of the novel) and transforms it into a collection of "sucking stones," also picked up from the seashore (Morton 184), which Molloy keeps in his pockets. Unlike Roquentin, however, who starts experiencing nausea "as soon as objects start existing in [his] hands" and begins to suffocate as "existence penetrates [him] from everywhere, through the eyes, the nose, the mouth" (Sartre 1972: 180), Molloy wards off his fear of organic dysfunction in the act of sucking the round, smooth firmness of the pebbles:

I took a pebble from my pocket and sucked it. It was smooth, from having been sucked for so long, by me, and beaten by the storm. A little pebble in your mouth, round and smooth, appeases, soothes, makes you forget your hunger, your thirst. (Beckett 1976: 238)

Molloy's preference for an imaginary, rather than a concrete, appeasement of his hunger and thirst is rooted in fantasies of regression which resonate with Kristeva's theory on the abject (as does the absent body of the protagonist's mother, which haunts him throughout the story), which is discussed in the closing chapter of this book. The act of sucking stones echoes the numerous dreams of infantile regression present in many of Beckett's other works. The function of the pebbles as a substitute for the mother's reassuring, nurturing presence is confirmed by Molloy's toothless mouth, which, in this context, evokes that of a suckling baby at least as much as the loss of teeth caused by age. But Molloy also suggests that the threat of a forced motherly nourishment is still real, as suggested by the figure of the social worker (an ominous mother substitute whose ample, vigorous forms create a stark contrast with Molloy's infirm body) and her "charitable gesture" in the passage cited above. The practice of forced nourishment (and, by extension, that of enforced charity and motherly affection) 


\section{Food, Poetry, and the Aesthetics of Consumption}

becomes a nightmare from which Molloy is trying to awaken. Molloy, who at the beginning of the novel finds himself residing in his mother's room, not knowing "how [he] got there" and determined to "finish dying" (212) finds momentary respite from the arbitrariness and violence of the outside world by becoming "forgetful of [his] mother" (232) who "brought [him] into the world, through the hole in her arse if [his] memory is correct" (225). He then begins to reminisce about the "first taste of the shit" with which his coming into being is now associated. The link between poverty and abjection evidenced in Molloy's reflection that "to him who has nothing it is forbidden not to relish filth" (235)-added to his description of himself "bent double over a heap of muck, in the hope of finding something to disgust [him] from eating"- establish his status as an absurdist avatar of Dällenbach's ascetic Modern. In the last analysis, Molloy emerges a literally tasteless creature obsessed with a primal gustatory scene of abjection and eventually lapsing down to the bottom of a ditch, longing to "roll on to [his] mother's door" (328). ${ }^{3}$

Much has been written about the mathematical method which underlies Molloy's sucking stones ritual. In a now famous "monologue" which has widely been interpreted as an "absurdist" attack on rational thinking and its claims to absolute (self-)control, Molloy attempts to distribute sixteen stones in his four pockets and tries every possible arrangement so that he can suck them in the same order over and over again. ${ }^{4}$ But no matter what we make of his compulsive attempts to regulate the traffic of the stones from pocket to mouth and back to pocket, what matters at the end as that Beckett's protagonist eventually acknowledges that "they all tasted exactly the same" so that "the solution [he] rallie[d] in the end was to throw away all the stones but one, which [he] kept now in one pocket, now another, and which of course [he] soon lost, or threw away, or gave away, or swallowed" (305). As Gigante puts it, "where there is no taste, there is only taste for Molloy, who not only fails to distinguish between tastes and smells that do exist, but who makes fine distinctions among stones that he admits have no taste" (Morton 195). Molloy's metaphysics of orality thus stresses the "disinterestedness necessary to exercise taste" (195), an attitude which defines the subject "according to a general economy in which waste and taste lose all distinction" (184). Gigante's appeal to Bataille's "general economies" seems apt indeed, as Molloy's consumption of the stones seems to point in the direction of useless and meaningless forms of expenditure "ultimately linked to the efficacity not only beyond all consumption but also beyond the inconsumable" (176)..$^{5}$

Another significant cooking and eating scene occurs in Beckett's early story "Dante and the Lobster," the opening story of More Pricks than Kicks (1934). In the following passage, the protagonist of the story, Belacqua Shuah (named after Dante's Belacqua, the lazy musician whose late conversion led him to spend the length of his mortal life in the Ante-Purgatory), is painstakingly preparing his lunch toast: 
The first thing to do was to lock the door. Now nobody could come at him. He deployed an old Herald and smoothed it out on the table. The rather handsome face of $\mathrm{McCabe}$ the assassin stared up at him. Then he lit the gas-ring and unhooked the square flat toaster, asbestos grill, from its nail and set in precisely on the flame. He found that he had to lower the flame. Toast must not on any account be done too rapidly. For bread to be toasted as it ought, through and through, it must be done on a mild steady flame. Otherwise you only charred the outside and left the pith as sodden as before. If there was one thing he abominated more than another it was to feel his teeth meet in a bathos of pith and dough. (Beckett 1976: 9)

Belacqua, who, like Molloy, cannot stand the sight or taste of the spongy bread pith, observes the "soft of the bread," "spongy and warm, alive" and concurs that "he would very soon take that plush feel off it, by God but he would very quickly take that white fat look off its face" (9). Poised between the raw and the cooked, the animate and the inanimate, Beckett's toasting scene is a concrete prelude to a symbolic act of cannibalism. ${ }^{6}$ But in order to spare his teeth the "bathos of pith and dough," the personified bread cut which Belacqua lays against his cheek-in an attempt to feel its moist, alive presence-must be ingested after it has been transformed back into a (dry) thing whose reassuring roundness ("a pair of neat rounds of raw bread" [9]) is the necessarily condition for a happy, successful meal prepared and consumed in "complete quiet and privacy" (8). By contrast, the slice of Gorgonzola cheese that Belacqua later inserts between the two bread slices must stench and feel "alive" (12) in order to qualify as a suitable ingredient for Belacqua's meal. "A faint fragrance of corruption" does not suffice, he concludes. "He did not want fragrance, he wasn't a bloody gourmet, he wanted a good stench" [12]). In Levi-Straussian terms, the piece of cheese emblematizes the cultural appropriation of the natural "rotten." Its insertion between the dry and odorless slabs represents a regressive mode of eating, the return of the natural repressed and its cultural appropriation by excessively refined culinary tastes.

But the real climax of "Dante and the Lobster" occurs at the end of the story when Belacqua goes to a fishmonger's to buy a lobster for his aunt. The fishmonger insists that the lobster is "lepping fresh" and Belacqua assumes that it has "very recently been killed" (16). Belacqua then goes to his Italian lesson during which the crustacean is nearly stolen by a cat. Shortly after his arrival at his aunt's house, Belacqua is horrified to discover that the lobster is still alive and moving. His aunt, ignoring his protests, insists that lobsters must be boiled alive and proceeds to boil the beast. Belacqua slowly recovers from his feeling of sickness and concludes that it will not be a quick death. The choice of the lobster was no doubt inspired by the recognition that the animal's agony will be slow (the narrator claims that it had about thirty seconds to live but scientific evidence 


\section{Food, Poetry, and the Aesthetics of Consumption}

suggest that they can survive up to 30 minutes or more) and therefore echoes a number of central death-related motifs in Beckett's work. As for the lobster itself, it is a liminal creature whose texture and status within the animal reign can inspire a repugnance not unlike that which Sartre felt towards the viscous. Once asked by Simone de Beauvoir about his least favorite food, he declared that crustaceans disgusted him because eating them was "like eating things from another world." More than anything, it is the idea of having to "extirpate" the flesh from a "near-mineral object" (Onfray 1989: 133), which repelled the philosopher. Once again, what is at stake here is the confusion between two states which should remain separate, whether it be the organic and the mineral (the lobster) or the fluid and the solid (the viscous). The lobster, like the viscous, "has the dubious character of a 'substance between two states.'” Located between the "in-itself" (the world of objects which exists independently from human consciousness) and the "for-itself" (the capacity of human beings to be self-conscious), the viscous enacts such an impossible compromise between subject and object, being and consciousness, action and inaction. This "compromising" matter is all the more dangerous as it can lead to a loss of self resulting from "the revenge of the in-itself" ("once it is believed to be possessed, there occurs a curious reversal by which it begins to possess me" [Sartre 1976: 655]). For Sartre, as for Belacqua, touching (not to mention eating) the viscous amounts to "risking losing oneself in viscosity" (656), a risk which culminates in Roquentin's disgust for his own "slimy" tongue.

\section{MORE CRUSTACEANS: A FEW THOUGHTS ON SALVADOR DALI'’S AND MARCEL BROODTHAERS' FOOD POETICS}

Visible, invisible, A fluctuating charm

$$
\text { —Marianne Moore, “A Jelly Fish” }
$$

As my readings of Ponge and Claudel have shown, and as the following sections and chapters will go on to demonstrate, the sense of physical and textural inbetweeness experienced by Beckett's characters in their relationship to food has haunted the entire history of contemporary literary gastronomy and eat art on and off the page. In the 1930s, the period in which Beckett's "Dante and the Lobster" saw the light, Salvador Dalís paintings contained a wealth of references to food and (self-)consumption, from the post-dada prank of the Lobster Telephone (1938) to the playful eroticism of the Portrait of Gala With Two Lamb Chops Balanced on Her Shoulder (1933) or the distorted, "soft" and liquefying bodies of Autumn Cannibalism (1936), which memorably shows two lovers devouring each other in a kiss, the man's left hand holding a spoon while the woman's uses a knife to 
cut a slice of her own left breast. The principle of (literalized) introjection underlying Dali's gastropoetics also pervades his creative and critical writings. Dalís own personal contribution to his "General catalogue" of Surrealist objects reads thus:

\section{OBJECT, BY SALVADOR DALI}

A woman's shoe, in which a glass of lukewarm milk has been placed, in the middle of a ductile paste that is excremental in color.

The mechanism dips a sugar cube painted with the image of a shoe, so as to observe the disintegration of the sugar cube and, as a consequence, the image of the shoe in the milk. Several accessories (pubic hairs stuck to a sugar cube, small erotic photo) complete the object which is accompanied by a spare bowl of sugar and a special spoon for stirring the grains of lead inside the shoe. (Dalí 1998: 138)

Characteristically, at least from a Surrealist perspective, the symbolic function of every single object contained in Dalís inventory is to make "the culture of the mind one with the culture of desire" (137). Dali's shoe fetishism become a platform for a discussion of the physical transformation and transfiguration of the painted sugar, which slowly leads to the final dilution of the erotic potential of the very image of the shoe in the "lukewarm milk." The Surrealist object thus acquires a significance which exceeds the imaginary scenarios of sexual possession and fusion that abound in the artist's visual work. Lastly, the abject proximity of the excremental to maternal nourishment and sexual fulfilment (Dalí once declared that "we love totally when we are prepared to eat the shit of the woman we love" [cited in Adamowicz, unpag.]) is further complicated by the intrusion of the "grains of lead" in the preparation, whose mineral solidity present a challenge to the predominantly fluid and "ductile" elements composing the rest of the "recipe."

In Soft Construction with Boiled Beans (Premonition of Civil War) (1936), the representation of food extends beyond such psychosexual symbolism and fulfils an altogether different function, one which reflects the role of "the colossal nutritive and cultural responsibility of Surrealism" in accounting for "the terrible jaw of the masses biting into the congestioned, bloody and biological rib by excellence which is that of politics" (Dalí 2004: 256):

In this picture I showed a vast human body breaking out into monstrous excrescences, arms and legs tearing at one another in a delirium of self-strangulation. As a background to this architecture of frenzied flesh devoured by a narcissistic and biological cataclysm I painted a geological landscape, that had been uselessly revolutionized for thousands of years, congealed in its "normal course." The soft structure of that great mass of flesh in civil war I embellished with a few boiled beans, for one could not imagine swallowing all that unconscious meat 


\section{Food, Poetry, and the Aesthetics of Consumption}

without the presence (however uninspiring) of some mealy and melancholy vegetable. (Dalí 1942: 357)

Dalîs impish suggestion that the "mealy and melancholy" beans make the painting's political content (which includes Dalís dubious attitude towards the Civil War and anticipates his public support of Franco after his return to Catalonia after WWII) more palatable to his audience expresses the conflation of artistic and gustatory taste while underlining the centrality of the grotesque body to Dalís politico-sexual imagination. Whatever we make of Dalís perception of the "useless" revolutionary forces at work during the Civil War, the importance of food in Soft Construction with Boiled Beans, far from being reduced to an "embellishment" of reality, stems more fundamentally from a new relationship with the world of objects and the need to take part "in the existence of these things and our yearning to form a whole with them are shown to be emphatically material through our sudden consciousness of a new hunger we are suffering from" (Dalí 1970: 95). It is therefore Dalí's desire to fully possess the world of objects-as well as their various symbolic and metaphorical meanings-by ingesting and incorporating them. This literal apex of Dalís aesthetic of introjection is reflected not only in his visual work but also in a anecdote related in a TV interview in which he confessed to having eaten a whole chest of drawers over the course of several months after having chopped it up into little cubes which were themselves crushed into wood powder which he subsequently diluted in his daily dose of coffee. ${ }^{7}$ Dalís gustatory imagination eventually stretches beyond the world of objects into a cannibalistic dream of complete fusion. This wish is evidenced in "Autumn Cannibalism" as well as in the above-mentioned "Portrait of Gala With Two Lamb Chops Balanced on Her Shoulder" which adumbrated Dalís public statement that he intented to eat Gala after her death. ${ }^{8}$

In a way that echoes Belaqua's repugnance to the liminal qualities of the lobster's material texture, Dalís "architecture of frenzied flesh" describes what has neither a clear form nor a definite name, the lack of integrity of the thing observed menacing the integrity and sanity of the observer. It also enacts the prospect of the complete dissolution of the body-self into the realm of the undifferentiated and the amorphous. In Dalís Surrealistic imagination, however, the soft, liquefying bodies are partly compensated for by a fascination with well-defined, well-rounded, edible forms (even the contorted contours of his limp watches and the stretched skins of his deformed elephant legs are always clearly defined). In the following fragment, from The Secret Life of Salvador Dali, Dalî's hatred of the stringy texture of spinach takes on a political dimension and is associated with his distrust of libertarian ideals and his adherence to strongly regimented political régimes:

In reality I only like to eat things that have a clear and comprehensible form. I hate spinach it is because it is as formless as freedom. The very opposite of spinach is armour. (Dalí 1952: 81) 
In the contemporary art world, "clear and comprehensible" shapes ranging from squares and circles to apples and eggs (the perfect, pristine shape which contains the viscous and amorphous goo) have inspired countless painters and sculptors who, for various reasons, have sought to emulate the pristine elegance of "pure," "perfect" forms and who, for equally various reasons, have been associated with the history of minimalist and reductionist art. Here, Dalís fear of the "formlessness" of freedom rather seems to describe the artist's private life as a consumer and a citizen whose reactionary politics manifest themselves in an attraction to the protective power of the solid. In less "political" works such as the Lobster Telephone the dialectics of the soft and the solid are embodied in an animal whose stable exoskeletal structure tends to domesticate the "soft and nutritive delirium" (Bonafoux 124) of their inner body. Dalís description of the crustacean is typical a kind of aesthetic which, like the famous paranoid-critical method, thrives on the necessary cooperation of the rational and the unconscious mind:

Crustaceans have realized the marvellous and essentially philosophical notion that bones should be located outside the body and preserve their delicate flesh like a dermoskeleton. Protecting their soft and nutritive delirium with this rigid anatomy, they are sheltering themselves from any profanation coming from the outside, locked in as they are in a solemn vase which only decortication will render vulnerable to the imperial conquests of our palates. (124)

Dali's assimilation of the mollusc's morphology to an "essentially philosophical idea" originating in the animal itself comes surprisingly close to Ponge's description of the snail's self-secreted shell is as a "monument" blurring the traditional borders of subjectivity and selfhood, "their very secretion produc[ing] itself in a way which permits its convertion into form" (Ponge 1999: 27). Perhaps the most extreme extension of the invertebrate dream shared by Dalí and Ponge is Marcel Broodthaers's little-known "Jelly Fish" poem. Far from constituting a menace to the self, the undecipherable amorphousness of Broodthaers's cnidarian holds the promise of a material being which might resist the systematizing and conceptualizing pressures of even the most self-referential art objects. The poem describes the free-floating jellyfish as a pure body without form. For Broodthaers, the medusa, which does not have any firm internal or external structure, skeleton, or shell, becomes an even more perfect structure than the mussel and eggshell sculptures for which Broodthaers himself became famous:

The Jellyfish

It's perfect

No mold

Nothing but body

(Broodthaers 1988: 28) 


\section{Food, Poetry, and the Aesthetics of Consumption}

It is the absence of shape which turns the jellyfish into a perfect body, the dream of a protean being which transgresses the boundaries of internal or external structure. The last line of Broodthaers's piece runs as follows: "Crystal of scorn, of great price at last, gob of spit, wave, wavering" (29). Here, the stinging, jelly-like creature becomes a symbol for the treacherousness of wavering, fluctuating forms. It also has the additional peculiarity of being already transparent and thereby precluding the possibility of internal exploration. It is its very transparency that paradoxically guarantees its inviolability from the observer's gaze, for the jellyfish, by showing its lack of outer structure, interrupts the dialectics of inside and outside and ensures that nothing is left to be revealed.

\section{ROBBE-GRILLET'S TOMATO QUARTER}

On the kitchen table there are three thin slices of ham displayed on a white plate.

$$
\text { -Alain Robbe-Grillet }
$$

Having established the aesthetic and phenomenological implications of Beckett's poetics of tastelessness and digressed on Dalî's culinary aesthetics, we can now turn to another important "moment" in the history of Western gastroliterary aesthetics. This moment occurs in a famous passage of Alain Robbe-Grillet's The Erasers (1953): Detective Wallas enters an "automatic restaurant" and finds himself surrounded with nickel-plated vending machines, each containing "placed on a series of glass trays-equidistant and superimposed-a series of earthenware plates on which the exact same culinary preparation reproduces itself, except for the size and shape of the salad leaves" ("placed on a series of glass trays, equidistant and superimposed upon each other-a series of earthenware plates in which the same culinary preparation reproduces itself exactly, leaf by leaf"; Robbe-Grillet 160). Wallas reaches the last machine and is confronted with six copies of the following "culinary composition":

On a slice of soft bread, spread with margarine, a large silver-blue skinned herring filet spreads itself; to the right, five tomato quarters, to the left three eggslices ; placed above them, at calculated distance, three black olives. Each tray also holds a fork and a knife. The soft discs of bread are made to measure, in all likelihood. (160)

As his use of the word "composition" indicates, the narrator's description of the tomato quarter considers the aesthetic as well as the nutritional values of fast food as inextricably linked. A couple of pages later, Wallas experiences stomach pain and realizes that he has "eaten too fast" (162), and the six herring dishes appear to him as so many "exemplars" of a 
nonexisting original, a simulacrum of culinary art which owes more to an abstract notion of visual and geometrical functionality rather than to the chef's style and imagination. Robbe-Grillet's vision of the fast-food industry clearly deplores the general uniformization of the culinary landscape that reduces our taste options and abolishes the traditional, "gestural" link between the cook and the client-which is here reduced to the fleeting vision of the "faceless hands" (160) that appear from behind the shelves of the machines and refurnish the empty trays. What happens to the customers' sense of themselves as subjective beings is envisaged as an extension of the mechanical processing and reproduction of foodstuff. The narrator's concentration on things rather than conventional characterization-a feature commonly identified as a trademark of the French Nouveau Romanindirectly draws attention to the reification of the customers, "groups of approximately fifteen people-continually renewed" eating their food "with rapid and precise gestures." The transformation of human beings into mechanized consumers eating under the force of habit rather than from appetite is further emphasized by the clinical functionality of the restaurant and the presence of young women wearing hospital clothes who continually clear away and clean the empty tables.

With its insistence on the salad leaf that distinguishes the dishes from one another, Robbe-Grillet's description of the automatic restaurant-which anticipates Warhol's first soup cans by almost ten years-reads in fact more like an ekphrastic anticipation of Wayne Thiebaud's still lifes: the focus here is on the "hardly visible accident" which makes the tomato quarter unique and therefore ceases to produce the illusion that all the "copies" are identical:

In truth, a faultless tomato quarter, machine-sliced from a perfectly symmetrical fruit.

The peripheral flesh, compact and homogeneous, with its beautiful chemical red, has a thick regularity between a strip of shiny flesh and the box containing the yellow, well-calibrated seeds, which are held in place by a thin layer of greenish jelly alongside the fruit's bulging heart. The latter, whose rosy color is attenuated and slightly grainy, begins, on the side of the inferior depression, with a beam of white veins, one of which extends towards the seeds-in a somewhat uncertain fashion.

Above all this, a hardly visible accident has occurred: a corner of skin, has come off the flesh for a millimeter or two and lifted itself, imperceptibly. (161)

Whereas the "perfect symmetry" of the greenhouse tomato from which the quarter was extracted evokes the artificial conditions in which it was grown, the very texture of the fruit's flesh looks and feels unreal precisely because of its aspiration to pure form (an aspiration ultimately denied, however, by the "somewhat uncertain" trajectories of the white veins that hold the structure of the fruit together). Like Ponge's "Piece of Meat" (see Chapter 


\section{Food, Poetry, and the Aesthetics of Consumption}

3 ), the hallucinating precision of Robbe-Grillet's hyperrealist still life once again expresses the paradox of an "organic factory" (one thinks, for example, of "the box containing the yellow, well-calibrated seeds") inscribing the self in a closed circuit of production and consumption. From a more formal point of view, however, Ponge's still lifes-with their emphasis on the "gestural" aspects of food production and consumption-are to Robbe-Grillet's sandwiches what Van Gogh's peasant shoes were to Warhol's "Diamond Dust Shoes." This distinction becomes clear when, after ordering his dish, Wallas immediately proceeds to "cut the food in little cubes" (161) whose depthless, geometrical regularity reminds the reader of the "custom-made" circles of bread that adorn the machine's dishes. Wallas's little cubes enact a further reduction of organic shape to simple, "depthless" forms as well as, by extension, a reduction of the complexities of human behavior to predictable gestural patterns.

\section{The Anorexic Poem}

Undue Significance a starving man attaches To Food-

—Emily Dickinson

Can I eat everything, can everything by eaten ?

-Christophe Tarkos, PAN

Robbe-Grillet's sandwiches and tomato quarters are reflected in the simplicity that characterizes the furniture of the restaurant which itself, with its two rows of little round plastic tables nailed to the floor, evokes the "clear and comprehensible" forms commonly associated with minimalist art and design. ${ }^{9}$ Because of the popularity of Mies van der Rohe's famous dictum, "less is more," minimalism has primarily become synonymous with an art of subtraction rather than addition, with intentional simplification and the rejection of complexity and sophistication. But in the history of American art, it also signalled a move away from the gestural quality of Abstract Expressionism and a tendency to embrace an aesthetics of radical sobriety as the sole legitimate context for the artist's subjectivity. Like the French Nouveau Roman, minimalism emerged in the 1950s as a result of what was perceived as the exhaustion of available compositional norms and conventions. It shares with Robbe-Grillet's fiction a desire to empty the work of art of its "bourgeois" decorative (and allusive) functions and foreground its structural and material condition. And, indeed, if one agrees with Dällenbach's claim that partisans of an aesthetic of "thinness" and frugality usually prefer compositions which oppose themselves to "the seamless and the creamy/unctuous" and "treat ingredients of a dish by exalting their "gustatory independence" (Dällenbach 115), one is tempted (at least 
in the context of a book on food poetics) to consider the anorexic poem as a written artifact which inevitably evokes the aesthetics of minimalism in its rejection of the notion of personal style and its exaltation of the material signifier. The typical "skinny poem," then, would look like something like E.E. Cummings's famous "leaf poem" ("l(a / le / af / fa / ll / s) / one / $1 /$ iness" [Cummings 673]). The radical concretism and typographical disjunctions of Cumming's poesia povera, which isolates the graphemes and letters from their immediate (con)textual environment, results in a vertical arrangement which allows the thinness of the composition to materialize on the page. Paradoxically, the anorexic poem, far from producing less meaning than a conventional poem, is an "open" work which, by multiplying the possibilities of interpretation, maximalizes its vectors of meaning. (The more minimalist the poem, the more maximalist the demands made on the reader who is to make sense of the poem. ${ }^{10}$ Not only are the isolated words and syllables of Cummings's poem meaningful (the two "l"s and the "one" would seem to confirm that the poem is as much about singularity as it is about "l-one-l-iness") but its visual effects on the reader also enrich the latter's interpretation of the text by, for example, visually suggesting the swirling movement of the falling leaf through the inversion of "af" and "fa," the parentheses or the simple presence of the letter "s."

\section{THE JOYS OF JAPANESE COOKING}

For the last three decades, the collusion of minimalism as well as the anorexic opposition to "seamlessness" has manifested itself in various forms of experimental poetry which exalt the "signifier as such" and reject conventional modes of composition in an effort to liberate the word from the chains of syntactic and referential norms. Whereas the deconstructive strategies of Cumming's "leaf" poem still manage to produce a distinctive style (his truncated words and lines are immediately recognizable), more recent minimalist poets have tended to produce works which seem to embody Barthes's theory of the "death of the author." As I have argued elsewhere, the subordination of inscription to expression, as well as that of process to self-present lyricism, reached its apex in the Language Poetry school's disjointed, paratactic poetry which aimed at a laying bare of the strategies which condition the very act of writing and preside over the destinies of poetic composition. Even though their critique of referentiality may have led to a large variety of forms and methodological approaches to poetry (ranging from the molecular puzzles of Clark Coolidge's early works to Ron Silliman's prose poems or the procedural poetics of Lyn Hejinian's Oulipo-inspired My Life), none of the representatives of the Language Poetry school can be credited with having developed a genuinely distinctive, personal "style." 11 (As we know, the disappearance of the notion of "personal style" itself, as well as that of other "deep" or "vertical" concepts such as "inspiration" or "genius," is a 


\section{Food, Poetry, and the Aesthetics of Consumption}

distinctive feature of postmodernism of the Jamesonian variety.) The following everyday choreographies of Language Poet Ray DiPalma's January Zero (which are contained in Silliman's foundational Language Poetry anthology In the American Tree), all expressed in sentences containing four to eight mono- or bisyllabic words, seem to take Barthes's degré zéro literally: ${ }^{12}$

I take a glass. I fill the glass. I drink the water. I wash the glass. I dry the glass. I give the glass to you. I take a bottle of milk. I put the bottle on the table. I open the bottle of milk. I take a clean glass. I fill the clean glass with milk. I give a glass of milk to you. I drink a glass of milk.

I go to the door. I stop at the door. I push the door open. I go out of the door. I go into the hall. I pull the door shut. I go to the EXIT. I stop at the EXIT. I push the door open. I go out of the EXIT. I go into the hall. I pull the door shut. (Silliman 1986: 464)

Commenting on the "neutral" writing inaugurated by Albert Camus's The Outsider (1942), Barthes writes: "if language, instead of being a cumbersome and uncontrollable act, achieves the status of pure equation, having no more solidity than algebra when faced with the hollowness of man, then Literature is beaten, the human predicament is laid bare and offered up, colorless; the writer is irredeemably an honest man." One has to keep in mind, of course, that Barthes' "style-less" mode (or "white writing") is a utopian state to which a literary work can only aspire (at least for Barthes, who clearly shares the "thin" camp's aversion to bourgeois creaminess). Barthes himself recognizes the inherent failure of "blank" writing to reach a state of total stylistic neutrality. Not only is writing never entirely innocent of ideological content (cultural codes and myths are always already inscribed in the words used by the scriptor), it is also the locus where new stylistic conventions will inevitably appear. The writer who thus "acced[es] to the classic" becomes "the epigone of his original creation, society makes his writing into style and sends him away, prisoner of his own formal myths" ("Unfortunately, nothing is more unfaithful than a blank piece of writing; automatisms develop where first there was freedom, a network of hardened forms squeezes tighter and tighter the first freshness of the speech, writing is reborn in the place of indefinite language." [Barthes 1953: 57]). The following excerpt from a recent book by Christian Bobin (I could have chosen a passage from a novel by, say, Emmanuelle Bernheim, Bobbie Ann Mason, or Erri De Luca and reached similar conclusions) betrays a number of stylistic tricks commonly used in conveying the impression of a "blank writing" ("écriture blanche") devoid of all superfluous details and capable of conveying the simple pleasures and disappointments of everyday life. Among these fashionable stylistic expedients, one must cite the use of simple subject-verbcomplement sentence structures often beginning with the now trademarked third person singular pronoun, occasionally spiced up by the irruption of free indirect discourse and three closing nominal sentences meant to bring 
some psychological depth to an otherwise factual and emotionally neutral account of apparently insignificant gestures and events:

She is in the kitchen. A waiter hands her a wet towel. She does not thank him, only sees the hand, takes the towel, lifts her dress, oh just a little, to see better, two stains, very clever. She rubs the dress with the towel, with too much vigor. The red becomes pink. The stain spreads, the heart becomes bigger, it takes all the room, what is happening, she lifts her head, at last she sees him. Both of them motionless. Motionless in the passion which is to come, which is already there. Tyranny of love. (cited in Jourde 213) ${ }^{13}$

Minimalist poetry, unlike its fictional (non-)equivalent, does not reduce the syllogistic movement of traditional narrative to its bare essentials in the hope of reaching an audience fond of such sentimental superficialities posing as wisdom in the name, perhaps, of postmodernism's rejection of what Jameson called the "deeply personal" style of the great modernists (Jameson 132-35). ${ }^{14}$ On the contrary, one of the most common poetico-minimalist mannerisms to have resurfaced over the last thirty years is precisely, as I have suggested, the self-reflexive, language-oriented style which undermines the very notions of narrative continuity and lyrical self-presence by giving priority to the physical materiality of language. Such a mode is liable to produce a number of familiar poetic "stances" variously described as ironic, areferential, metapoetic, or anti-lyrical. The opening "lines" of Ron Silliman's early collection, Mohawk (1973), with its emphasis on the word-as-unit, seems inspired by Oulipo's use of constraints (a significant but underestimated influence on Language Poetry) in its use of a limited number of words which are repeated and permutated throughout the whole volume:
wet
loom
star
wicker
silt
very
blue
drift
orchid
rube
orb
stoop

(Silliman 1973: unpag.)

The unpunctuated words of Silliman's poem stand in semi-isolation and fail to deliver a coherent, linear picture of "what they mean to say." ${ }^{15}$ But 


\section{Food, Poetry, and the Aesthetics of Consumption}

these considerations should not detract us from the formal and thematic unity of the piece. Not only are all the words of the poem either mono- or bisyllabic (and highly consonant to each other, as shown in the repetition of the letters $t, l$ and $r$ ) but they are also predominantly related to the natural world. And, indeed, it would be tempting to read this "experimental" poem as a conventional landscape poem chopped up into fragments. While the emphasis on pure color ("blue") is reminiscent of (post-)impressionist paintings, one also thinks of the "looming" appearance of a watery surface ("wet," "blue," "drift") or of the "orb" of the sun at dawn. Finally, the word "stoop" calls up the position of a walker bending down to observe an "orchid" or perhaps a willow tree ("wicker"), a vision of pastoral grace comically interrupted and deflated by the irruption of the country bumpkin (or "rube") and, half a page later, by the word "curry" whose ambivalent meaning can alternately make the reader visualize a dish seasoned with curry powder or refer back to the countryside setting described earlier in the poem (the verbal form "to curry" can refer to the act of grooming a horse with a "currycomb").

In different but related ways, the short factual sentences of Ray DiPalma's January Zero, the isolated words of Silliman's Mohawk and the lowercase post-lyricism of E.E. Cummings-in which every word, every grapheme, acquires equal meaning)—embody the old dream of an unhierarchical structure uncontaminated by the vagaries of individual style and characterized by a supposedly "open," unprescriptive dialogue between work and reader. These texts would thus seem to fit the three conditions which characterize the agenda of Dällenbach's modern mosaic (Dällenbach 131):

(1) the modern mosaic must "affirm its fragmentary identity" in acknowledging its own status as "a discontinuous assemblage of detached parts" (123)

(2) it must avoid the temptation of seamlessness and subscribe to Mallarmé's "raison des intervalles et des blancs" (125)

(3) it must promote "a strict hierarchical equivalence between its compositional units" (126).

This kind of writing clearly partakes of the Moderns' above-discussed aversion to "the royal place which [traditional bourgeois gastronomy] reserves for the seamless and the creamy/unctuous" (115), a cooking mode whose speciality is to "dissolve natural ingredients and thereby render them unrecognizable." Transposed onto the domain of writing, this cult of homogeneity is radically opposed to the avant-garde emphasis on the material signifier (the [semi-]isolated letters and words are the direct equivalent of Dällenbach's "natural ingredients" in the field of literary composition), a tendency which allies such diverse contemporary experimental writers as Stevens, Stein, Beckett, Cummings, or Robbe-Grillet. In various ways, these writers have sought to undermine the "logical glue" of causality which 
characterizes realism and whose immediate effect on the reader is to draw attention to the whole (a highly suspicious quality for Dällenbach's "Moderns") rather than the parts/fragments, to the composition d'ensemble rather than the unit of composition. ${ }^{16}$ Dällenbach borrows the expression "logical glue" ("colle logique") from Barthes (Barthes 1970: 162), who describes elsewhere his fascination with Japanese cooking, where "on the table, on the tray, food is always necessarily a collection of fragments, none of which appears to be privileged by order of ingestion: to eat is not to follow a menu (an itinerary of dishes) but to select, with a light touch of the stick, a particular color, or another one ..." (Barthes 2005: 33). Barthes' celebration of the "democratic" joys of Japanese cooking is an apt metaphor for the Moderns' fondness for aesthetic structures which encourage readers to participate in the creation of meaning and allow the "word as such" to function independently from its referential destinies within the totality of the art work. As my "conventional" reading of Silliman's "experimental" poem tends to indicate, the aesthetics of disjunction which underlie many minimalist works paradoxically underlines the persistence of referentiality and "meaning" and the impossibility of truly dissolving the "logical glue" of narrative and semantic conventions in order to divert the reader's attention away from the "creamy" whole to the individual parts. Ultimately, the modern mosaic, which, like Arcimboldo's paintings, enacts the paradox of an ambivalent, "singular object" (Dällenbach 176), a fragmented whole whose repressed totality allows each of its singular parts to function independently from their referential and representational destinies and possibilities. 


\section{Uncontrollable Materialities Food and the Body in Performance}

\section{ENTER THE BARONESS}

In the early 1920s, New York Dadaist expatriate Baroness Elsa Von Freytag-Loringhoven could been seen walking around Greenwich Village wearing such adornments as a tomato soup can bra, "a peach basket for a hat . . . trimmed with gilded carrots, beets, and other vegetables . . long ice-creamsoda spoons . . . teaspoon earrings," or nothing but "metal teaballs attached to her pendulant breasts" (Lane, unpag.). ${ }^{1}$ A poet of and for the body, the Baroness once offered to give William Carlos Williams syphilis because, she said, it would "free his mind for serious art." In a letter she wrote to Djuna Barnes, the Baroness listed what she wore one evening to a soirée at the French Consulate in Berlin:

... wearing a large wide, sugarcoated birthday cake upon my head with 50 flaming candles lit—I felt just so spunky and afluent [sic]! In my ears I wore sugar plums or match boxes-I forget which. Also I had put on several stamps as beauty marks on my emerald painted cheeks and my eyelashes were made of gilded porcupine quills_-rustling coquettishlyat the consul-with several ropes of dried figs dangling round my neck to give him a suck once and again-to entrance him. I should have liked to wear gaudy colored rubber boots up to my hips with a ballet skirt of genuine goldpaper white lacepaper covering it [in the margin: to match the cake] but I couldn't afford that! I guess-that my inconsistency in my costume is to blame for my failure to please the officials? (Hjartarson and Kubla 20)

The Baroness's "art of madness" also caused some controversy after some of her poems had been published in The Little Review, under the editorship of Margaret Anderson and Jane Heap. (After Jane Heap's departure for Paris, the Baroness lost her only publishing venue, returned to Germany, and led a life of poverty and desperation. In 1926, she moved to Paris, where she died a few months later at age 53, asphyxiated by gas from an oven.) Reading her poetry against the backdrop of her public happenings, one 
gets the feeling that her published work-for all its desperate flamboyance and organic, uncontrolled buoyancy-fails to live up to more controlled exuberance of her public appearances and proto-body art performances. More than anything, it is the Baroness's Bohemian antics that impressed her contemporaries, and the very few critics who have expressed an interest in her published work have (rightly) tended to concentrate less on her importance as an experimental poet than on her role as a Dadaist activist, whose outrageous public performances ranged from "rebellious" acts of kleptomania to countless memorable appearances at Dada soirées wearing all kinds of objets détournés almost systematically involving foodstuff upon her naked or half-naked body. ${ }^{2}$ The literary transposition of the social and cultural concerns underlying the Baroness's body art have often resulted in wild experiments in free verse conveying the cyclothymic predispositions and despair which prefigured her tragic death. A quick look at the following passage from her posthumous poem, "A Dozen Cocktails—Please," is reminiscent of Gertrude Stein's use of the edible still life, especially with regard to the use of food as a euphemistic expression of sexual activity. But the difference lies in the transparency of the Baroness's poetry, which makes such analogies explicit, uses more obvious puns and imagery (such as the need to wear red lipstick or makeup from "celluloid tubes" to express her animal nature), and, ultimately delivers a much more conventional style, more typical of the modernist lyricism of the interior monologue, than Stein's more oblique psychosexual narratives:

No spinsterlollypop for me-yes-we have

No bananasI got lusting palate-I

Always eat them-

They have dandy celluloid tubes—all sizes-

Tinted diabolically as a baboon's hind-complexion.

(“A Dozen Cocktails—Please”; Freytag-Loringhoven unpag.)

In contrast, the Baroness's body art experiments, which were only recently rediscovered and documented by literary and cultural critics, ${ }^{3}$ emerge as a radical alternative to both Duchamp's ascetic modernism and Stein's literary representation of food in performance, an art of exuberance and exaggeration that aspires to "the blindness of pure sensation ... walk[ing] perilously near (if she has not passed over) the edge beyond which the vision of delirium melts into the blank self-enwrapped exaltation of trance," to quote Evelyn Scott in a 1919 issue of The Little Review (Lane, unpag.). In many ways, the Baroness's poetic, confrontational activism transcends what many perceive as its anecdotal value within the history of the avant-garde in delineating an aesthetics which stands as an exception to the general neglect for food displayed by Dada. Perhaps the best way to summarize her contribution to the international avant-garde is to quote Marcel Duchamp (who collaborated with Man Ray on a short 1921 film titled "The Baroness Shaves Her Pubic 


\section{Food, Poetry, and the Aesthetics of Consumption}

Hair") and conclude that "The Baroness [was] not a futurist, she [was] the future" (quoted in Rexroth 77). And, indeed, her experiments with food were also less futurist or dadaist than a hors-d'œuvre of things to come, especially in the realm of body and performance art.

\section{THE WAR AGAINST PASTA}

As if a cook-book had anything to do with writing.

-Alice B. Toklas, The Alice B. Toklas Cookbook

And you, as you put on your lengthy spit the modest fowl and the superb turkey, my son, alternate them, as the old Malherbe loved well to alternate his long lines of verse with the short ones; thus shall your roasts, in strophes, turn before the flame!

\section{—Edmond Rostand, Cyrano de Bergerac}

Although the Baroness remains a minor but highly emblematic transitional figure in the history of food art and performance, the first contemporary attempt to create a systematic "living" aesthetics of food came not from New York Dada but from Italian Futurism. "Futurist Lunch," the opening part of the now-lost film, Vita futurista, directed by Arnaldo Ginna in 1916, features an old gentleman (played by Futurist painter Lucio Venna) eating a bowl of soup outside a restaurant in Piazzale Michelangelo in Florence. The old man suddenly finds himself harangued by a group of young Futurists who accuse him of representing the passéist culinary establishment. ${ }^{4}$ Sixteen years later, the publication of Filippo Tommaso Marinetti's Futurist Cookbook (1932) confirmed the centrality of food and eating to Futurist aesthetics and philosophy. A late avatar of the movement, Marinetti's cucina futurista was the first systematic attempt to launch a design for a practical and performance-oriented aesthetics of food. ${ }^{5}$ Ever the enemy of satiety and limiting contentment, Marinetti launched a series of public campaigns and manifestoes promoting a new culinary art which purported to "renew totally the Italian way of eating and fit it as quickly as possible to producing the new heroic and dynamic strength required of the race" (Marinetti 1989: 33), thereby establishing a direct link between his fascist sympathies and his new dietetic credo. The first task the Futurist cooks assigned themselves was to abolish pastasciutta, a passéist food accused of making people "sceptical, slow and pessimistic" (Marinetti's cookbook also cites Schopenhauer's remark that it is "the food of the resigned" [49]) and deemed unpatriotic because of its impact on the national economy. Indeed, in the "Manifesto of Futurist Cooking" (first published on 28 December 1928 in the Gazzetta del Popolo in Turin), Marinetti writes that, in addition to developing a "starchy" neutralism and "nostalgic inactivity" in its consumers, pasta was 
also an impediment to economic prosperity in that its production required massive importation of foreign wheat. ${ }^{6}$ Its abolition would thus "free Italy from expensive foreign grain and promote the Italian rice industry" (37), a suggestion embraced by the fascist regime which also sought to boost the production of locally grown rice, an ingredient considered more "virile" and which had historical origins in the industrial North, whereas pasta was identified with the economically backward South and the "barbaric" mores of the Ostrogoths (50). ${ }^{7}$

In order to demonstrate the viability of their theories, Marinetti and his partner the "Aeropainter" and diet theorist Fillìa devised hundreds of recipes in which they endeavored to dissociate food from nourishment and shift the discourse and practice of cookbooks to art production and consumption. They even went as far as founding a Futurist restaurant ("The Holy Palate") which officially opened in 1931, in Turin, and in which they staged numerous culinary events. At a time of world economic crisis, Marinetti's opportunistic campaigns resonated with the urgency of global economic and political concerns. These campaigns were echoed in the press worldwide and, however unpopular they may have been with defenders of the old cuisine, they were endorsed by a number of prominent politicians and clinicians who voiced their support of Marinetti's anti-pasta propaganda in numerous articles and open letters full of pseudoscientific evidence. One of the most famous defenders of the anti-pasta campaign was the now infamous Professor Nicola Pende, then Rector of the Università Adriatica Benito Mussolini in Bari and one of the coauthors of the "Manifest of Racist Scientists," published in July 1938 in the Giornale d'Italia. In a pamphlet that appeared in the journal La cucina italiana in 1930, Pende typically argues that pasta makes its consumers "forget the lofty dynamic obligations of the race and the searing speed and most violent contradictory forces that constitute the agonizing rush of modern life" (41). To Marinetti and his scientist supporters, people should abstain from eating pasta because "unlike bread [it] does not undergo sufficient preparation through mastication" (42). In order to counter the threat of indigestion caused by bloating of the digestive system, Marinetti calls for "the abolition of volume and weight in the conception and evaluation of food" (37), an aspect of the manifesto which has so far been neglected by critics and historians of the movement and which nonetheless prefigures subsequent developments in the history of Western cuisine, of which the Nouvelle Cuisine and the current fashion for light food are two of the most famous and best-selling manifestations. (In order to avoid the dangers of ingesting insufficiently prepared or masticated food, Marinetti also advocated the use of "powder or pills, albumoid compounds, synthetic fats and vitamins" (38), such as modern chemistry was to prove itself able to produce.) But what is stake here is not just the future of the Italian (male) eater but also his ultimate transformation into a passive, desexualized body whose "exaggerated abdominal volume" neither encourages "physical enthusiasm for a woman" nor favors "the possibility of possessing her at 


\section{Food, Poetry, and the Aesthetics of Consumption}

any time" (41). Pasta thus stands accused not only of devitalizing the Italian people but also of destabilizing the distribution of gender codes and biological roles. ${ }^{8}$ In Western culture, the threat to sex distinctions constituted by the bloated stomach has a long history that goes back to the Pythagorean ban on beans, which was based on the belief that beans contained the human embryos of reincarnated souls and could make their eater's bodies pregnant (Huffman, unpag.). Reflecting upon food prohibitions and taboos, Robert Graves writes, in The White Goddess:

The Pythagorean mystics ... were bound by a strong taboo against the eating of beans and quoted a verse attributed to Orpheus, to the effect that to eat beans was to eat one's parents' heads ... The Platonists excused their abstention from beans on the rationalistic ground that they caused flatulence; but this came to much the same thing. Life was breath, and to break wind after eating beans was a proof that one had eaten a living soul-in Greek and Latin the same words, anima and pneuma, stand equally for gust of wind, breath and soul or spirit. (cited in Watson 3)

Whereas for the Pythagoreans eating beans amounts to endocannibalism (and farting to an abject form of abortion), in what Bataille might have called Marinetti's "general economy" of food production and consumption, flatulence becomes the conceptual ground of a politics of waste that points to unutilizable forms of food ingestion resulting in dangerous symbolic reversals of gender and natural differences between the sexes. ${ }^{9}$ More generally, Marinetti's vitalist philosophy, which purports to combat the deadening effects of "quantity, banality, repetition and expense" (Marinetti 1989: 21), condemns the dispersal of energy caused by the task of transforming heavy food into nourishing matter. The conjunction of diet and discourse in Futurist culinary theory ultimately gives way to a vision of the gradual closing of the Italian mind under the weight of spaghetti and tagliatelle, a vision which culminates in the "piggish enjoyment" experienced by an eater who aspires to a state of perfect fusion with his daily meal:

Our pasta is like our rhetoric, only good for filling up our mouths; its enjoyment lies entirely in the way it forces the jaws wide open, the way it demands voluptuous self-abandonment, the way it sticks to the palate and the intestines, the way the eater feels he has become one with it, knotted into a sticky ball and re-fashioned. (45)

\section{F. T. Marinetti and the Dissociation of the Senses}

The stupefying virtues of pasta, the eater's sense of "self-abandonment," and his identification with the "sticky ball" that fills his stomach-a form of 
symbolic, introjective autophagy-allegedly thwarted the Futurists' project to pave the ground for a new humanity whose Icarian movement towards freedom and imagination committed it to "an art of self-nourishment" which, like all the other Futurist arts, "eschew[ed] plagiarism and demand[ed] creative originality" (21). Typically, Marinetti's dismissal of rhetoric (political and philosophical discussions were banned from the Futurist banquets and were supposed to give way to various kinds of musical and poetic accompaniments) is indicative of his aversion to all forms of self-absorption and his call for a activist, vitalist approach to life and art. But the peculiar blend of political, economic, and psychosexual desires and anxieties which underlies Futurist food poetics should not obscure the Futurist emphasis on form, structure, composition, and movement. The "Manifesto of Futurist Cooking" itself also had strong formalist overtones which are more central to the concerns of this book. The first formal innovation concerned the necessary cooperation of the five senses in the apprehension and appreciation of food. The Futurist program for the "total renewal of food and cooking" (33) comprised all manner of synaesthetic experiments encouraging the interaction of taste and the other senses. The sense of touch was systematically enhanced through the banishment of knives and forks, which allowed the eater's body to become more fully involved in the process of holding and handchewing the food. Some of the more sophisticated experiments in "prelabial tactile pleasure," such as Fillìa's "tactile dinner party," (125) clearly anticipate some of the Eat Art performances analyzed later in this chapter (one thinks, for example, of Alicia Rios's "masticating body") while simultaneously embodying, somewhat paradoxically, the delights of infantile regression and the dream of a new, more "civilized" eating culture. ("Until now," Marinetti argued, "men have fed themselves like ants, rats, cats or oxen. Now with the Futurists the first human way of eating is born" [21].) Fillia's "formula" (Marinetti's preferred that term over "recipe") required its guests to wear pyjamas covered with "different tactile material such as sponge, cork, sandpaper, felt, aluminium sheeting, bristles, steel wool, cardboard, silk, velvet, etc." and eat "magic balls" (125), each one filled with something different, served from small bowls also covered with various "tactile materials." They were then asked to bury their faces in a large plate containing raw and cooked vegetables which they had to empty without the help of their hands, the purpose of the culinary experiment being to bring food into direct contact (or conflict) with the skin of the cheeks. The "party" ended with the promise of sexual gratification, as the guests were free to "let their fingertips feast uninterruptedly on their neighbour's pyjamas” (126).

The sense of touch, which has often occupied an intermediary position between the sensuous and the cognitive in Western philosophy, was considered by Kant as more objective than subjective in that, like vision and hearing, it "aroused the consciousness of the affected organ" (cited in Korsmeyer 57). Unlike taste and smell, which, from a Kantian perspective, "draw attention away from their objects and toward the perceiving 


\section{Food, Poetry, and the Aesthetics of Consumption}

body" (58), touch enables the whetted appetite to apprehend the textures and temperatures of different substances before they are actually ingested, converting foodstuff into objects worthy of tactile aesthetic contemplation (an ambition Kant denied the "lower" senses of smell and taste, which were disqualified from the realm of aesthetics because they could not surrender universal judgments). More often than not, however, Futurist cooking chose to ignore all such distinctions between the cognitive and the bodily senses. On the contrary, it strove for a reassessment of the body's global involvement in the operation of the senses and of how this involvement can lead to a reconsideration of the symbolic and cultural values of edible matter.

Building upon the realization that "the distinction of the senses is arbitrary," to quote the earlier "Manifesto on Tactilism," Futurist recipes and dinners also often comprised musical backgrounds. "Raw Meat Torn by Trumpet Blasts," for example, sets out to "divide" each mouthful from the next by "vehement blasts on the trumpet blown by the eater himself," whereas the "Drum Roll of Colonial Fish" (a portion of poached mullet marinated for twenty-four hours in a sauce of milk, rosolio liqueur, capers and red pepper") was to be eaten "to a continuous roll of drums" (Marinetti 1989: 102). Olfactory props were also common. They ranged from the "conprofumo ${ }^{10}$ of carnations" sprayed on the necks of the eaters of Fillia's "Aerofood" (144) to the "ozonizer," a kitchen appliance that "will give to liquids the taste and perfume of ozone" (56). Marinetti's two-day long "Extremist Banquet," where no one eats and "the only satiety comes from perfumes" (116), aims at a further dissociation of smell from taste which implicitly conceptualizes the ways in which the two "lower" senses can cooperate or conflict with one another in a single sensory operation. Indeed, part of the thrill experienced by Marinetti's guests is that they are inhaling "vaporizing food sculptures" through a sense which is bound to remain "ambiguous in its phenomenal placement" (Korsmeyer 96-97). Poised between intentionality and nonintentionality, the inside and the outside, the smell sensation is "'in' the body; but the smell qualities are perceived as belonging to the object of smell in such a way that one perceives a greater distance between the site of sensation and the producer of sensation than one does in the case of taste" (97). It is precisely the ambivalent distance of smell sensations that leaves the guests at Marinetti's "Extremist Banquet" alternately "thoughtful" and "astonished" until they "begin feverishly chewing the emptiness" (Marinetti 1989: 117). The "obtrusive nature" of smell (Gigante 150), which compels eaters to inhale the scent whether they want it or not, led natural philosophers like J. G. Spurzheim to conclude that it was the only unmediated sensation because "smell in its immediate functions perceives odorous particles emanating from external bodies, without any reference to the object" (149), a reflection that echoes Kant's pronouncement that smell, like taste, is a private, passive sense without claim to aesthetic judgment. For Hans Ruin, "the paradoxical objectivity of smell is that it is more intruding, more immediate, than any other sensation, and at the 
same time essentially fleeting and elusive ... The nose must continue to act incessantly, without being able to store the impression. The impression does not become more dense, it is not solidified as when we concentrate on a tone or a color" (Kirshenblatt-Gimblett 7). More recently, Derrida wrote that "by limitlessly violating our enjoyment, without granting it any determining limit, [smell] abolishes representative distance. ... It irresistibly forces one to consume, but without allowing any chance for idealization" (Korsmeyer 150). Barbara Kirshenblatt-Gimblett makes a similar claim when she writes that "while taste is an analytical sense-we can clearly distinguish between sweet, salt, sour, and bitter-smell is widely held to be a holistic sense" (Kirshenblatt-Gimblett 6). In Marinetti's "Extremist Banquet," the resistance of olfactory sensations to analytical representation would thus seem to account for the guests' complete disorientation and their desperate attempts to ward off the overwhelming scents produced by the experiment, "us[ing] their hands like shields" (117) and diverting them to the "powerful suction fan" (116) located in a corner of the dining room. The inability of olfaction to integrate stable objects and pause to "store impressions," confirms the status of smelling as a tasting activity in immediate relation to itself, which preempts reflexive self-examination. In this respect, the disorienting ambivalence of smell is clearly in line with an aesthetic that subordinates analysis to movement, rhetoric to action, and thwarts any attempt to oppose the intelligence of the mind to that of the body, preferring to explore the eater's somatic knowledge of the world around him (a principle best summarized by the "critical rumble" [124] produced by the intestines of the guests at the "Aeropoetic Futurist Dinner").

The body in Futurist food aesthetics is also the site of a living experiment that questions the very notion of selfhood. The absence of full-fledged characters in the formulas and culinary stories in the Futurist Cookbook (they are almost always referred to as interchangeable "guests"), added to their authors' tendency to dissociate and individualize the guests' body parts (Marinetti and Fillia refer to "the stomach of the human diner" and "the mouth of the human diner" [124] as separate entities), results in an allegorical landscape that paves the way for a radical redefinition of body, art, and world. In "White and Black," a recipe created by Futurist poet Farfa, this principle extends to the interior body as the inside surface of the eater's stomach becomes an organic canvas covered with "free-form arabesques of whipped cream sprinkled with lime-tree charcoal" (156). If "White and Black" is the only recipe that makes the reader visualize the inner surfaces of the eater's viscera, the wealth of stuffing recipes in the Cookbook continually insists on the necessity to consider the body as a fragile totality liable to be upset by the cook's transgression of inside and outside boundaries.

The "one-man-show on the internal walls of the Stomach" (156) of "White and Black" indicates that the Futurists, for all their obsession with synaesthetic meals, did not neglect the visual dimensions of their art of cooking. Still, the visual arrangements described in Futurist recipes were 


\section{Food, Poetry, and the Aesthetics of Consumption}

far from living up to the standards for experimentalism set out by Marinetti's revolution of the palate. On the contrary, they often verge on the merely decorative and largely subscribe to the traditional laws of symmetry and "harmony," a word used repeatedly in Marinetti's recipes, which often capitalize on a network of synaesthetic "affinities" between specific flavors, smells, sounds, and tactile impressions. The majority of the recipes in the Futurist Cookbook incorporate simple geometrical forms, which show that the Futurist cult of the mechanically-produced and the inorganic extends to their culinary practices. These forms include circles, balls, and cylinders arranged in equal spacings, as in the "synoptic-syngustatory plate" (105) of the "Springtime Meal of the Word in Liberty" (which features "peppers, garlic, rose petals, bicarbonate of soda, peeled bananas and cod liver oil equidistant from each other" [105]) or in the twenty different kinds of salad "placed in a pattern of squares" (122) of the "Aeropictorial Dinner in the Cockpit." Although Mino Rosso's "Network in the Sky" emerges as a poor attempt to emulate the dynamic curves of a Futurist sculpture, P. A. Saladin's "Cubist Vegetable Patch" had more affinities with the simple, proto-minimalist geometrical design of the Russian constructivist variety than with the more dynamic and perspectival tensions of analytical and synthetic Cubism:

1. Little cubes of celery from Verona fried and sprinkled with paprika;

2. Little cubes of fried carrot sprinkled with grated horseradish;

3. Boiled peas;

4. Little pickled onions from Ivrea sprinkled with chopped parsley;

5. Little bars of Fontina cheese; (156)

Saladin's specification that "the cubes must not be larger than 1 cubic centimeter" is symptomatic of the Futurist emphasis on form as a means of controlling and limiting the body's appetite. The Futurists, who believed that "modern man must have a flat stomach, under the sun, to think clearly" (55), favored servings which were only a few mouthfuls in size. This reductionist bend climaxes in Marinetti's advocacy of synthetic food and vitamins, which would achieve "a real lowering of the cost of living and of salaries," as well as the complete separation of food from nourishment. As suggested above, the Futurist cult of harmonious and pure forms is typical of a movement caught between its cult of formal freedom, imagination, experimentalism, and its entanglement in fascist politics. The conservative nature of the Futurist "geometrical meals"-which also found its architectural correlative in the shining, streamlined furniture of their real and imaginary dining rooms and restaurants—-betrays the need for order, symmetry, and uniformity which lurked beneath the "revolution of the senses" promoted by the movement as a whole. As epitomized by the perfect cube of beef of "Raw Meat Torn by Trumpet Blasts" and the identical discs of chicken meat of "The Flavor of Steel" (77), the Futurists' devotion to perfect forms 
reflected their phantasmagorical and libidinal investment in a mechanically ruled world devoid of the messiness and contingencies of the subjective and the organic. As Peter Nicholls aptly puts it, "the triumph of the mechanical over the natural" in Futurist poetics "encapsulates the capacity of the modern subject to experience himself as pure origin, as uncontaminated by tradition" (Nicholls 86).

\section{Boiled Fish and Banana Slices: The Simultaneist Meal}

This principle also affected the Futurist approach to aesthetic and sensory pleasure, which was touched upon above in my discussion of the "Extremist Banquet," an olfactory orgy whose eleven guests (five women, five men and a "neuter" 11 [116]) are confined to an isolated villa for a period of two days and whose scrupulously defined parameters are not unlike those of the Sadian orgy, which also took place in enclosed spaces and whose language of sexual and psychological freedom was paradoxically controlled by various forms of rational obsessions. As in the case of Sade, who, as Barthes puts it, "makes pleasure, happiness, communication depend on an inflexible order or, to put it even more offensively, a combinatory art" (Barthes 1971: 7), Marinetti's regimentation of pleasure is the other side of the coin whose obverse is the liberation of the senses. Even though the abundance of food in Sade's orgies ${ }^{12}$ contrasts with Marinetti's more frugal meals, and though the latter are deprived of the former's rituals of pain, violence, and death, the two share an approach to food which is essentially "functional and systematic" (128), repeated, and serialized, one that can only express itself in painstakingly constructed scenarios of imaginary pleasure, titillation, and power. In the worst of cases, they also give theatrical expression to the monstrous rationality of fascism which Pasolini allegorized in Salò or The 120 Days of Sodom. ${ }^{13}$

Sometimes, the power relationships that unite the dominant and the dominated are transposed onto the antagonism between the cooks and the clients. In the "Extremist Banquet," for example, this leads to a reversal of roles in which the increasingly nervous (and hungry) clients confronted with the vaporizing food sculptures are scolded by their cooks and waiters who become exasperated by their constant chattering ("You are the bosses, but you're rascals too! Are you or are you not going to eat these exquisite dishes which we great artists have prepared for you? Stop all this mumbling or we'll boot you!" [117]). Like the "Extremist Banquet" and many other "formulas" in the collection, "Springtime Meal of the Word in Liberty" (105) also typically takes the form of a lyrical narrative told in the present tense and whose factual tone is akin to the shot-by-shot film script format. The "formula" begins with three young men walking across a spring garden whom "the gentle flames of a dawn full of childish timidity" have plunged into "a state of literary and erotic anxiety that cannot be appeased by a normal meal" (105). They are immediately served "a synoptic-syngustatory 


\section{Food, Poetry, and the Aesthetics of Consumption}

plate" and begin to make "unusual metaphorical connection[s]" between the dish's peppers (a "symbol of rustic strength") and the cod liver oil (a "symbol of ferocious northern seas and the need to cure sick lungs"). They then proceed to wrap cloves of garlic in rose petals, "thus entertain[ing] themselves with the coupling of poetry and prose" (an apt metaphor given the hybrid status of Marinetti formulas, which generally hesitate between the utilitarian, transparent logic of prose and the ambivalent and self-referential functions of poetry). Eventually, "a buxom country young girl in her twenties" enters the scene "holding in her arms a huge bowl of strawberries floating in well-sweetened Grignolino wine." At the end of the script, the alliance of gastronomy and eroticism gives way to a fable of infantile and animal regression, a stylized, spasmodic poetico-culinary pastoral inspired by the flamboyant aesthetics of the celebrated Futurist parole in libertà:

The young men invite her with high-flown words-in-liberty devoid of all logic and directly expressing their nervous condition, to serve them as quickly as possible. She serves them by tipping it over their heads. They end up eating, licking, mopping themselves up, fighting each other across the table with illuminating adjectives, verbs shut between full stops, abstract noises and animal cries which seduce all the beasts of springtime, as they ruminate, snore, grumble, whistle, bray and chirrup in turn.

Marinetti's "formulas" literalize Barthes' pronouncement that taste can "develop somewhat like a narrative or a language" (Bruissement 304), a process which, far from being linear, "practices multiple and successive apprehensions: beginnings, recurrences, overlaps, a whole counterpoint of sensation" (303-04). The parole in libertà-which were themselves an attempt to defeat the linearity of reading and writing and sought to allow the lyric self to deploy itself in a state of "pure" spatial deployment-also aimed at a spatialization of the complex duration of gustatory taste. The explicit references to words-in-freedom that abound in the Futurist Cookbook clearly point to the contrapuntal, and eminently poetic, nature of the living experiments of Futurist cuisine. According to Marinetti himself, these recipes were a culinary equivalent of the aesthetics of simultaneity which characterized the earlier manifestations of the movement, especially in the field of literature. ${ }^{14}$ The Futurist cook must generate "surprises with illogical syntheses and dramas of inanimate objects" (36) which manifest themselves in unexpected juxtapositions and the alliance of contraries: combinations (they were often preferred to mixtures as they allowed the separate ingredients to remain identifiable) of sweet and salty, bitter and sour ingredients, such as mortadella and caramel or boiled fish and banana slices, ${ }^{15}$ were encouraged. To the twenty-first century reader, the results of such combinations are often disappointing and largely fail to live up to Marinetti's ambition to allow "experiment, intelligence and imagination [to] economically take the place of quantity, banality, repetition and expense" (21). The 
Futurist concept of "simultaneist food," for example, was often reduced to a simple alliance of antithetical terms (Giuseppe Steiner's "simultaneous ice cream" only consisted of "dairy cream and little squares of raw onion frozen together" [152]). Worse, at least if one bears in mind Marinetti's wish to renew the whole Italian character through a culinary revolution, they are far from being innovative; many of these juxtapositions and "innovations" (including the combination of sweet and savory flavors and the use of subtle mixtures of spices and herbs) date back to medieval times and continued to prevail until the nineteenth century, which saw the emergence of the "bourgeois" cuisine of Antonin Carême and his followers. ${ }^{16}$

This being said, the examples discussed earlier show that the "poeticity" of Futurist cooking does not limit itself to the bombastic imagery and inflated diction of the "Springtime Meal." After Gertrude Stein's Tender Buttons, Marinetti's Cookbook is the second important example of an aesthetic détournement of the language of cooking towards a poetics of microsensations and polysensory inspirations. If we agree with anthropologist Mary Douglas that the meal is a structured system that "distinguishes order, bounds it, and separates it from disorder" and that "the more appropriate comparison for [its] interpretation is versification" (Counihan 44), then the function of poetic form - versified or not-is to contain the potential organic excesses of the hungry, unfinished body and the dangers of open form. Far from confining itself to an act of poetic "defamiliarization" of foodstuff, Marinetti's Futurist Cookbook appears as a logical extension of his more general attitude towards the lyrical mode which sought to surpass the limits of free verse in the name of the pictorial dynamism and "unchained lyricism" of the parole in libertà. In the "Technical Manifesto of Futurist Literature," Marinetti argued for the destruction of punctuation and syntax and pronounced himself in favor of a "lyric obsession with matter" (Marinetti 1991: 95) that would do away with the subjectivist, sentimental, and nostalgic premises of Symbolist and decadent poetic language ("Destroy the $I$ in literature: that is all psychology" [95])..$^{17}$ As we have seen and will see, the Futurist obsession with matter and its ambivalent relationship with the lyric have remained a constant in the poetic food experiments of the contemporary avant-garde, from Stein and Marinetti to their later successors Carolee Schneemann and Karen Finley, which have continued to treat cooking as an attempt to redefine the parameters of the edible and the nonedible while acknowledging the dangers and attractions of mixing life and art.

\section{THE LEGACY OF EAT ART}

Since the 1960s, in particular, the peculiar mixture of gastronomy, eroticism, and aesthetics that characterizes Marinetti's food poetics has reached a number of visual and theatrical climaxes in the experiments of performance artists such as Carolee Schneemann, Allan Kaprow, Daniel Spoerri, 
Alicia Rios, and Karen Finley, to cite but a few of the most spectacular and sensational Eat Art performers of the last forty-odd years. The works of these artists can be grouped into two main categories:

(1) There are those- by far the most documented ones-whose physical engagement with foodstuff leads them to develop an aesthetics of corporeality which explores the unstable boundaries between the self and (edible) matter. In this category, we find the strongly politicized, activist works of Carolee Schneemann, Paul McCarthy, Hannah Wilke, Karen Finley, the Blue Man Group, Eleanor Antin, Jana Sterbak, and Janine Antoni.

(2) There are those, who, following the Futurists' "tactile dinner parties" and "polyrhythmic salads," lead kinesthetic experiments which offer viewers an opportunity to explore the nongustatory (i.e., tactile, sonorous, olfactory, and visual) aspects of food. Some of the most famous names associated with this "neo-Futurist" trend include Allison Knowles, Alicia Rios, Allan Kaprow, and Daniel Spoerri.

The first category was inaugurated by Viennese Actionist Hermann Nitsch, whose early 1960s performances began to use blood, viscera, and freshly slaughtered meat in a series of "dionysic-dynamic" (Sandford 363) happenings combining various mythic references ranging from Ancient Greek Drama to the writings of Freud and Otto Rank. It was prolonged, a little later, by Carolee Schneemann's famous "Meat Joy" performance, which was first presented as part of Jean-Jacques Lebel's First Festival de la Libre Expression at the American Center in Paris in 1964. Like its Viennese actionist counterparts in the works of Nitsch, Günter Brus, and Rudolph Schwartzkogler, "Meat Joy" - which involves a group of people writhing through heaps of raw fish, chickens, sausages, wet paint, plastic, rope, and shredded scrap paperclearly considers the body less as an object of inquiry ("the focus is never on the self, but on the materials"; Schneemann 253) than as "a primal, archaic force" (cited in Sayre 96) that precludes the possibility of a strictly formalist apprehension of Schneemann's abject choreographies. Forcing the audience to experience the directness of the live action in a way that establishes an immediate contact with material bodies and objects, "Meat Joy" encourages performers to develop new, semi-improvised relationships with other performers and/or the heaps of "wet fish, heavy chickens [and] bouncing hot dogs" they are eventually inundated with (Schneemann 261). Described by Schneemann in a letter to Lebel as a work "relating to Artaud, McClure, and French butcher shops" (255), "Meat Joy" was typically designed to "alert the total sensibility" of the audience and enlarge its "basic responsive range of empathic-kinesthetic vitality" (246). "The movements of the performers [were] explored through gesture, position and grouping in space (density, mass), color, and their own physical proportion" ; the performers' voices were also used as "instruments of articulation" liable to produce "unique 
sounds possible only during specific physical actions and which provide[d] an implicit extension and intensification of the actions themselves" (248). Although the reference to Michael McClure underlines the "poeticity" of her performance, Schneemann writes elsewhere of the necessity to emulate Walt Whitman's "most interiorized, tactile, plastic-poetic" images (250) and combine them with Allan Kaprow's art of "concordance," by which she refers to the need for the audience to agree to be physically drawn into the happening. Her instructions for the performers read like a form of spatial poetry that alternates passages in English printed in bold type (mainly describing the technical actions and gestures that are meant to be performed by the participants) and italicized fragments in French, which undermine the apparent factuality of Schneemann's "instructions":

\section{MEAT JOY (certain instructions)}

The images are realized by a process which unites visual obses-

et un concombre sans encombrement encombrer concombre cul

sions and spontaneous physical action.

encombrer (253)

The phonic proximity of "cucumber" and "encumber," which is further complicated by the bilingual pun on "cul" (the French word for "ass," which is phonemically contained in the English "cucumber") and the first syllable of "concombre" (the French slang for the female genitals), once again points to Sartre's ritual 'mastic' and its suggestion that the fundamental conjunction of food and sex (and, in this particular case, vaginal or anal masturbation) lies in the act of filling holes. This theme was developed a decade later by Paul McCarthy's "Hot Dog” (1974), a performance where the artist stuffed himself with sausages while smearing his body with various edible products including ketchup (instead of blood) and mustard. But where Sartre's sacrificial ritual was meant to bring about a sense of "plenitude," McCarthy's "Hot Dog" and Schneemann's "Meat Joy" create a space where the embodied subject is subordinated to the instrumental body which is itself coextensive with the matter that surrounds it. As in Julia Kristeva's discussion of the abject, a notion which possesses an ambivalent status between subject and object, food for Schneemann becomes a crucial element in the blurring of corporeal limits, as well as of the distinction between what is us and what is no longer us. Ultimately, "Meat Joy" is about the self's willingness to surrender the principle of "uncontrollable materiality" (Grosz 72) that defines our relationships with the unfinished body.

Karen Finley's use of food in such performances as "Yams Up My Granny's Ass" (1986) and "The Return of the Chocolate-Smeared Woman" (1988) are clearly indebted to Schneemann and McCarthy's "body-smearing" performances. Still, Finley's happenings, which are laced with poetry readings and songs, show a rather different kind of visceral art, one which exacerbates the 


\section{Food, Poetry, and the Aesthetics of Consumption}

tension between the use of savory foodstuffs (such as chocolate and honey) and the harsh realities described in texts and songs dealing with such subjects as sexual violence, insanity, incest, and suicide. Finley's "The Return of the Chocolate-Smeared Woman" is undoubtedly her most notorious performance event, though part of the agitation it caused was generated less by its intrinsic qualities than by the controversy surrounding Senator Jesse Helms's attacks on her work under "decency" issues. The artist relates the genesis of the performance as follows: "In 1987, a sixteen-year-old African-American female was found, dazed and semi-conscious, in a trash bag in an apartment complex in upstate New York. When she was found she was covered with human excrement" (Finley 83). The young woman's alleged story of physical and moral humiliation-she later declared that she had been sexually abused by several white police officers-provided the subtext for Finley's performance, whose discursive analysis of the interaction of race, class, and gender remains firmly grounded in the material dynamics of production, exploitation, and waste. After smearing her naked body with chocolate (a material euphemism for excrement), Finley proceeded to cover herself with red candy hearts in an attempt to prove that "after a woman is treated like shit she becomes more lovable" (84). She then covered herself with bean sprouts which "smelled like semen and looked like semen-because, after a woman is treated like shit, and loved for it, she is jacked off on." Then she spread tinsel all over her body "like a Cher dress-because, no matter how badly a woman has been treated, she'll still get it together to dress for dinner."

Compared to Finley's extreme scenarios of real and imaginary (self-)abuse and abjection, Janine Antoni’s Gnaw (1992) —an installation which comprised two 600 pound cubes of lard and chocolate, which she proceeded to "carve" with her teeth-expressed a more benign form of physical engagement with matter. ${ }^{18}$ Out of the chewed lard and chocolate removed from the cubes Antoni made lipsticks and heart-shaped chocolate packages, respectively, which were subsequently exhibited in a mirrored room. Besides the performative challenge presented by Antoni's installation, her use of mirrors and high-calorie food symbolically interrogate the commercial and cultural exploitation of accepted standards of health and physical appearance. Other recent performances using foodstuff in order to challenge the body's fixed limits include Ann Hamilton's Untitled (mouth/stones) (1993); Karen Finley's Pollockian breast milk paintings on black velvet; Janine Antoni's "Girl Made Out of Butter" (Antoni's butter was also made from breast milk); Hannah Wilke's "S.O.S.-Starification Object Series" (with its self-chewed vagina-like chewing gum micro-sculptures); the Blue Man Group's splattering, splashing, and sputtering TUBES experiments (1991); Wim Delvoye's 2001 Manzoni-inspired “Cloaca” project (which is discussed in the last section of this book); and Massimo Guerrera's 1995 "Cantine" (originally subtitled "Redistribution and Transformation of Earthly Food"), a wheeled installation the artist paraded in the streets of Montreal while distributing free sandwiches as well as original, handmade drawings to passers-by. (The main "theme" of Guerrera's performance, however, 
was less that of the eating body itself than that of a possible transition from a capitalist to a gift economy in the broader context of the social body.)

For the Prague-born artist Jana Sterbak, the body-in life as well as in art-becomes the battleground in which the battle for subjectivity is fought. In Vanitas: Flesh Dress for an Albino Anorectic (1987), Sterbak wears a dress made of 50 pounds of raw flank steak "which starts out red and moist, then gradually dries out into a tough leathery substance" (KirshenblattGimblett 5). By drawing attention to the corruptibility and transiency of the flesh, Sterbak's dress, a still life meant to be worn like a second skin, would seem to confirm that Kristeva's "uncontrollable materiality" includes the insistent materiality of decay and death, of which more will be said in the closing section of this study. ${ }^{19}$

Lastly, the work of Joseph Beuys, even though it clearly exceeds the parameters of contemporary Eat Art, comprises some of the most political foodbased experiments that have seen the light in the last half century. Beuys's installation, Economic Values (1980) comprised a collection of (mostly nonbranded) packaged food products from Eastern Germany placed on shelves in the midst of a room whose walls were covered with bourgeois paintings made during Karl Marx's lifetime. In other food-based works, Beuys's use of organic materials, such as fat, honey, and fruit, is put to the service of a critique of consumption centered on the relationships between energy production, the body, and the machine. His 1985 Capri Battery, a piece which is emblematic of the artist's ecological concerns and, in particular, the theme of renewable energy, displayed a yellow lightbulb whose socket was inserted in a lemon and marked with a sticker saying "change battery every 1000 hours," the lemon acid (potentially) providing the low electric current needed to light the bulb. As for Beuys's "Honeypump in the Workplace" installation (1977), to which Delvoye's "Cloaca" is clearly indebted, it was activated by a margarine-lubricated engine that pumped tons of honey through plastic tubes. The production and circulation of honey becomes a metaphor for the larger circulation of social, food, and energy in contemporary culture. Beuys's interest the body's metabolic conversion of food into energy and warmth (as well as their symbolic and "healing" potential in a society dominated by economic interests, compulsive consumerism, and spiritual dearth) is also central to an earlier work such as "From Kunstlerpost" (1969), which confronted the viewer with a heap of fat whose liminal status between the solid and the liquid returns us to the Sartrean viscous and the phenomenology of texture that underlies many of the works discussed in this book.

\section{FLUXUS AND BEYOND}

In different but complementary ways, Schneemann, McCarthy, Finley, Sterbak, and Beuys belong to that category of artists whose concrete and material engagement with food directly or indirectly contributes to 


\section{Food, Poetry, and the Aesthetics of Consumption}

a reassessment of accepted distinctions between subject and object, self and thing. Such experiments are less indebted to Futurist aesthetics than to Antonin Artaud's idea of "cruelty," a passionate, cathartic, convulsive mode "in which one is shocked bodily into an awareness of the undomesticated or the uncanny" (Tharu 57). In contrast, Allison Knowles' 1962 "orchestral" piece "Making a Salad" (at then end of which the audience is invited to consume a salad prepared by the artist to the accompaniment of music); Allan Kaprow's "Persian Rug" (which invited the audience to "eat their way through the designs right across the room"; KirschenblattGimblett 22); and Ben and Annie Vautier's "Sweet" (in which Vautier's wife distributed candies to the audience, who performed the "musical" part of the piece by rustling the wrappings) clearly belong to the second, neo-Futurist category cited above. And so does, in the last analysis, Allan Kaprow's "Environment," "Eat," which took place in the Ebling Brewery Caves, Bronx, New York, in January 1964. The participants in Kaprow's happening were invited to visit the damp, inhospitable caves, observe various wooden sculptures and installations and eat diverse kinds of food (including apples, fried bananas, sliced bread, and boiled potatoes), which were prepared and served to them by Kaprow's performers. The visitors' progression through Kaprow's installations was made more difficult by the presence of several obstacles, including rivulets of running water, wooden steps, platforms, and ladders, one of which they had to climb in order to reach the "potato man" crouched in a small, hidden cave at the far end of one the bays. Kaprow himself described his "Environment" as a "quasieucharistic ritual" meant to foreground "contrasts between symmetries and asymmetries of physical things and activities, intended as a reciprocal rhythm between the stable and the unstable" (cited in Sandford 49).

But the most famous follower of Futurist culinary activism is undoubtedly Rumanian-born Swiss artist Daniel Spoerri. Like Knowles, Vautier, and Kaprow, Spoerri was associated with the Fluxus movement. (Interestingly, the movement's founder, George Maciunas, borrowed the word "Fluxus" from medical terminology; the word originally referred to defecation and described the movement of the body in the process of emptying itself.) His famous tableaux-pièges presented unconsumed mealtime leftovers fixed on the table on which they were eaten and whose main purpose was to provide the spectator with "a piece of information, a provocation, an indication for the eye to look at things which one usually does not look at" (cited in Sandford 336). Spoerri's reduction of his work to a mere exercise in the fusion of art and life, the "poetic" defamiliarization of everyday objects, as well as his insistence that "there is no other meaning behind it" (336), hardly do justice to his essential contributions to the development of contemporary Eat Art. Like his Futurist predecessors, Spoerri refused to separate actual cooking from culinary aesthetics and went as far as opening his own restaurant in Düsseldorf in 1968. Far from being random experiments, his gastro-

nomic happenings used foodstuffs whose forms, colors, and textures were 
carefully selected and thus limited the element of chance involved in the "spontaneous" creation of the final "sculptures." For despite Spoerri's claim that his goal was to delineate the "topography of chance" revealed by the final "arrangement" of the leftovers, the question here-as with Duchamp's ready-mades-remains that of whether the tableaux-pièges eventually end up "trapping" the leftovers themselves, the eater's eating choices and habits (as manifested in his/her "topographical" unconscious), or the viewer, who is often under the illusion that the installations are "completely" determined by chance. Spoerri's Eat Art is only one of many examples of postwar avantgarde installations engaging with waste and trash as the logical outcome of consumption, culinary and otherwise. Still, for all their experimental quality, the tableaux-pièges remain very conservative in their presentation and treatment of foodstuffs, at least in the context of the history of the Western still life. Spoerri's decision to glue the unconsumed leftovers (and the kitchen utensils which surround them) together in a "frozen," timeless moment ironically betrays his nostalgia for the classical still life. Spoerri's later works, such as his recent "bronze chamber" entitled "Ik, James Ensor"-which was included in the 2003 "Triennale d'art contemporain sur mer" in Ostende-have marked a return to the classical model of the still life, evoking the memento mori tradition with its inclusion of a metallic fly and miniature skulls on the plate. Spoerri's bronze chamber is in fact a reproduction of the small room at the Hotel Carcassonne, located on Rue Mouffetard in Paris' Latin quarter, where the artist lived and worked from 1959 to $1964 .{ }^{20}$ Although the skulls and dried fishes contained in Spoerri's room can be seen as a tribute to the art of James Ensor, the concept of the bronze chamber is of course firmly grounded in his earlier "trap pictures" as well as, more generally, in his "new realist" aesthetics. ${ }^{21}$ Lastly, the inclined position of the room adds to the visitors' sense of uncertainty as they find themselves forced to grab one of the room's mummified objects in order to maintain their balance.

Other related "neo-Futurist" eat artists include Maureen Connor (whose 1991 piece, The Senses, featured an installation comprised of circular video monitors set as "plates" on a table) and Spanish food historian Alicia Rios, whose "Organoleptic Deconstruction in Three Movements" (1993), in which she proceeded to "chew" food with her fingers, aimed to explore "the texture, sound, and appearance of various substances out of their usual context" (Kirschenblatt-Gimblett 4). This particular example recalls Marinetti's experiments in "prelabial tactile pleasure" and, more generally, his totalizing and synaesthetic vision and representation of cooking and consumption as a process which encapsulates the whole life of the senses. Compared to Finley's radical poetics of abjection, Beuys's utopian installations, or even Spoerri's "trap-pictures," Rios's "The Feast of the Five Senses" appears as a rather weak rehash of Futurist simultaneist and synaesthetic poetics, with its predictable load of fruit and vegetable sculptures, edible mobiles, and tactile boxes. In recent years, Rios has tended to concentrate on "performative 


\section{Food, Poetry, and the Aesthetics of Consumption}

activities for communities" (Rios 177), such as "Eating the City," an experiment first carried out in Melbourne in 2004 in which fifteen different communities in the city were involved in an attempt to build an "edible map" laid out on sixty square meters of tables. The "map" was later consumed by visitors to the exhibition. Rios sums up the ambitions of her "urbanophagous" projects as follows:

The miracle of gustatory pupils consists in seeing things, physical, external things, from the perspective of, up to then, ignored sensory qualities: the buildings, the parks, the transportation and vehicles, the human beings and other living creatures, all can be perceived as rough, satin, smooth, cold, warm, savoury, sweet, acid, blue, hot, red, yellow, brown, piquant, poignant, tender substances, from which, after manipulating and cooking the appropriate ingredients, you build at scale, and in 3D, the map of your town. (185)

Rios's edible city is a culinary hymn to a multi- and transcultural age as well as to the oft-ignored and underestimated "sensory qualities" which sustain the complex network of identities, aspirations, and hungers that build up a community. Her community-based project brings the whole adventure of Eat Art to a logical (albeit provisional) conclusion. Urging visitors to devour a miniature version of their immediate environment and architectural surroundings, speculating on the participants' abilities to "decipher hidden and/or manifest dimensions of reality" and evaluate the "code of [their] edibility" (179), it prolongs Marinetti's "lyric obsession with matter" (Marinetti 1991: 95), as well as his culinary plea for a radical redefinition of self, body, art, and world through the material and symbolic potential of food. 


\title{
Epilogue: The Food and Hunger Poet at the Turn of the Century Anorexia, Anthropoemia, and Abjection
}

\author{
ELEANOR ANTIN'S “CARVING” AND \\ THE NUTRITIVE NIGHTMARE
}

For all their differences, the works of Schneemann, Kaprow, Antoni, and others-with their commitment to a physical engagement with the materiality and textu(r)ality of food-seem antipodal to what Lucien Dällenbach describes as the "nutritive nightmare" of the Moderns (Dällenbach 119), a condition marked by various "aversions and phobias rather than [by] the pleasures of the table and a happy appetite" (116). The last examples I would like to consider in this concluding section display singular responses to Dällenbach's understanding of the "visceral fight which has opposed the fat and the skinny since the beginning of time" (115). The two works I will consider in detail, Eleanor Antin's "Carving" and Wim Delvoye's "Cloaca," in particular, both enact a radical critique of the consuming body, the first by addressing the issue of anorexia and converting it into an artistic strategy by which to assess the limits of the self, the second by reevaluating the poetics of abjection practiced, to various ways and degrees, by Stein, Joyce, Finley, and others while testifying to the "triumph of the mechanical over the natural" (Nicholls 86) proclaimed by Futurist food aesthetics.

Antin's "Carving" documents a 36-day diet undertaken by the artist in the summer of 1972. It consists of 144 snapshots of the artist's nude body taken from four different vantage points (front, back, left, and right profile) which sardonically evoke the status of woman both as a sexual object and an object of scientific enquiry. Feminist interpretations of "Carving" have emphasized the idea that, for women, dieting takes "the creative place of art and that in this culture women themselves are the art product" (Marrow and Raven 44). As the work's subtitle, "a Traditional Sculpture," indicates, the procedural aesthetics of Antin's "Carving" is analogous to the process of subtraction involved in carving a block of marble into a statue that reflects the beauty standards of the age. But instead of being a mere critique of standard cultural expectations of the female silhouette, the documentary, almost mathematical compulsiveness of the work's structure (the day, the time, and Antin's current weight are written underneath 


\section{Food, Poetry, and the Aesthetics of Consumption}

each column) evokes the obsessive mental states of the anorexic while foregrounding the presence of the body as meat, as the double meaning of the word "carving" suggests. As Antin herself has suggested, this methodical presentation is ironical, as it satirizes both the claims to objective truth of scientific documentation and the alleged clinical neutrality of much conceptual art. Distancing herself from the early, "primitive" conceptualists, she writes: "Contrary to their belief, documentation is not a neutral list of facts. It is a conceptual creation of events after they are over. All 'description' is a form of creation. There is nothing more biased than scientific documentation. It presents a non-psychological image of the 'natural order' with no more claim to 'objective' truth than William Blake's symbolic universe" (cited in Fox 44).

If, according to Roland Barthes, photography began "as an art of the Person: of identity, of civil status, of what we might call, in all senses of the term, the body's formality" (Barthes 1982b: 79), the punctum of Antin's selfportraits may lie in their capacity to destabilize accepted notions of subjectivity as the locus of a real or imagined sense of wholeness and integrity. By turning the structural and material condition of the body itself-stripped of its metaphorical and metaphysical content-into the photographer's field of investigation, Antin's hunger artist expresses the fear of loss of control over one's body and one's physical appearance, a space which for some remains "one of the few arenas of control we have left in the twentieth century" (Counihan 228). Seen from the angle of structure and repetition, Antin's "Carving" considers anorexia as an extreme form of ritualistic behavior that aims to contain the potential excesses of the body, one which is based on the strict observance of radical diet, calorie-counting, and, more often than not, the calculated consumption of food which is easy to regurgitate (or quickly excrete by means of diuretics and laxatives). As Susan Bordo notes in her assessment of the cultural psychopathologies of anorexia, the Western body (from Plato to Saint Augustine to Descartes and beyond) is predominantly experienced as "confinement and limitation" and "a source of distractions ... liable also to diseases which overtake and impede us in the pursuit of truth" (Bordo 231), or, as this section will show, purity or sanctity. But another specificity of the Platonic/Augustinian ethic of subjectivity is that it allows the idea of control to become an end in itself. This process becomes addictive as "the more consciousness is individualized by the success of the will, the more everything outside the individual seems to be a threat-including ... the uncontrolled spontaneity of one's own body ... every success in control therefore demand[ing] a further success, so that the process cannot stop short of omnipotence" (231). It is not just food, then, or even the body, but hunger itself, which is experienced as an alien entity liable to destroy the subject's capacity to preserve (himself/herself) from the combined fears of contingency, alterity, and decay. The abstinent anorexic's never-ending battle against the body's hungers and desires ${ }^{1}$ thus becomes for many a battle for power and self-control, one which is geared towards a 
total mastery of the body, especially at times when one experiences the rest of one's life as out of control.

For Antin, the conversion of anorexy into an artistic strategy voices the need to attend to the body as "an alienation of the physical aspect of the self" and "make the leap from 'the body' to 'my body' ... an aspect of 'my self' and one of the means by which my self projects itself in the physical world" (cited in Jones 159). Conceptualizing the gap between body and self entails a number of important implications for food or hunger artists who, like Antin, assume that their body art brings with it the potential for social and personal critique as well as transcendence. Whereas the bulimic's body aims to digest and assimilate the space that surrounds it and therefore disappears as body-thereby momentarily losing its sense of itself as an autonomous, self-contained being-the anorexic retreats into herself/himself and seeks to attain what Jean Baudrillard calls "the ecstasy of the empty body" (42). For artists who, like Antin, tackle this theme in their works, anorexia becomes an art of disappearance and absence. Like the mystic body, which "feeds on itself" (Brown 170), the anorectic artist prepares $\mathrm{him} /$ herself symbolically (and/or, in the case of Antin's photographs, physically) for the ultimate sacrifice, that of the "separateness of the self; selfsacrifice, self-slaughter, self-annihilation" (171). In Antin's "Carving," the systematic denial of all consumerist temptations is radically opposed to the wish to eat or engage physically with edible matter, which characterizes the culinary aesthetics of most of the poets and performance artists discussed above, a process that essentially brings about a movement from blockage to release. As the unfinished body becomes the site of endless mental and physical self-manipulations-as well as the battleground in which the battle for subjectivity is fought-the "ultimate, fatal dream" of Antin's anorexic persona (like that of her more recent teenage anorexic heroin, Jeanie Quinn, featured in the 1997 film, Music Lessons) is "to become immaterial, a being no longer of this world, a traveler to a finer realm" (Fox 154).

The dream of annihilation embodied by Antin's diet experiment also evokes Barthes's notion of the "that-has-been," which captures a thing or person in a moment of time, a feature which Barthes sees as the specific character of the photographic image and which causes the photographed subject to experience a "micro-version of death." It also echoes Vito Acconci's autophagous Trademarks (1970), in which the artist memorably sets out to bite as many parts of his body as he could attain, reversing the naturalistic view by changing the eater into what he eats (Brown 170). Acconci's decision to take the dream of (partial) incorporation beyond the realm of the metaphorical (and into "real" presence) also reverses the process by which Christianity translated human sacrifices into the spiritual and the symbolic (and into the principle of presence in absence which underlies transubstantiation). The actual biting/eating body thus becomes actualized as an integral part of a regressive model, which takes us back to the pagan notion that to eat is to incorporate (and therefore neutralize) the enemy. To some extent the 


\section{Food, Poetry, and the Aesthetics of Consumption}

enemy, for Acconci as for Antin, is of course the body itself which must disappear for fear of losing itself in the throes of various somatic dependencies, biological urges, and consumerist impulses. But the marks left by the artist's mouth in Acconci's Trademarks also reaffirm the importance of the body as trace in a way which envisions its possible reunion with the self in the act of biting and chewing. ${ }^{2}$ Acconci's decision to photograph the traces left by his own saliva on his flesh and print inked impressions of his skin marks (Dworkin 101) reminds us that Acconci, like Antin, began his career as a poet and editor. Ultimately, Trademarks amounts to what Craig Dworkin has described as an attempt to "dramatize[] and make[] visible the physical, material, hard-edged, textual production of what can come from the poet's mouth" (101). Acconci himself recognized the potential for extending the expressive and poetic functions to the movements and traces of the mouth itself in considering his performances as "analogous to a word-system" for which "there was an attempt made to 'parse' the body" and exploit its full "grammatical" resources and abilities.

\section{Repletion and Anthropoemia}

In America, Baudrillard defines anorexia as a "fatal strategy" which is symptomatic of "a culture of disgust, of expulsion, of anthropoemia, of rejection" which is itself "characteristic of a period of obesity, saturation, overabundance": ${ }^{3}$

The anorexic prefigures this culture in rather a poetic fashion by trying to keep it at bay. He refuses lack. He says: I lack nothing, therefore I shall not eat. With the overweight person, it is the opposite: he refuses fullness, repletion. He says: I lack everything, so I will eat anything at all. The anorexic staves off lack by emptiness, the overweight person staves off fullness by excess. Both are homeopathic final solutions, solutions by extermination. (42)

Baudrillard's typically emphatic rhetoric uses the term "poetic" in a loose sense, meaning something along the lines of "oppositional," "excessive," or perhaps simply "unrealistic." Whatever we may think of it, the etymological slip of the pen which confuses anthropo-emia (the suffix here comes from the Greek "emein" meaning "to vomit") and poesis in Baudrillard's description of anorexia gives us an opportunity to consider the relationships between such performances as Antin's "Carving" and the art of poetry. Antin, who began her creative career as a poet and claims to have been influenced as much by Diane Wakoski and Jackson Mac Low as by the manifestations of Fluxus Art, which began to emerge in the early 1960s (Fox 197), ${ }^{4}$ clearly partakes of an aesthetic that refuses to reduce orality to the verbal or poetry to the written word. To paraphrase Bill Viola-who like Antin, Schneemann, and Finley is prone to citing poets 
(and Blake, in particular) as a major influence on his visual art-the poet at the turn of the twenty-first century is "not necessarily someone who writes well, but someone who thinks well." 5 In this perspective, the poetic "function" of Antin's "Carving" would seem to lie in its willingness to explore the conjunction of art and foodstuff in ways that encourage a reappraisal of contemporary notions of the body, language, and subjectivity. In doing so, Antin also distances herself from the dominant paradigms of contemporary Eat Art, which generally enacts the body's alteration and redefinition through the preparation and consumption of food rather than stressing the necessity to control the self. As the following section will make clear, a historical perspective on the spiritual and artistic avatars of anorexia reveals the deepest implications of Antin's experiment; these include the need for autonomy and freedom of the female self from various kinds of cultural and material constraints.

\section{Saint Catherine's Plight}

If one agrees that anorexia is a figure by which "the greedy subject states that he is not hungry in order to draw attention to his desire for hunger, his desire for a desire" (Richard 146), it follows that the main issue at stake here is how to control the potential excesses of the body through a series of rituals which serve the more general need "to obliterate every human feeling of pain, fatigue, sexual desire" so that hunger remains "the master of oneself" (Lupton 133). Self-starvation thus becomes a means of achieving a sense of autonomy and identity. According to Deborah Lupton, "fasting, now commonly described and diagnosed as eating disorder anorexia nervosa has ... existed for hundreds of years as a practice of the self, a means of constructing identity":

The meanings around fasting have changed over the centuries, and are specific to the particular historical moment in which the practice is carried out ... What appears prominent, however, is the discourse of self-control over the desires of the body that underpins fasting. The term "anorexia nervosa," literally meaning loss of appetite due to a personality disorder, is somewhat misleading, for most people diagnosed with anorexia do not experience loss of appetite but in fact voluntarily starve themselves regardless of any hunger they may feel for food. (Lupton 133)

Drawing upon Rudolph Bell's historical account of self-starving women in Holy Anorexia, Lupton points out that women in particular have been attracted to this radical means of self-control and that "in the medieval period and the Renaissance it was women rather than men who adopted extreme self-starvation to display their religious piety and devotion." Lupton's assessment of anorexia shows that, despite the modern, vanguardist character of Antin's experiments, anorexic body art is by no 


\section{Food, Poetry, and the Aesthetics of Consumption}

means a contemporary invention. Amongst earlier "holy anorexics," the example of Saint Catherine of Siena is worth describing at some length:

Saint Catherine of Siena, born in the mid-fourteenth century subsisted on bread, water and raw vegetables from the age of about sixteen. She wore rough woollen clothing and an iron chain bound so tightly against her hips that it inflamed her skin. Catherine imposed upon herself a vow of silence for three years while living with her family, and reduced her sleep to as little as possible, lying on a wooden board. Three times a day she flagellated herself with an iron chain, for over an hour at a time. For Catherine, this behavior represented rebellion and an attempt to establish a sense of self, in a society where there were few avenues other than the religious to achieve autonomy. ... Some holy anorexics went so far as to drink the pus from wounds or the water used to wash lepers' bodies, in which floated bits of putrefied human flesh, as a sign of austerity, self-control and holiness. ... For women such as Catherine of Siena, who had also vowed to remain, or become chaste, food was the only external thing that "invaded" their bodies by their own volition. (133)

The life of Saint Catherine of Siena prefigures the conversion of fasting into dieting and latter-day anorexia nervosa in a secular society. Although Saint Catherine's vow of silence amounts to a decision to allow the body itself to express her determination, the intrusion of the abject in the act of drinking the pus from wounds or the water used to wash lepers points in the direction of homophagy and cannibalism at the same time as it condemns all potential links between concupiscence and oral, gustatory pleasure. If one refers to Levis-Strauss's theories on symbolic cooking in The Raw and the Cooked, Saint Catherine of Siena's decision to eat only raw vegetables indicates a refusal to transform raw matter into a "cultural" item liable to distract her from her ethic of renunciation. It also reasserts the need to consider the body as un unfinished and uncontained entity: for other, more radical "holy anorexics," eating putrefied human flesh or drinking bodily fluids (like excrement, urine, vomit, blood, and saliva, pus and open wounds are one of the manifestations of Kristeva's abject) amounts to denying the boundaries between self and other as well as the limits between life and death.

\section{The Fatal Strategies of Eat Art}

Saint Catherine of Siena's rejection of the cultural and the civilized body is clearly consonant with the food experiments of the women artists discussed above, from Sterbak and Finley to Antoni and Antin, whether or not they use fasting and anorexia nervosa as their principal theme. ${ }^{6}$ What most contemporary women performance artists working with food ${ }^{7}$ have 
in common is that they conceive the site of feminist discourse as a place where subjectivity makes its mark on the body's materiality. By doing so, they address questions of subjectivity and identity that clearly exceed traditional gender and class analysis. As Lupton writes, traditional gender stereotypes and the division of labor have strengthened the notion that "philosophy is masculine and disembodied" and that "food and eating are feminine and always embodied." As we have seen, the elevation of thought and visuality over embodiment in Western art, science, and philosophy has led to a general neglect of both eating and cooking as a practical, physical activity liable to upset and demethodize the mechanisms of thought and perception.

As I have just suggested, Saint Catherine's relationship to the abject is particularly relevant to the recent development of Eat Art performances. As Kristeva has pointed out in her discussion of the abject - a notion which occupies an intermediary position between subject and object-food is a crucial element in the blurring of corporeal limits, one which results in the dissolution of identity faced with what she describes as the principle of "uncontrollable materiality" (Kristeva 43-44) which governs our relationship to the body. For Kristeva, the act of eating (or excreting, or vomiting, which is a crucial part of the anorectic's daily ritual), in particular, traumatically reminds us of our uncontrollable and unfinished condition. Ingestion, digestion, and excretion thus partake of the abject as a reaction against the threat of a breakdown of meaning caused by the loss of the distinction between self and world, between what is us and what is no longer part of us. Ultimately, Kristeva's "uncontrollable materiality," with its insistence on the physicality of death, reminds us of one of the traditional functions of the still life-of which the invention of Eat Art is a logical conceptual extension-which is to teach the observer a secular Tenebrae Lesson in the inevitability of putrefaction and decay.

In the recent history of contemporary art, the abject, the scatological, and the disgusting have made a number of memorable appearances ranging from Carolee Schneemann's Meat Joy to Karen Finley's euphemistic "Chocolate-Smeared Woman," Paul McCarthy's Hot Dog, Andres Serrano's Piss Christ $(1987)^{8}$, and Maureen Connor's more recent "Taste Two" (1992), which features a weighing scale with a built-in monitor displaying a woman stuffing herself with food and then regurgitating it when the videocassette rewinds itself (Streitfeld 25). The suggestion that Kristeva's abject, with its disrespect for borders, positions, and rules (Kristeva 4) can also be extended to extreme forms of collective suffering such as Auschwitz, ${ }^{9}$ is a concern which runs through Sarah Tuft's video, "Don't Make Me Up" (1986). This video juxtaposes commercial images of women's bodies taken from various advertisements and rock video clips with photographs of emaciated concentration camp prisoners. "Don't Make Make Up" suggests that the obsession with thinness that governs the current rules of beauty marketing and the infliction of mass suffering in the 


\section{Food, Poetry, and the Aesthetics of Consumption}

concentration camps both partake of a logic which draws us to a place where meaning collapses.

\section{FROM PIERO MANZONI'S “MERDA D’ARTISTA” TO WIM DELVOYE'S “CLOACA”}

Arrhe est à l'art ce que merdre est à merde. ${ }^{10}$

$$
\text { -Marcel Duchamp }
$$

The long history of scatological art, from Chaucer and Rabelais to Jarry and Manzoni, is fraught with endeavors to confront the audience with the physical reality of bodily functions and argues that excretion is the Great Leveler which symbolically abolishes all distinctions between different levels of society (and art production). In the early 1960s, abject art of the scatological variety seemed to reach its logical and literal apex in Piero Manzoni's “Merda d'artista" (1961), which consisted of ninety packed and sealed cans, each allegedly containing the artist's own excrement and whose commercial value was based on the current price of gold. In an article linking Manzoni's canned shit to psychoanalytical theories on anal eroticism, Gerald Silk suggests that the artist's interrelation of art and excrement was anticipated by Freud's statement that "the contrast between the most precious substance known to men and the most worthless, which they reject as waste matter . . . has led to this specific identification of gold with faeces" (cited in Silk 66). From a Freudian point of view, faeces is also one of the first things a child "makes" and perceives as a personal property liable to make him feel independent from the rest of the world. Be that as it may, the central paradox in Manzoni's transubstantiation of defecation into art is that each can contains a substance "producible by anyone, although the make-up of one's faeces is distinctly his or her own" (Silk 68). In other words, each turd is simultaneously universal by virtue of its content and unique by virtue of its form. In Manzoni's "Merda d'artista," it becomes both a common product and a marketable good which "produces a personal and actual version of the product-types favored by Pop artists"; Warhol's first Campbell's Soup can serigraphs were produced the year before Manzoni's cans, which suggests a direct, albeit ironic filiation. ${ }^{11}$

Wim Delvoye's "Cloaca" (2001) emerges as the logical outcome of contemporary art's preoccupation with food and excrement; it embodies-or, rather dis-embodies-Joyce's vision of the human body as a shit factory which needs to be fed "like stoking an engine" (Joyce 145), as well as his likening of art production with the movement of food through the entire digestive process. Devised in collaboration with scientists from the University of Antwerp, Delvoye's machine comprises a stepladder allowing access to a pierced tray which functions as the machine's "mouth" and into which 
actual meals are poured (they are catered by the museum or, more occasionally, by famous restaurants). The food is then "digested" by six glass receptacles connected by tubes and pumps maintained at body temperature and monitored by computers regulating the enzymes and acids that metabolize the process of digestion. Delvoye's "Cloaca" is a Duchampian "Bachelor Machine" 12 whose uselessness is the measure of its power to interpellate shock viewers/smellers (the end product of the chain smells like "real" excrement) into a reconsideration of their own physical finitude. It thus functions as a memento mori for the Biotechnological Age in the purest tradition of the Western still life. As Peter Bexte has argued, one of the preconditions for the transformation of edible matter into excrement in Delvoye's machine is the thermostat, which reminds us that we are precarious, unstable, and unlikely entities as evidenced by the narrowness of the temperature range within which human life itself can be sustained: "below $36^{\circ} \mathrm{C}$ we are liable to die of hypothermia, above $40^{\circ} \mathrm{C}$ we go into delirium. Within this narrow range of $4^{\circ} \mathrm{C}$, we live on a globe surrounded by the coldness of outer space" (Bexte 14). Delvoye's defecation machine thus rehearses not only the inexorable putrescence and decay of the body but also the latter's ominous premortem incarnation in the form of organic waste, a substance which must be expelled from the (concrete, political, and/or social) body in order to preserve the latter's apparent integrity and homogeneity. Dominique Laporte's now famous History of Shit has examined the social value of the production and disposal of excrement and concluded that "to touch, even lightly, on the relationships of a subject to his shit, is to modify not only that subject's relationship to the totality of the body, but his very relationship to the world" (Laporte 29). Milan Kundera's metaphysical interpretation of excrement in The Unbearable Lightness of Being assimilates an artist's fascination with faeces to an attempt to understand the Western world's nonacceptance of shit. For Kundera this repression of the excremental results in kitsch, a condition marked by a "categorical agreement with being" which "excludes everything from its purview which is essentially unacceptable in human existence" (Kundera 251). But perhaps Clive Bloom's description of excrement as an ambivalent sign of presence and absence, identity and alterity, best sums up the dynamics of Delvoye's art-and, indeed, the whole history of scatological art from Rabelais to our present days-by describing "the products of defilement" as "unassimilable and alien" products "undermin[ing] our identity by their presence as both not-us and us" and "tak[ing] on a ritualistic and totemic symbolism determined by questions of what is clean/dirty, what is I/not-I, what is inside/outside" (cited in Punter 164). Like some of the performances discussed above, "Cloaca" addresses the emotional and ontological stability of the ego not only by urging us to consider the issue of where the body begins and ends but also by dispensing with the body altogether and replacing it with an eating machine which paradoxically "incorporates" food while remaining uninvolved with anything but itself, 


\section{Food, Poetry, and the Aesthetics of Consumption}

stressing the supremacy of function to the detriment of any real or imaginary notion of selfhood or embodiment.

The "actualization" of the digestive process effected by "Cloaca" displays one of the most extreme uses of the abject in recent food art experiments. Delvoye's conflation of expression and release is depersonalized and reduced to a mechanistic simulacrum of the body's metabolism, which derives its uncanny powers from the erasure of any trace of organic differentiation or identification. The clinical outlook of Delvoye's installation adds to the sense of unease experienced by the visitor who is confronted with a parody of his own internal processes. In the last analysis, what happens to gallerygoers confronted with a machine that mimics one of their more ordinary activities is akin to Marinetti's dream of an uncontingent, mechanistic world epitomized by his above-discussed "lyric obsession with matter" (Marinetti 1991: 95). But where the Futurists' cult of the mechanically-produced and the inorganic largely confined itself to the metaphorical or the analogical, Delvoye's machin-ation does more than merely blur the traditional separations between life and art—or art and science—-to convey the "intense feeling of transition, states of pure, raw intensity denuded of their figure and their form," which Deleuze and Guattari identify as the essence of the "Bachelor Machine" (Sterckx 32). The radical dissociation and autonomization of the excremental function performed by Delvoye's "Cloaca" is of course illusory since the machine needs to be fed (and regulated by computers and thermostats) in order to be operational. Still, because of its radical uselessness, the devouring machine ultimately produces nothing more and nothing less than the illusion of pure movement and pure production.

A different, historical perspective on Delvoye's biotechnological art reveals its affinities with precontemporary styles, such as the Gothic and the Baroque. The neo-Gothic stained-glass windows displayed opposite the machine at exhibitions feature $\mathrm{x}$-rays of body parts (including intestinal bowels $)^{13}$ so clearly indicate that the artist's interest in exploring the "transparent body" points to earlier antecedents, including the Baroque Age's fascination with automata. As Bexte has remarked (12), one of the famous antecedents for "Cloaca" is the moving anatomy of Jacques de Vaucanson's mechanical duck (1739), which was allegedly capable of pecking up grains, gulping them, digesting them, and excreting them in the form of small pellets. ${ }^{14}$ Delvoye's sphincteral humor revisits Vaucanson's take on the mechanization of labour (digestive or otherwise) made possible by the progress of science and industrialisation. By identifying the absent subject with his personal waste, Delvoye reduces human life to its primary function, creating a caricature of the incompleteness of the devouring and defecating body whose final outcome is ironically inscribed in the closed circuit of production, consumption, and disposal of matter dictated by consumer society. Indeed, the end product of Delvoye's machine-like Manzoni's canned shit-is commercialized in the form of vacuum-packed shit doses sold together with their corresponding food menus. Unlike the alchemist in 
Alejandro Jodorowksy's Holy Mountain, Delvoye's "Cloaca” does not turn excrement into gold but, rather, into a perfectly useless commodity whose official logo is a fusion of the Ford and the Coca-Cola logos, which revives Pignatari's "coca-cola-cloaca" pun discussed earlier in this book.

Delvoye's shit factory enables gallery visitors to trace the food from the mouth along the alimentary canal and out through the anus. It thus forces them to identify with the machine and recognize the grotesque, repetitive mechanicality of their own bodily functions. "Cloaca" also reasserts the continuing popularity of food as a subject and a medium for late twentiethand early twenty-first century artists and its importance as a cultural (and literalized) symbol liable to describe, and deride, the totality of art production as an organic phenomenon that comprises all the stages of ingestion, digestive and peristaltic transformation, and expression. That Delvoye's installations and other recent avatars of Eat Art have tended to focus on the themes of anorexia, disgust, and abjection suggests that a conflictual, sometimes even neurotic, approach to food continues to characterize the Moderns' relationship with gustation and digestion. In many ways, "Cloaca" verifies Dällenbach's thesis concerning Modernism's aversion to food, a condition reinforced by the avant-garde's more general engagement with the physicality of concrete and textual matter and which some will diagnose as a symptom of a world dominated by repletion and overconsumption. Be that as it may, "Cloaca" prolongs the dissociation of need and desire, hunger and gustatory taste, which provides the ground for the whole history of gastroaesthetic experimentalism. It takes us into a space where the very notion of taste is perverted and neutralized by the machine's self-directed functionings. Delvoye's art would thus seem to represent the logical (perhaps ultimate) theatralization of Barthes's earlier-cited description of BrillatSavarin's gastronomy as "the luxury of desire ... an unconditional loss, a kind of ethnographic ceremony by which man celebrates his own power, his freedom to burn his energies 'for nothing"' (Barthes 1984: 304), a gesture which enacts imaginary mediations between the subjective and the objective, violates the limits between the inside and the outside, unsettles the distinctions between life and nonlife, and ultimately aims to digest the process of digestion itself. 


\section{Notes}

\section{NOTES TO THE INTRODUCTION}

1. These crystallize in a number of familiar features of the classical still life, such as the joint themes of the brevity of life and the inevitability of decay displayed in the vanitas tradition.

2. The [semi-]isolated letters and words are the direct equivalent of Dällenbach's "natural ingredients" in the field of literary composition) and its efforts to undermine the "logical glue" of causality which allegedly characterizes realism and whose immediate effect on the reader is to draw attention to the whole (a highly suspicious quality for Dällenbach's "Moderns").

3. As we will see, the Moderns' aversion to the fat and the creamy (long before the Nouvelle Cuisine and Deprivation Chic became trendy fashions with the rich and the privileged) was prompted by a feeling of disgust for what was perceived as the ample, well-fed forms of bourgeois art and literature, a tendency apparent in the seamless richness of detail and texture of "realist" modes of description and narration.

4. With the exception of David Bevan's collection, Literary Gastronomy, which focuses on examples drawn from twentieth century fiction, and despite the considerable growth in "diet studies" over the last ten or fifteen years, the great majority of books and articles on literary gastronomy-including Morton and Gigante's foundational research-deal with pre-contemporary, predominantly Romantic examples.

5. One thinks of the scatological works of Piero Manzoni and Wim Delvoye and their endeavors to deal with how society deals with the excrementally repressed.

\section{NOTES TO CHAPTER 1}

1. The film was originally intended as a critique of Thatcherism and the brutality of the new entrepreneurial spirit of the 1980s. For a detailed discussion of Greenaway's films and Thatcherism, see Michael Walsh's "Allegories of Thatcherism: The Films of Peter Greenaway" in Friedman 255-77.

2. See also Gaston Bachelard's critique of the "myth of digestion" (Bachelard 169).

3. "You shall have a bit. / Do you like chocolate? Let it melt in your mouth / Mummy, there is a bone in it. / No, my love, it is an almond. / The little boy wants to eat the whole box. / My, he is greedy! / His mummy gently tells him not to: he must not make himself sick. / How dreadful! He is stamping with rage" (Satie 22). See also Satie's piece "Eating his Bread and Butter" which 


\section{Notes}

plays on the superstitious fears associated with the sin of greed: "Get used to seeing bread and butter without feeling the need to pinch it. / It could make your head swell up if you touch a friend's bread and butter" (22).

4. Translations are mine unless otherwise indicated.

5. Arcimboldo's collage of dead matter-a still-life ("nature morte") in the literal sense-embodies a more modern continuation of Breughel's infernal chain of ingestion and regurgitation in "The Big Fish Eat the Little Fish," a pre-postmodern trompe l'oeil based on a playful recognition of the interdependency of figure and ground.

6. Or phanopoeia. Pound would use this term to describe the ways poetry appeals to the visual imagination.

7. The word is used here in the broadest sense to describe the verbal representation of visual representation.

8. Rilke used this expression to refer to his endeavors to present "concrete objects ... with factual precision and in symbolic concentration" (Preminger 295).

9. Braque's famous quote reads: "A lemon and an orange placed next to each other cease to be a lemon and an orange and become fruit. Mathematicians follow this law. So do we" (cited in Careri 115).

10. Silliman's use of the word "gestural" refers to the process which distinguishes the original from its copies and "serves solely to mark the connection between the product and its maker" (Silliman 9). For Silliman the repression of the gestural quality of textual production is one of the most important consequences of "the subjection of writing to the social dynamics of capitalism" (9). It has to be noted that Grenier's typewritten Sentences, unlike his later work, reacts against the fetishization of language while simultaneously undermining the effect of "genuine" lyrical authenticity of the poem.

11. To use Marjorie Perloff's now famous expression.

12. Bly translates "opiniâtrement" as "bull-headedly," thus reinforcing the interanimalistic mtephorical strain of the poem. One could, of course, opt for the more neutral "stubbornly."

13. Like Bly's oyster, Ponge's pebble is also an opportunity for the poet to recapture the distant past, "beyond the Deluge" (50).

14. The word "pebble," which have reintroduced into Bly's translation, is closer to the French original ("galet") and preserves the intertextual connection with Ponge's poem "The Pebble," which I discuss later in this chapter.

15. Bly translates the French "sachet" ("bag") as "pillow."

16. Ponge's poem concludes: "Occasionally-it is rare-a beautiful expression rises in their mother-of-pearl throats, and you find good reason to adorn yourself" (Ponge/Bly 23).

17. Bly's poetics of depth explicitly rejects W. C. Williams' famous motto "no ideas but in things" on the grounds that it leads to a poetry where "keeping close to the surface becomes an obsession," and the poet appears "only as a disembodied anger or an immovable eye" (Bly 1991:13).

18. The Deep Image is often characterized by unexpected juxtapositions and surrealist "leaps" and a resonant, flamboyant style inspired as much by Charles Olson's Projectivism as by the "deep song" (cante jondo) of Andalusian gypsies and the poetry of Federico García Lorca.

19. Such a revelation, Bly explains, is meant to elicit "no sentimentality, only the ruthless body performing its magic, transforming each of our confrontations into energy, changing our scholarly labors over white-haired books into certainty and healing power, and our cruelties into an old man with missing fingers" (Bly 1977: 29)

20. Or, say by Simic's haiku-like "Watermelons": "Green Buddhas / On the fruit stand / We eat the smile / And spit out the teeth" (Simic 49). 
21. In The Morning Glory, such anthropomorphizing or "culturalizing" comparisons result in a number of emotional climaxes or moments of insight, as in the image of the lily pads rising above the water "like hands held up to receive" ("A Poem about Tennessee" [32]) or of the "Lobsters Waiting to Be Eaten in a Restaurant Window," turning up to the sky "as if praying after some catastrophe" (27).

22. See also Ponge's description of the poet's a quest for "the best concrete approximations to pure reality" ("On Natural Crystals"; 632).

23. The word "consumption" seems more appropriate than "consummation," which appears in Bie's otherwise flawless translation of Ponge's prose poem.

24. Ponge's successive revisions of his object poems show that he hesitated between an emphasis on the usefulness of the object and a more nuanced advocacy of the dialectics of diet and discourse, consumption and philosophy or contemplation. While the second manuscript version of "The Potato" states that "the potato is not a subject which lends itself to philosophy" (1155), an earlier version of "Bread" concludes that "bread should be a object of respect and consumption" (905).

25. This can be usefully related to Ponge's definition of "ontological suicide" as an expression of "the nostalgy of oneness" (Higgins 38), an incapacity to think of oneself and conceive of personal identity in terms which do not account for the necessary, dialectical interaction of self and object.

26. Interestingly, Ponge's "Wine" does not suggest the same threat, as the grape's pulp is transmuted into the "solid" shining splendour of the ruby-colored wine (Ponge 1999: 744). As Higgins explains, Ponge sees not in food but in natural crystal the ideal "coordination" of the stone-like and the liquid and one of the "best concrete approximations of pure reality, that is to say pure idea" (Ponge 1999: 632).

27. Ponge once used the obsolete French word "sapate" to describe his objectist poetry (305) - the word designates an ordinary object in which another, more precious object is hidden.

28. See also "The Fig," where Ponge's allegory becomes a manifesto for a poetry which promotes the "elasticity of words (to the spirit) - and of poetry as I intend it" (805).

29. The translation is Beverly Bie's (Ambit No 64 (2001) 88-89.

30. Or Braque's oranges and lemons for that matter (see footnote 9).

31. Which include the image of the vanquished fish's sword-shaped bones which are about to be scattered on the floor.

32. For a full analysis of "Plat de poissons frits," see Higgins' remarkable chapter-long description of Ponge's poem (Higgins 67-93). In a letter to Higgins, Ponge clearly indicates that the poem originates in a concrete situation and describes it as nothing more and nothing less than "my (literary) response to a violent impression experienced in a dining room framed by picture windows (giving onto the sea) where my friends of the 'Cahiers du Sud' had invited me. I had, of course, eaten a portion of (grilled) bass with fennel while watching the small boats sail by. It is also an exercise in, if I may say so, linguistic frying" (Higgins 133-34). In conversation with Higgins, Ponge later added that the notion of "linguistic frying," far from being merely a synaesthetic figure, was the expression of "the linguistic adequation of the passage from the raw to the cooked" (134).

33. The pun here is on the French "c'est" ("it is"), which makes "Sète alors que la haute fenetre s'ouvre" sound like "It is then that the high window opens."

34. Schelling's ruminations on molluscs in the Lectures on the History of Modern Philosophy offer a different perspective on the shellfish's relationship between the organic and the inorganic by arguing that the animal's shell shows that 


\section{Notes}

"matter always seeks to maintain its independence" from assimilation: "the inorganic, matter that lays claim to being itself has here already entered the service of the organism, but without being completely conquered by it" (cited in Morton 130).

35. The French verbs baiser and honorer are both euphemism for having sex.

36. As well as those of Bachelard and Valéry; see Stéphane Dawans and Michel Delville, "Corps architectural et utopie organique: le rêve de l'escargot." Unpublished manuscript.

37. Ponge specifies that snails are "saints that obey precisely their own nature" (27).

38. Ponge's radical materialism may be antipodal to Claudel's Catholicism, the former nonetheless expresses his ambition to emulate the tradition of "the great prose poem of Rimbaud, Lautréamont and Claudel" (cited in Higgins 137). On the unlikely alliance of Ponge's and Claudel's poetics, see Guy Lavorel's "Ponge et Claudel" (Gleize 315-25), in which he considers Claudel as a thinker whose materialism was ultimately inspired by his faith in God ("In the Creation," Claudel writes, "God provides for everything, the primal idea, the image, the model to be realized. And, likewise, he furnishes the matter underneath" [323]), whereas Ponge's attachment to things was the reflection of a humanist faith in the power of man to "transform the world and strives for a different life" (323). In an interview with Loïs Dahlin, Ponge, commenting on "The Meadow" explicitly distinguishes his "semantic materialism" from a "search for the sacred word" and argues that his main purpose is to "ground himself in the temporality, the oldness of language-with the mother, the grandmother, the oldest ancestor of a word, or a prefix ..." (528).

39. The poem, of course, is not completely devoid of moralizing overtones, as its "moral" indicates: "Glutton, bawdy readers! If I present you with this model, say the truth: something fails to fully satisfy you. The body is not sufficient unto itself and the doctrine it teaches us is not vain" (67).

\section{NOTES TO CHAPTER 2}

1. See Perloff 1983 (67-108) and Ruddick (190-252), respectively.

2. See chapter 1 of my The American Prose Poem: Poetic Form and the Boundaries of Genre.

3. See "Roastbeef," "Breakfast," "A Carafe, That is a Blind Glass," "Dirt and Not Copper," "A Piano," "A Cloth," and "Rooms."

4. Excre* ate (?), v. t. [L. excreare, exsreare; ex out + screare to hawk.] To spit out; to discharge from the throat by hawking and spitting. [Obs.] Cockeram. (Webster's Dictionary, 1913).

5. For a discussion of Stein's essentialist poetics and her empiricist faith in the power of language not just to describe the object's "thingness" but also to describe the totality of human nature and attend to "the daily life the complete daily life and the things shut in with that complete daily life" (Stein 1967: $35)$, see the opening chapter of my The American Prose Poem. Such claims to absolute comprehensiveness are of course diametrically opposed to the relativism and pessimism which was to pervade the whole history of Modernist aesthetics which extends, beyond language, to all moral and epistemological certainties.

6. Stein's Tender Buttons is haunted by the notion of usefulness. The word "use" and its substantive, adjectival, and verbal derivatives occurs fifty-six times in the collection (and no less than five times in the opening "Breakfast"). 
7. In Tender Buttons, Alice's role as seamstress is acknowledged in “A Substance in a Cushion."

8. See also her later poem "Pink Melon Joy" and the entry "Salmon," cited above, with its pun on the French "fond(s)" which can refer to the "bottom" of the "bin" and/or to the "melting" of butter or flesh.

9. As suggested in the preceding chapter, the "concretist" quality of the "blocks of prose" of Tender Buttons is an example of Stein's desire to emulate the twodimensional squareness of the canvas.

10. Both responses were published in the "Letters" section of a Summer 1971 issue of The New York Review of Books (the complete issue is available in unpaginated form at the following URL: http://www.nybooks.com/contents/19710701). In the same issue, Virgil Thomson writes: "And what if Tender Buttons were a bilingual pun from the French tendres boutons, the early buddings of a tree or plant? In that case it would mean that the writings included were a new development like the eclosion of leaf, flower, or branch. And whatever erectile suggestiveness may go along with this would imply that we are in the presence of a natural force moving toward explosion."

11. " ... food is the "mastic" which will seal the mouth; to eat is, among other things, to block oneself . . . To fill the hole is originally to sacrifice my body to allow plenitude to exist, that is to say, the passion for the for-itself in order to enact, perfect and redeem the totality of the in-itself" (Sartre 1976: 705-06). As Barbara Kirshenblatt-Gimblett has noted, this is by no means a contemporary phenomenon for, "given that gastronomy and eroticism share not only touch but also appetite and oral pleasure, Enlightenment thought associated the two, particularly in the figure of the libertine and the orgy" (KirshenblattGimblett 2).

12. Kristeva's discussion of the abject, which is examined in the following chapters, mentions her description of the sense of repulsion towards the skin on milk (Kristeva 2-4).

13. This cannibalistic thread undergoes a reversal when Tarr is disgusted by "the ugly whiteness" of Bertha's "large thigh ... slid[ing] out of [her dressing gown]," and becomes unable to see it as anything other than a piece of meat "looking dead, and connected with her like a ventriloquist's dummy with its master" (50).

14. Tarr's culinary demise strongly contrasts with his earlier boastful assertion, at the beginning of the novel, that he, unlike Flaubert who "grumbled and sighed over his food," "takes the stuff up in his arms and bur[ies] [his] face in it" (17).

15. Joyce's relationship to food is more complex than this quote tends to indicate. Bloom's lunch in the "Calypso" chapter takes us in a significantly different direction, as discussed later in this chapter.

16. "All culinary operations signify and celebrate the transformation of matter ... acting simultaneously on time, form, texture and color amounts to an aesthetic practice" (Onfray 1995: 212-13).

17. By contrast, the earlier "Coffee Mill" (1911), with its arrow and its rotating handle painted several times to create the illusion of movement and retinal persistence, was still indebted to the Cubist aesthetics of simultaneity.

18. See Dällenbach's discussion of Claude Simon and Balzac (Dällenbach 12122).

19. See, for example, Marjorie Perloff's reading of the poem and her suggestion that Duchamp's female alter ego Rrose Sélavy might allude to Stein and "her predilection for what was, in Duchamp's day, an uninteresting, bourgeois female name" (Perloff 2002: 85). 


\section{Notes}

20. "It could be a spoonful of sugar / It could be a spoonful of tea / But one little spoon of your precious love / Is good enough for me (Dixon unpag.)

21. The last three stanzas of Bishop's poem, however, bring about an important reversal by which food ceases to be used in a metaphorical sense and becomes the material link between self and community, dream and reality, subject and object.

22. See also Joyce's three-page description of Shaun the Post's gargantuan meal in Finnegans Wake in which Shaun, poised "between gormandising and gourmeteering" (407), experiences the effects of "prelove appetite and postlove pricing good coup" (Joyce 1975: 406).

\section{NOTES TO CHAPTER 3}

1. Erica Hunt is another notable exception. For an introduction to the history and development of Language poetry, see Linda Reinfeld's Language Poetry: Writing as Rescue (Louisiana State UP, 1992) and Bob Perelman's The Marginalization of Poetry: Language Writing and Literary History (Princeton UP, 1996).

2. Responding to Elisabeth Frost's comments about her departure from "the tradition from the first-person, lyric 'I'," Mullen acknowledges that she "hadn't done that for the two books before [Muse and Drudge], Trimmings and $\mathrm{S} * \mathrm{PeRM}{ }^{*}{ }^{*} \mathrm{~K}$ T. It's the culture speaking, definitely" (Frost 408-09).

3. The collection contains other references to the inevitability of body leakage, as in the following excerpt from an earlier poem: "Every orifice leaks. No cap is tamper proof" (unpag.)

4. Although her food poetics is by no means devoid of class consciousness, as indicated in her pun- and alliteration-ridden evocation of bread against a background of class and racial injustice: "Well bread ain't refined of coase dark textures never enriched a doughty peasant. The rich finely powdered with soft white flours. The poor got pasty pale and pure blands ingrained inbred." (unpag.).

5. For a detailed discussion of Richon's still lifes and his role in transferring food from the margins to the center of religious iconography, see Maria Giulia Dondero's “La nourriture et le sacré en photographie" (Delville 2007: 79-86).

6. See, for example, Goldsmith 310-11.

7. See also John Yau's more flattering comment that "the difference between Warhol and Duchamp, who is considered the innovator of an art which questions the distinction between art and life, is that the former aestheticizes everything while the latter attempts to reveal how aesthetics is an act of denial" (Yau 27).

8. As Kuspit writes, in a 1976 article which contains in nuce most of Jameson's arguments about Warhol's art as an art of acceptance, not subversion or resistance, the coming together of "low" and "high" forms of communication in Pop Art is not carried out "in the name of greater over-all success of communication, and not because they have often the same information content and point to their methods, but because underneath their apparent differences they are in the service of the same ideal of psycho-sexual control" (Kuspit 32).

9. Unlike the example used by Jameson, some of the pieces of the series feature are colorized. But Warhol's use of color in this series is as spectral as his use of negatives in Warhol's lilacs, blues, greens, and reds, which do not fully cover the dark background of the prints that threatens to invade and contaminate them. 
10. The author found no evidence of this quote famously attributed to Warhol.

11. That same year, Indiana built a twenty-foot electric sign saying «EAT » for the New York Pavilion at the World's Fair.

12. In the 1990s, Damien Hirst also referred back to da Vinci's Last Supper in an installation featuring a formica table surrounded by 13 ping-pong balls representing Jesus and his disciples kept up in the air on jets of red wine. While a detailed consideration of the predominance of Catholic or lapsed Catholic artists such as Thek, Warhol, Serrano, and Hirst in the recent history of the still life clearly lies outside the scope of this study, I will return to the dialectics of the body and the sacred in Western food aesthetics in my discussion of Saint Catherine of Siena's anorexic mysticism in the closing chapter of this book.

13. According to Gomringer's 1954 manifesto "From Line to Constellation," concrete poetry was part of a broader movement towards a universally readable language: "Our languages are on the road to formal simplification, abbreviated, restricted forms of language are emerging. The content of a sentence is often conveyed in a single word. Moreover, there is a tendency among languages for the many to be replaced by a few which are generally valid. So the new poem is simple and can be perceived visually as a whole as well as in its parts ... its concern is with brevity and conciseness" (unpag.).

14. At the time of this writing, this later version is available at : http://www.imediata.com/BVP/Decio_Pignatari/deciobeba.html

15. Which is not to be confused with the installation described in an earlier footnote to this chapter.

\section{NOTES TO CHAPTER 4}

1. Malone, Beckett's other famous toothless character, ritualizes the proximity of food and excrement by putting his full chamber pot on the table next to the bowl of soup. Like Molloy, he refuses to regard eating as a necessity and eats his soup "one time out of two, out of three, on an average" (Beckett 1956: 7). See also Mercier's unexpected decision to destroy the cream horn Camier brought him at his request, crushing it between his fingers, his "staring eyes filled with tears" ("Mercier and Camier"; Beckett 1976: 186). Once again, the Moderns seem to experience some difficulty in digesting the creamy and the unctuous.

2. Sartre's famous distinction refers to the dialectic between the subjective and the objective in which the for-itself, which stands for consciousness' experience, is opposed to the in-itself, a pre-reflective spontaneous state, which is unaware of itself and resists the observer's gaze.

3. Although "longing" may be too strong a word, as Molloy himself eventually admits that his desire to "go back into the forest" is "not a real longing" (329).

4. This passage from Molloy belongs in the second, "problem-solving" category of permutation/repetition identified by Bruce Kawin: (1) "Listing every relevant fact or object in an attempt to fence in the phenomenon ..."; (2) "Listing the logical permutations in an attempt at problem solving ...”; and (3) "Carrying logical permutation to the language itself" (cited in Brienza 34).

5. On Bataille's distinction between "restricted" economies of meaningful, wastefree circulation and "general" economies of meaningless expenditure, see The Accursed Share.

6. Although this chapter examines the eating scenes of Beckett's fiction, an equally detailed study could be devoted to the fantasies of being eaten which invade his characters' consciousness. See, for example, the "Unnamable"'s 


\section{Notes}

daydream of "escap[ing] being gnawed to death as by an old satiated rat" (349).

7. "Divin Dalí.” ARTE, May 7, 2004.

8. Dalí also claimed that the lamb chops on Gala's shoulders were "the expiatory victims of [his] aborted sacrifice, in the same way as Abraham had preferred to eat the lamb and Wilhelm Tell to aim at the apple" (Bonafoux 120).

9. The nearest visual equivalent to Robbe-Grillet's tomato quarter is perhaps Wayne Thiebaud's serial still lifes. Robbe-Grillet's fast food invites a comparison with Thiebaud in that they both document the effects of standardization and, more largely, modernism's desire to think "in multiples." They are both interested in simple objects and simple shapes like triangles and circles and were both associated with certain forms of "minimalism."

10. See also Jan Baetens's remark that the prestige enjoyed by an art work is proportionate to its potential to multiply the vectors of meaning: "the conviction ... that an excess of meaning is preferable to a unique meaning, both in terms of the pleasure of reading (it is more 'enriching') and in terms of authorial gratification (the plurality of meanings is reputedly more difficult to achieve and would seem to convey the grantauteur's craft)" (Baetens 109).

11. For a detailed discussion of the stylistics and poetics of the Language group, see chapter 5 of my The American Prose Poem: Poetic Form and the Boundaries of Genre.

12. The examples discussed here are by no means representative of the huge number of poems published under the Language-oriented banner in the 1970s and 1980s. The conceptual and theoretical roots of Language Poetry clearly encompass much more than contemporary minimalism; they include the procedural poetics of John Cage and Jackson Mac Low (who featured prominently in Ron Silliman's seminal "language-centered" anthology, In the American Tree [1986]), the prose poems of Gertrude Stein, the theoretical works of the Russian formalists, the objectivist poetry of Charles Reznikoff and George Oppen, John Ashbery's deconstruction of the conventional "voice" poem, and a good deal of French theory ranging from to Louis Althusser to Gilles Deleuze.

13. For a detailed critique of the mannerisms of recent French "blank" minimalist fiction, see Pierre Jourde's excellent book, La littérature sans estomac.

14. Jan Baetens cites Anne-Marie Albiach, Jean Daive, Roger Laporte, and Edmond Jabès as examples of poetic minimalism in French literature. For Baetens, the emergence of a new kind of minimalist poetry in the 1970s and the success story of the postwar school of French minimalist fiction are two different, though related, phenomena. The generation of the "Jeunes Minuits" which followed in the footsteps of the Nouveau Roman (the names of Patrick Deville, Christian Oster, Christian Gailly, and Jean-Philippe Toussaint come to mind) largely reflects "an effort, often self-defeating and clumsy, to reinvent narrative fiction after the age of Suspicion, that is to say after the final, most caustic stages of the critique of narrativity, followed by its downright destruction in the successive waves of the Nouveau Roman, the Nouveau Nouveau Roman and Tel Quel's 'textual writing'” (Baetens 104). In contrast, the works of Albiach, Royet-Journoud, and others are more akin to painterly and architectural minimalism in their continual embodiment of an aesthetic which aspires to "more and more purity and more and more essence." By attempting to "bring the art of writing closer to what is irreducibly specific within it," poetic minimalism can thus been seen as a continuation of the great modernist avant-gardes which simultaneously promotes the autotelic vocation of discourse and the radical autonomy of the art work. It also enacts the conjunction of literary and philosophical models, at a time when poetry's "philosophical turn" coincides with 
contemporary philosophy's increasing tendency to rely on linguistic thought models. For Baetens, the collusion of poetry and philosophy indeed constitutes "minimalism's secret weapon" (105).

15. The role of punctuation in the "poetic mosaic" is extremely complex as it simultaneously relates and separates the different parts of the poem; at the level of the poem-as-unit, however, the effect created would seem to be more synthetic than analytical, especially when we deal with such "disjunctive" works.

16. See Dällenbach's discussion of Claude Simon and Balzac in Mosaïques 121-22.

\section{NOTES TO CHAPTER 5}

1. In the January-March 1921 issue of The Little Review, Ezra Pound published a humorous poem entitled, "To Bill Williams and Else von Johann Wolfgang Loringhoven y Fulano." Interestingly, the piece, which parodies the styles of both Williams and the Baroness, is built around a culinary joke:

Codsway bugwash

Bill's way backwash

FreytagElse 3/4arf an'arf

Billy Sunday one harf Kaiser Bill one harf

Elseharf Suntag, Billsharf Freitag

Brot with thranen, con plaisir ou con patate pomodoro

(Lane, unpag.)

2. For more examples of the Baroness's food-adorned costumes, see Lane (unpag.)

3. See Paul Hjartarson and Tracy Kulba's The Politics of Cultural Meditation: Baroness Elsa von Freytag-Loringhoven and Flelix Paul Greve and Irene Gammel's Baroness Elsa: Gender, Dada, and Everyday Modernity.

4. The synopses of this long lost film, as recounted by Ginna himself, are available on Bob Osborn's website Futurism and the Futurists: http://www.futurism.org.uk/cinema/cinema.htm

5. Although it was by no means the first use of the term applied to cooking, as attested by Jules Maincave's early La cuisine futuriste (1913), whose revolutionary ideas about sweet and salty juxtapositions and unconventional use of spices probably inspired Marinetti's cookbook.

6. In contrast, the abundance of exotic fruits in Futurist dishes was a symptom of the fascist regime's desire for a firmer imperialist expansion in Africa.

7. Marinetti's nationalist food aesthetics also extended to his criticism of the international cuisine of the grand hotels and his opposition to the importation of foreign words into the vocabulary of Italian cuisine.

8. This is not to say that Marinetti's gender politics are limited to the Futurist cult of virility. In the "Manifesto of Futurist Cooking" Marinetti gets carried away by his own praise of voluptuousness, flexibility, and movement and argues that the Italian male should "harmonize more and more with the Italian female, a swift spiralling transparency of passion, tenderness, light, will, vitality, heroic constancy" (36). More generally, Marinetti's rejection of the feminine in life and art was fundamentally directed at the representation of woman as "a magnet for sentimental passion or lust" (Marinetti 1991: 81).

9. Still on the subjects of breath, flatulence, and sexuality, Hinduism also considers food as a symptom of the progressive degradation of the primal breath that determines human life and relates it to the wholeness of Brahma (also known as the world soul "ātman" which, in Sanskrit, means both "self" and 


\section{Notes}

"breath"). Whereas in the Golden Age of original time, “a man's vital breath (prāna) resided in his bones," he subsisted on air alone, "enjoyed a lifespan of 100,000 years and reproduced asexually" (Feher 496), we now live in the fourth epoch of the world cycle and "the vital breath resides in the grain we eat, we live to a maximum age of 125 , and few are virtuous enough to attain even this modest target" (497). The connection between sex and food that underlies Hindu cosmology is once again reasserted by a doctrine which warns its followers against the health hazards of indulging in irregular or excessive dietary and sexual practices, which proves that, contrary to the common view, the rejection of the body considered as a "dirt-producing factory" (499) is by no means an exclusively Western phenomenon.

10. The term indicates "the tactile affinity of a given material with the flavour of a given food" (172).

11. The function of the ungendered guest in the formula seems to be that of a neutral witness whose detachment from sexual activities allows him to report on the diners' potential lapse into cannibalism ("For pity's sake, beautiful cooks, bring us something to chew on, otherwise, we will see the ugly mouths of these rude men bite into the insipid flesh of our five lady friends" [117]).

12. For a detailed description of what Sade's libertines and their slaves eat, see Barthes 1971: 21-23.

13. Barthes himself was of a completely different opinion and considered Pasolini's analogy between sadism and fascism as dangerously misleading: "Fascism is too serious and too insidious a danger to be treated by simple analogy, the fascist masters coming 'simply' to take the place of the libertines. Fascism is a coercive object: it forces us to think it accurately, analytically, philosophically. All that art can do with it, if it deals with it, is to make fascism believable, to demonstrate how it happens not to show what it resembles" (cited in Romanska unpag.).

14. Despite Marinetti's claims, however, the "poeticity" of Futurist recipes lies less in their form-which usually resorts to traditional descriptive and narrative formats-than in their content (i.e., the unusual visual and gustative juxtapositions they produce). If one had to look for stylistic affinities between poetry books and cookbooks, however, one would have to consider a literary tradition which runs from Edmond Rostand's Cyrano de Bergerac (see the epigraph cited earlier in this book) to Stein's Tender Buttons, Alice B. Toklas's Cookbook, and beyond. According to Sara Pitzer's How to Write a Cookbook and Get It Published (1984), potential writers should follow the basic rules stated William Strunk's The Elements of Style (1918):

1. Use simple words.

2. Use short sentences.

3. Use the active voice.

4. Use strong verbs.

5. Arrange words in sentences ... with nothing between them unless you have a good reason for deviating from this pattern. (Pitzer 73)

These edicts reflect different degrees and standards of concision and parataxis which apply to certain forms of experimental "disjunctive" poetry. It would be silly to suggest that Stein's syntactic idiosyncrasies stem from the rhetoric of cookbooks-Stein's own theories about her use of syntax clearly indicate otherwise. Still one cannot help thinking that the cookbook, by necessity, shares with the poetry collection a tendency to foreground its own methodological dynamics. And in many ways, M. F. K. Fisher's advice that "a good recipe, for modern convenience, should consist of three parts: name, ingredients, method" seems an apt description of Stein's own poetic "method," which privileges method and process over representation. The list format inherent 
in the cooking recipe also dictates a kind of truncated style that is often primarily paratactic and asyntactic (recipes often comprise unfinished sentences, the lack of the definite article as in "place chicken in baking dish" or direct complement as in "place in a bowl and add salt") which characterizes the neutral, imperative mode of the cookbook. What distinguishes Stein's use of parataxis from that of cookbooks is, of course, that syntactic continuity is implicit by virtue of the conventions of cookbook style. As Susan Schultz cleverly remarks, "Pinch of curry powder," may resemble a line of poetry, but it is not a sentence (Schultz, unpag.).

15. See Fillìa's "Edible Alphabet" (144) and "Italian Sea" (143), respectively.

16. Paradoxically, however, Marinetti's aversion to "volume and weight" and his attention to texture and visual detail prefigured the development of the Nouvelle Cuisine and of the later "culinary art" of Ferran Adria and his followers. For a brief and informative overview of the history of bourgeois gastronomy, see chapter 6 of Michel Onfray's La raison gourmande.

17. One of Marinetti's favorite targets was Gabriele D'Annunzio who, to him, symbolized the "sickly, nostalgic poetry of distance and memory" (Nicholls 68).

18. Besides Finley and Antoni, other chocolate-based Eat Art experiments include Edward Ruscha's Chocolate Room (first presented at the Venice Biennale in 1970), a room whose walls were covered with paper covered with chocolate "paint"; the edible nude torso of Hannah Wilke's 1985 Venus Pareve (the word "pareve" refers to meals prepared without milk or meat and other derivatives and which can be eaten with both dairy products and meat according to Jewish dietary laws); Dieter Roth's “self-portrait," "Chocolate Lion” (1971); and, more recently, Sonja Alhaeuser's display cases and pedestals made of the finest Belgian chocolate which are destined to be progressively eaten away by the visitors.

19. Dieter Roth's "self-portrait," "Chocolate Lion," (1971) offers another, earlier example of an art that allows the materiality of the work itself to describe the process of decay of edible matter. As for Sterbak's recent "Bread Bed" (1996) and "Cake Stool" (1996), they are more conventional exercises based on analogies between the textural softness of real bread and cake with that of mattresses and cushions. The art of William Pope L. makes use of rotting food in a way that leads to a kind of visual, performative poetry of direct political statement, especially as regards the critique of consumerism. The space designating the United States on his billboard-style "Map of the World" (2002) was originally filled with dozens of hot dogs which, due to mold and humidity, were meant to "explode" during the course of the exhibition.

20. Another reproduction of this room is located in Spoerri's "sculpture garden" in the South of Tuscany.

21. The contents of Spoerri's bronze chambers also evoke the bronzed chairs and fruits of Giacomo Manzù. See, for example, Manzù's early Chair with Fruit (1960), which consists of a life-size chair covered with over-life size vegetables.

\section{NOTES TO THE EPILOGUE}

1. There is a puritanical dimension to anorexia which often extends to the denial of sexual hunger and the wish to avoid sexuality by becoming "androgynous." According to Hilde Bruch's The Golden Cage: The Enigma of Anorexia Nervosa, "the avoidance of any sexual encounter, a shrinking from all bodily contacts" (cited in Counihan 233) is characteristic of many anorexics.

2. As we have seen, the symbolic reversals of Acconci's Trademarks were recently extended in Janine Antoni's Gnaw (1992), another related installation dissociating biting and chewing from nourishment described in chapter 5 . 


\section{Notes}

3. As indicated in the Introduction to this volume, Susan Bordo comes to a similar conclusion when she suggests that the "will to conquer and subdue the body" "expresses an aesthetic or moral rebellion" against cultures "characterized by gross excesses in consumption" (Counihan 237). See also Baudrillard's description of the compulsive jogger: "The jogger has yet another solution. In a sense, he spews himself out; he doesn't merely expend his energy in his running, he vomits it. He has to attain the ecstasy of fatigue, the 'high' of mechanical annihilation, just as the anorexic aims for the 'high' of organic annihilation, the ecstasy of the empty body and the obese individual seeks the high of dimensional annihilation: the ecstasy of the full body" (Baudrillard 42).

4. One of Antin's first Fluxus-inspired experiments was Blood of a Poet Box (1965-68), a collection of blood samples dabbed on glass microscopic slides from one hundred poets she knew and which was originally meant as a tribute to Jean Cocteau's 1930 film, Le Sang d'un poète.

5. "The twentieth-century artist is not necessarily someone who draws well, but someone who thinks well" (Viola 64).

6. This is of course a very reductive account of Saint Catherine of Siena's life and achievements. In her mid-twenties, Saint Catherine left her withdrawn life and became a public activist and pacifist and wrote hundreds of letters to Pope Gregory XI urging him to work for peace.

7. Who, incidentally, like the holy anorexics, largely outnumber their male counterparts.

8. Serrano's photograph revives the wedding of abjection and spirituality discussed in connection with the life of Saint Catherine of Siena.

9. "The abjection of Nazi crime reaches its apex when death, which, in any case, kills me, interferes with what in my living universe, is supposed to save me from death" (Kristeva 232).

10. Which translates roughly as "money deposit is to art what merdre is to shit" (Duchamp 37), the word "merdre," which is borrowed from Jarry's Ubu Roi, being a bastardized form of the French word for shit.

11. Manzoni's interest in food precedes his fascination with excrement by at least a year as his 1960 performance, Uova con impronta (Egg with Thumbprint), comprises seventy eggs signed with his thumbprint. During this performance, Manzoni proceeded to eat a few and offered the remainder to the gallery visitors to eat.

12. The Duchampian strain in Delvoye's work is also apparent in the name he gave to his most famous tattooed pig, Marcel.

13. Delvoye's "Cloaca" machine is part of a larger project comprising visuals and installations which includes painted objects, mosaics, stained-glass, and even live tattooed pigs kept in an "art farm" in China.

14. This device of course proved to be a fake, as the pellets lay hidden in a section of the duck corresponding to its rectum, waiting to be ejected by means of a secret mechanism. 


\section{Works Cited}

Adamowicz, Elza. "Exquisite excrement. The Breton/Bataille Polemic.” Aurifex 2 (2003): unpag.

Anderson, Beth. "Imperturbable Things: On Still-Life Poetics." The Impercipient Lecture Series 1.5 (1997). Providence, RI.

Bachelard, Gaston. La formation de l'esprit scientifique: Contribution à une psychanalyse de la connaissance objective. Paris: Vrin, 1993.

Baetens, Jan. "Pour en finir avec la poésie minimaliste." Interval(le)s 1 (2004). 74 82. e-journal:<http://www.cipa.ulg.ac.be/intervalles1/contents.htm>

Barthes, Roland. Le Degré zéro de l'écriture. Paris: Seuil, 1953.

- S/Z. Paris: Seuil, 1970

. Sade, Fourier, Loyola. Paris: Seuil, 1971.

- L'obvie et l'obtus. Paris: Seuil, 1982.

- Camera Lucida: Reflections on Photography. New York: Hill \& Wang, 1982.

Le Bruissement de la langue: Essais critiques IV. Paris: Seuil, 1984.

"Toward a Psychosociology of Contemporary Food Consumption."

In Counihan, Carole, and Penny Van Esterik, Food and Culture: A Reader. New York and London: Routledge, 1997.

. L'empire des signes. Paris: Seuil, 2005.

Baudrillard, Jean. America. London: Verso, 1989.

Bataille, Georges. Accursed Share: An Essay on General Economy. Vol. 1. New York: Zone, 1991.

Beckett, Samuel. Malone Dies. New York: Grove Press, 1956.

. Collected Shorter Prose: 1945-1966. London: Calder \& Boyars, 1967.

. Watt. London: Calder, 1970.

I Can't Go On, I'll Go On: A Samuel Beckett Reader. New York: Grove Weidenfeld, 1976.

- Murphy. London: Calder, 1993.

Bell, R. M. Holy Anorexia. Chicago: U of Chicago P, 1985.

Bénéjam, Valérie. "Innards and Titbits: Joyce's Digestive Revolution in the Novel." In Le ventre de l'écrivain/The Belly of the Writer. Ed. Michel Delville. Special issue of Interval(le)s, the online journal of CIPA: 25-37. <http://www.cipa.ulg. ac.be/intervalles1/interintro.htm>

Bergin, Paul. "Andy Warhol: The Artist as Machine." Art Journal 26.4 (Summer 1967): 359-363.

Bexte, Peter. “Anges aux ailes maculées de boue.” Delvoye 11-20.

Bishop, Elizabeth. The Complete Poems. London: Chatto \& Windus, 1969.

Bly, Robert. Leaping Poetry: An Idea with Poems and Translations. Boston: Beacon Press, 1972.

- The Morning Glory. New York: Harper and Row, 1975. 


\section{Works Cited}

This Body Is Made of Camphor and Gopherwood. New York: Harper and Row, 1977.

. Talking All Morning. Ann Arbor: U of Michigan P, 1980.

Selected Poems. New York: Harper Collins, 1986.

Ten Poems of Francis Ponge Translated by Robert Bly \& Ten Poems of Robert Bly Inspired by the Poems of Francis Ponge. Riverview, New Brunswick: Owl's Head Press, 1990.

- American Poetry: Wildness and Domesticity. New York: Harper Collins, 1991.

What Have I Ever Lost by Dying? New York: Harper Collins, 1992.

Bonafoux, Pascal. La beauté comestible. Paris: Editions Plume, 1998:

Bordo, Susan. "Anorexia Nervosa: Psychopathology as the Crystallization of Culture." Counihan 226-50.

Brienza, Susan D. Samuel Beckett's New Worlds: Style in Metafiction. Norman: U of Oklahoma P, 1987.

Broodthaers, Marcel. “Ten Thousand Francs Reward.” October 42 (Fall 1987): 39-48.

. Writings, Interviews, Photographs. Cambridge: MIT Press, 1988.

Brown, Norman O. Love's Body. New York: Vintage, 1966.

Budgen Frank. James Joyce and the Making of Ulysses. London: Oxford UP, 1972.

Careri, Giorgio. "Physicists and Painters: The Similar Search for Meaning." Leonardo 22.1 (1989): 113-15.

Cazé, Antoine. "Conceptual Lyricism: Abstract Constructions of the Self in Recent American Poetry." Unpublished ms. Presented at the international conference Transgressing Boundaries and Strategies of Renewal in American Poetry. University of Salamanca, Spain. May 2000.

Charters, Ann, and Samuel Charters, eds. Literature and Its Writers: An Introduction to Fiction, Poetry, and Drama. Boston: Bedford Books, 1997.

Claudel, Paul. Connaissance de l'est. Paris: Gallimard, 1974.

Colòn, David. "Now what the DEFILL can that mean! The Latin-American Roots, Rhetoric and Resistance of Latin American Concrete Poetry." Journal of LatinoLatin American Culture 1.1 (Fall 2003): 47-60.

Connor, Steven. Samuel Beckett: Repetition, Theory and Text. Oxford: Blackwell, 1988.

Counihan, Carole, and Penny Van Esterik. Food and Culture: A Reader. New York and London: Routledge, 1997.

Cummings, E. E. Complete Poems 1904-1962. New York: Liveright, 1991.

Dalí, Salvador. "The Object as Revealed in Surrealist Experiment." Surrealists on Art. Ed. Lucy Lippard. Englewood Cliffs, New Jersey: Prentice Hall, 1970.

. The Secret Life of Salvador Dali. Dial Press, New York, 1942.

- La Vie secrète de Salvador Dali. Paris: La Table Ronde, 1952.

. Oui: The Paranoid-Critical Revolution: Writings 1927-1933. Trans. Yvonne Shafir. Boston: Exact Change, 1998.

- Oui : La révolution paranoïaque-critique/L'archangélisme scientifique. Paris: Denël, 2004.

Dällenbach, Lucien. Mosaïques: Un objet esthétique à rebondissements. Paris: Seuil, 2001.

Delville, Michel. The American Prose Poem: Poetic Form and the Boundaries of Genre. Gainesville: U of Florida P, 1998.

— (Spring 2007): <http://www.cipa.ulg.ac.be/intervalles1/interintro.htm>

Delville, Michel, and Christine Pagnoulle, eds. The Mechanics of the Mirage: Postwar American Poetry. Liège: L3, 2000.

Delvoye, Wim. Scatalogue. Gent: MERZ/Luc Derycke \& Co, 2001. 
Dixon, Willie. "Spoonful." I am the Blues. Mobile Fidelity CD B00000293E, 2003. Duchamp, Marcel. Duchamp du signe. Paris: Flammarion, 1994.

Dworkin, Craig. "Fugitive Signs." October 95.5 (Winter 2001): 90-113.

Feher Michel, ed. Fragments for a History of the Human Body. Vol. 2. New York, Zone Books, 1989.

Fifer, Elizabeth. "Is Flesh Advisable? The Interior Theater of Gertrude Stein." Signs 4.3 (Spring, 1979): 472-83.

Finley, Karen. A Different Kind of Intimacy. New York: Thunder's Mouth Press, 2000.

Fox Howard N. Fox, ed. Eleanor Antin. Los Angeles: Los Angeles County Museum of Art, 1999.

Freytag Loringhoven, Elsa von. “A Dozen Cocktails—Please.” <http://www.writing. upenn.edu/ afilreis/88/dozen.html>

Friebert, Stuart, David Walker, and David Young, eds. A Field Guide to Contemporary Poetry and Poetics. Oberlin: Oberlin College P, 1997.

Friedman, Lester, ed. Fires Were Started: British Cinema and Thatcherism. Minneapolis: U of Minnesota P, 1993: 255-77.

Frost, Elisabeth A. “An Interview with Harryette Mullen.” Contemporary Literature XLI. 3 (2000): 396-421.

Gammel, Irene. Baroness Elsa: Gender, Dada, and Everyday Modernity. Cambridge: MIT P, 2002.

Gigante, Denise. Taste: A Literary History. New Haven: Yale UP, 2005.

Gleize, Jean-Marie, ed. Francis Ponge. Les Cahiers de l'Herne. Paris: Editions de l'Herne, 1986.

Goldsmith, Kenneth, ed. I'll Be Your Mirror: The Selected Andy Warhol Interviews. New York: Carroll \& Graf, 2004.

Gombrigh, E. H. "Tradition and Expression in Western Still Life." The Burlington Magazine. Vol. 103, No 698 (May 1961): 174-80.

Gomringer, Eugen. "From Line to Constellation." Trans. Mike Weaver. <http://www. ubuweb.com/papers/gomringer01.html>

Grenier, Robert. Sentences. Cambrige, MA: Whale Cloth Press, 1978.

Grosz, Elisabeth. Sexual Subversions: Three French Feminists. London: Allen \& Unwin, 1989.

Higgins, Ian. Francis Ponge. London: The Athlone Press, 1979.

Hjartarson, Paul and Douglas O. Spettigue, eds. Baroness Elsa: The Autobiography of Baroness Elsa von Freytag-Loringhoven. Ottawa: Oberon, 1992.

Hoover, Paul. Postmodern American Poetry. New York: Norton, 1994.

Huffman, Carl. "Pythagoras." The Stanford Encyclopedia of Philosophy (Spring 2005 Edition). Ed. Edward N. Zalta. <http://plato.stanford.edu/archives/spr2005/ entries/pythagoras/>

Jameson, Fredric. Postmodernism, or, The Cultural Logic of Late Capitalism. London: Verso, 1991.

- Signatures of the Visible. New York and London: Routledge, 1992.

Jones, Amelia. Body Art / Performing the Subject. Minneapolis: U of Minnesota P, 1998.

Jourde, Pierre. La littérature sans estomac. Paris: L'esprit des péninsules, 2002.

Joyce, James. Finnegan's Wake. London: Faber and Faber, 1975.

. Ulysses. London: Penguin, 2000.

Kahl, Timothy James. "The Object Poem.” <http://www.mongryl.com/creativewriting/object.poem.html>

Kirchenblatt-Gimblett, Barbara. "Playing to the Senses: Food as a Performance Medium.” Performance Research 4.1 (1999): 1-30.

Knight, Christopher J. "Gretrude Stein, Tender Buttons, and the Premises of Classicalism.” Modern Language Studies. 21.3 (1991): 35-47. 


\section{Works Cited}

Korsmeyer, Carolyn. Making Sense of Taste: Food and Philosophy. Ithaca and London: Cornell UP, 1999.

Kristeva, Julia. Powers of Horror: An Essay on Abjection. New York: Columbia UP, 1982.

Kundera, Milan. The Unbearable Lightness of Being. London: Faber, 1985.

Kuspit, Donald. "Pop Art: A Reactionary Realism.” Art Journal 36.1 (Fall 1976): 31-38.

La Haye, Marcel. Poésies. Châtelineau: Editions Le Taillis Pré, 2004.

Lane, Christopher. "A Short Biography of the Baroness Else von Freytag-Loringhoven, Including Some of her Writings." < http://home1.gte.net/zzyzlane/write/ essay/baroness.html.>

Laporte, Dominique. History of Shit. Cambridge: MIT Press, 2000.

Lensing, George S., and Ronald Moran. Four Poets and the Emotive Imagination: Robert Bly, James Wright, Louis Simpson, and William Stafford. Baton Rouge: Louisiana State UP, 1976.

Lewis, Wyndham. Tarr. 1928. London: Penguin, 1982.

Lupton, Deborah. Food, the Body and the Self. London: Sage, 1996.

Lyotard, Jean-François. The Postmodern Condition: A Report on Knowledge.

Marcadé, Bernard. Il n'y a pas de second degré: remarques sur la figure de l'artiste au Xxe siècle. Nîmes: Editions Jacqueline Chambon, 1999.

Marinetti, F. T. The Futurist Cookbook. Trans. Suzanne Brill. San Francisco: Bedford Arts, 1989.

—. Let's Murder the Moonshine: Selected Writings. Trans. R. W. Flint and Arthur Coppotelli. Ed. R. W. Flint. Los Angeles: Sun \& Moon Classics, 1991.

Marrow, Deborah, and Arlene Raven. "Eleanor Antin: What's Your Story?” Chrysalis: A Magazine of Women's Culture 8 (Summer 1979): 44.

Mattei, Florent. Email to the author. 25 April 2007.

Mink, Janis. Marcel Duchamp: Art As Anti-Art. Cologne: Taschen, 1995.

Monroe, Jonathan. "Syntextural Investigations." Diacritics 26.3/4 (Fall-Winter 1996): 124-41.

Moore, Marianne. The Poems of Marianne Moore. London: Penguin, 2003.

Mullen, Harryette. $S * P e R M^{* *} K^{*} T$. Philadelphia: Singing Horse Press, 1992.

Nelson, Howard. Robert Bly. New York: Columbia UP, 1984.

Nicholls, Peter. Modernisms: A Literary Guide. London: Macmillan, 1995.

Onfray, Michel. Le ventre des philosophes. Paris: Grasset, 1989.

- La raison gourmande. Paris: Grasset, 1995.

Ortega y Gasset, José. The Modern Theme. Trans. James Cleugh. New York: Harper \& Row, 1961.

Paz, Octavio. Marcel Duchamp: Appearance Stripped Bare. New York: Arcade, 1991.

Peppis, Paul. "Anti-individualism and the fictions of national character in Wyndham Lewis's Tarr." Twentieth Century Literature 40.2 (1994): 226-55.

Perloff, Marjorie. The Poetics of Indeterminacy: Rimbaud to Cage. Evanston: Northwestern UP, 1983.

- The Dance of the Intellect: Studies in the Poetry of the Pound Tradition. Evanston: Northwestern UP, 1985.

-Radical Artifice: Writing Poetry in the Age of Media. Chicago: U of Chicago P, 1991.

. 21 $1^{\text {st }}$ Century Modernism: The "New" Poetics. London: Blackwell, 2002. 2004.

Pinsky, Robert. The Situation of Poetry: Contemporary Poetry and Its Traditions. Princeton: Princeton UP, 1976.

Pitzer, Sara. How to Write a Cookbook and Get it Published. New York: Writers Digest Books, 1984. 
Ponge, Francis. Comment une Figue de paroles et pourquoi. Paris: Flammarion, 1977.

. Oeuvres complètes. Vol. 1. Paris: Gallimard, 1999.

. "The Orange." Trans. Beverley Bie. Ambit 164 (2001): 88-89.

. Oeuvres complètes. Vol. 2. Paris: Gallimard, 2002.

Preminger, Alex, ed. Princeton Encyclopedia of Poetry and Poetics. Princeton: Princeton UP, 1974.

Proust, Marcel, A la recherche du temps perdu. I. Du côté de chez Swann. Paris: Gallimard, 1992.

Punter, David, ed. A Companion to the Gothic. London: Blackwell, 2001.

Quartermain, Peter. Disjunctive Poetics: From Gertrude Stein to Louis Zukofsky and Susan Howe. Cambridge: Cambridge UP, 1992.

Rabaté, Dominique, ed. Figures du sujet lyrique. Paris: PUF, 1996.

Rexroth, Kenneth. American Poetry of the Twentieth Century. New York: Herder and Herder, 1973.

Ricaud, Lucy. "Anorexia and Misogyny: The Aesthetics of Wyndham Lewis's novel Tarr." Rouyer 213-224.

Rimbaud, Arthur. Album Zutique: Suivi de pièces diverses. Paris: Mille et une nuits, 2000.

Rios, Alicia. "Eat Art and Communities: From Oxford to Melbourne." In Moving Worlds: A Journal of Transcultural Writings 6.2 (2006): 177-86.

Robbe-Grillet, Alain. Les gommes. Paris: Minuit, 1955.

Romanska, Magda. "Sade/Salò." Proceedings of the Red River Conference on World Literature 5 (2003). <http://www.ndsu.edu/RRCWL/V5/romanska.html>

Rothenberg, Jerome. Pre-faces \& Other Writings. New York: New Directions, 1981.

Rouyer, Marie-Claire. Food for thought ou les avatars de la nourriture. Bordeaux: PU de Bordeaux, 1998.

Ruddick, Lisa. Gertrude Stein: Body, Text, Gnosis. Ithaca: Cornell UP, 1991.

Sandford, Mariellen, ed. Happenings and Other Acts. New York and London: Routledge, 1994.

Sanouillet, Michael, and Elmer Peterson, eds. The Essential Writings of Marcel Duchamp, London: Thames and Hudson, 1975.

Santich, Barbara. "The Communities of Food Scholars." In Moving Worlds: A Journal of Transcultural Writings 6.2, 2006: 6-13.

Sartre, Jean-Paul. La Nausée. Paris: Gallimard, 1972. 1976.

Satie, Erik. A Mammal's Notebooks. New York: Serpent's Tail, 1996.

Savitzkaya, Eugène. Fou Civil. Paris: Les Flohic, 1999.

Sayre, Henry. The Object of Performance: The American Avant-Garde Since 1970. Chicago: U of Chicago P, 1992.

Schneemann, Carolee. "From More than Meat Joy." Sandford 246-67.

Schultz, Susan. “'Grandmothers and Hunters': Ronald Johnson and Feminine Tradition." Unpublished ms.

Schwartz, Lloyd, and Sybil P. Estes, eds. Elizabeth Bishop and her Art. Ann Arbor: U of Michigan P, 1983.

Silk, Gerald. "Myths and Meanings in Manzoni's Merda d'artista." Art Journal 52.3 (Fall 1993): 65-75.

Silliman, Ron. Mohawk. Bowling Green: Doones Press, 1973.

- In the American Tree. Orono: National Poetry Foundation, 1986.

Simic, Charles. Selected Early Poems. New York: Braziller, 2000.

Solt, Concrete Poetry: A World View. Bloomington: Indiana UP, 1968.

Spicer, Jack. After Lorca. Toronto: Coach House Books, 1974. 


\section{Works Cited}

Stein, Gertrude. Look at Me Now and Here I Am: Writings and Lectures 1909-45. London: Penguin, 1967.

. A Primer for the Gradual Understanding of Gertrude Stein. Ed. Robert Bartlett Haas. Los Angeles: Black Sparrow Press, 1971

. The Yale Gertrude Stein. Ed. Richard Kostelanetz. New Haven and London: Yale UP, 1980.

Sterckx, Pierre. "Wim Delvoye." In Delvoye: 21-33.

Stewart, Susan. On Longing: Narratives of the Miniature, the Gigantic, the Souvenir, the Collection. Durham: Duke UP, 1993.

Stiles, Kristine, and Peter Selz, eds. Theories and Documents of Contemporary Art: A Sourcebook of Artists' Writings. Berkeley: U of California P, 1996.

Streitfeld, Lisa Paul. "L'être désirant et désiré: le croisement de la nourriture et de la beauté dans l'art contemporain." esse : arts + opinions 50 (Winter 2004): 24-27.

Sweetlove, William. Still Lives. Brussels: Artiscope, 1997.

Tharu, Susie J. The Sense of Performance: Post-Artaud Theatre. Atlantic Highlands: Humanities P, 1984.

Todorov, Tzvetan. La littérature en péril. Paris: Flammarion, 2007.

Tsujimoto, Karen. Wayne Thiebaud: Exhibition Catalogue. Washington: The U of Washington P, 1985.

Viola, Bill. Reasons for Knocking at an Empty House, Writings 1973-1994. London: Thames and Hudson, 64.

Watson, Ben. Art, Class \& Cleavage. London: Quartet, 1998.

Yau, John. In the Realm of Appearances: The Art of Andy Warhol. Hopewell: Ecco P, 1993.

Zukofsky, Louis. A. Berkeley: U of California P, 1978. 


\section{Index}

